\title{
Predição de tags usando linked data: um estudo de caso no banco de dados Arquigrafia
}

\author{
Ricardo Augusto Teixeira de Souza
}

\author{
DISSERTAÇÃO APRESENTADA \\ $\mathrm{AO}$ \\ Instituto De MatemáticA E EstatísticA \\ DA \\ UnIVERSIDADE DE SÃO PAULO \\ PARA \\ OBTENÇÃO DO TÍTULO \\ $\mathrm{DE}$ \\ Mestre em CiênCia da ComputaÇÃo \\ Programa: Ciência da Computação \\ Orientadora: Profa. Dra. Leliane Nunes de Barros
}

São Paulo, dezembro de 2013 


\title{
Predição de tags usando linked data: um estudo de caso no banco de dados Arquigrafia
}

\author{
Este exemplar corresponde à redação final da \\ dissertação devidamente corrigida e defen- \\ dida por Ricardo Augusto Teixeira de Souza \\ e aprovada pela Comissão Julgadora.
}

Banca Examinadora:

- Profa. Dra. Leliane Nunes de Barros (orientadora) - IME-USP.

- Prof. Dr. Pierre Yves Andrews - IME-USP.

- Prof. Dr. Fábio Gagliardi Cozman - EP-USP. 
À José Aparecido Gonçalvez de Souza, que sempre esteve comigo 
"Veni, vidi, vici"

(Julius Caesar) 


\section{Agradecimentos}

Agradeço a minha namorada Magnolia Astrid, por todo o amor, apoio, paciência, força e compreensão que me deu nas fases mais difíceis desse mestrado. Agradeço aos meus pais, Dulci e Valter, e irmãos, Rodrigo e Amanda, por todo o apoio durante o mestrado. Agradeço a Karina Schmidt (a querubim) pela força e compreensão, que foram importantes principalmente no último ano; a Talita por ouvir meus problemas; e ao meu gato Mignon por ajudar nos momentos de distração. Agradeço também a todos os integrantes do LIAMF (e agregados), entre eles, Paulo de Tarso, Viviane Menezes, Fabio Franco, Viviane Urbano, Esdras Bispo, Fabiano, Fillipe Resina, Erika, Ricardo Andrade, Ricardo Sekeff, Ricardo Hermann, Mijail, Luis, Marisol, Adalberto, Ignasi, Letícia, José David, e tantos outros que tiveram importante papel durante essa etapa. Igualmente agradeço aos meus amigos do SENAC - Sto Amaro por todo o apoio, entre eles, Fabio Lubacheski, Leonardo Takuno, Eduardo Takeo, Marcelo Hashimoto, Anderson Borba, Renato da Silva, Pedro Silva, Diane Rizzotto, Danielle Mingatos e Gustavo Calixto. Agradeço também aos professores da banca, Prof. Dr. Fábio Cozman e Prof. Dr. Pierre Andrews, pelos comentários ao trabalho. Agradeço novamente ao Prof. Dr. Pierre Andrews pela ajuda em alguns momentos durante o desenvolvimento deste projeto. E agradeço à professora Leliane pela oportunidade dada, que fez com que eu amadurecesse pessoal e profissionalmente. 


\section{Resumo}

Dada a grande quantidade de conteúdo criado por usuários na Web, uma proposta para ajudar na busca e organização é a criação de sistemas de anotações (tagging systems), normalmente na forma de palavras-chave, extraídas do próprio conteúdo ou sugeridas por visitantes. Esse trabalho aplica um algoritmo de mineração de dados em um banco de dados RDF, contendo instâncias que podem fazer referências à rede Linked Data do DBpedia, para recomendação de tags utilizando as medidas de similaridade taxonômica, relacional e literal de descrições RDF. O banco de dados utilizado é o Arquigrafia, um sistema de banco de dados na Web cujo objetivo é catalogar imagens de projetos arquitetônicos, e que permite que visitantes adicionem tags às imagens. Foram realizados experimentos para a avaliação da qualidade das recomendações de tags realizadas considerando diferentes modelos do Arquigrafia incluindo o modelo estendido do Arquigrafia que faz referências ao DBpedia. Os resultados mostram que a qualidade da recomendação de determinadas tags pode melhorar quando consideramos diferentes modelos (com referências à rede Linked Data do DBpedia) na fase de aprendizado.

Palavras-chave: Recomendação de Tags, Web Semântica, Linked Data, Mineração de dados. 


\section{Abstract}

Given the huge content created by users in the Web, a way to help in search and organization is the creation of tagging systems, usually in a keyword form (extracted from the Web content or suggested by users). This work applies a data mining algorithm in a RDF database, which contain instances that can reference the DBpedia Linked Data repository, to recommend tags using the taxonomic, relational and literal similarities from RDF descriptions. The database used is the Arquigrafia, a database system available in the Web which goal is to catalog architecture projects, and it allows a user to add tags to images. Experiments were performed to evaluate the quality of the tag recommendations made considering differents models of Arquigrafia's database, including an extended model which has references to DBpedia. The results shown that the quality of the recommendations of some tags can be improved when we consider different models (with references to DBpedia Linked Data repository) in the learning phase.

Keywords: Tag Recommendation, Semantic Web, Linked Data, Data Mining. 


\section{Sumário}

Lista de Figuras $\quad$ xiii

Lista de Tabelas $\quad$ xv

Lista de Símbolos $\quad$ xvii

1 Introdução $\quad 1$

2 Web Semântica $\quad 5$

2.1 Linguagens da Web Semântica . . . . . . . . . . . . . . . . . . . . 6

2.1.1 eXtended Markup Language (XML) . . . . . . . . . . . . . . . . . . 6

2.1.2 Resource Description Framework (RDF) . . . . . . . . . . . . . . 8

2.1.3 Web Ontology Language (OWL) . . . . . . . . . . . . . . . . . . . . 11

2.2 Linked Data . . . . . . . . . . . . . . . . . . . . . . . . . . . . . . . . . 12

2.2.1 Publicação e Consumo . . . . . . . . . . . . . . . . . . . . . . . . . 15

$2.2 .2 \quad$ O projeto DBpedia . . . . . . . . . . . . . . . . . . 16

2.2 .3 Sesame . . . . . . . . . . . . . . . . . . . . . 17

3 Recomendação de tags $\quad 19$

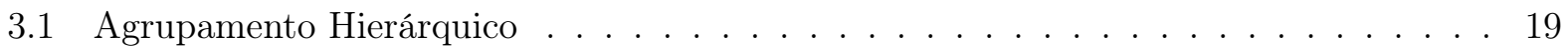

3.1.1 Usando agrupamento hierárquico para predizer tags . . . . . . . . . . . . . 24

3.2 Métrica de similaridade entre instâncias RDF . . . . . . . . . . . . . . . 26

3.2.1 Similaridade Taxonômica . . . . . . . . . . . . . . . . . . . . . . 28

$3.2 .2 \quad$ Similaridade Literal $\ldots \ldots \ldots$. . . . . . . . . . . . . . . . . . . . . . . . . . . 29

3.2 .3 Similaridade Relacional . . . . . . . . . . . . . . . . . . . . . . . . . 30

3.3 Outras métricas de similaridade entre instâncias RDF . . . . . . . . . . . . . . . . 32

3.3.1 Métrica baseada na distância de vetores . . . . . . . . . . . . . . . . . 32

3.3.2 Métrica baseada em grafos . . . . . . . . . . . . . . . . . . . . 33

$\begin{array}{lll}4 & \text { O Sistema ArquiTag } & 37\end{array}$

4.1 Módulo Conversor RDF . . . . . . . . . . . . . . . . . . . . . 37

4.2 Módulo Explorador . . . . . . . . . . . . . . . . . . . . . . . . . 40

4.3 Módulo Treinamento . . . . . . . . . . . . . . . . . . . . . . . . . 40

4.4 Módulo Recomendação de tags . . . . . . . . . . . . . . . . . . . . . . . 41

4.5 Avaliação . . . . . . . . . . . . . . . . . . . . . . . . . 41

4.6 Remodelando o Sistema Arquigrafia e criando referências para o Linked Data do DBpedia . . . . . . . . . . . . . . . . . . . . . . 42 
4.6 .1 Modelo estendido do Arquigrafia . . . . . . . . . . . . . . . . . 43

4.6.2 Referências feitas do modelo estendido do Arquigrafia para o DBpedia . . . . 44

4.7 Trabalhos relacionados . . . . . . . . . . . . . . . . . . 47

5 Avaliação Experimental $\quad \mathbf{5 1}$

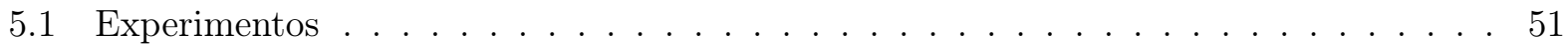

5.1 .1 Recomendação do conjunto completo de tags . . . . . . . . . . . . . . . 51

5.1 .2 Recomendação das 10 tags mais populares . . . . . . . . . . . . . . . 52

6 Conclusão e Trabalhos Futuros $\quad 57$

Referências Bibliográficas $\quad 59$ 


\section{Lista de Figuras}

1.1 Exemplo de um recurso Web do sistema Arquigrafia. A Uniform Resource Identifier (URI) definida para este recurso é "http://www.arquigrafia.org.br/photo/1220". . . . 2

2.1 Camadas da Web Semântica (Figura traduzida de [Koivunen e Miller, 2001]). . . . . 5

2.2 Exemplo de documento XML . . . . . . . . . . . . . . . . . . . . . 6

2.3 Código eXtended Markup Language Schema (XML-S) que valida o código XML apresentado na Figura $2.2 \ldots \ldots \ldots \ldots \ldots \ldots$

2.4 O grafo de uma tripla RDF. . . . . . . . . . . . . . . . . . . . 8

2.5 Grafo RDF que representa a frase "Palácio Gustavo Capanema fica na cidade de Rio de Janeiro". . . . . . . . . . . . . . . . . . . . . . . . . . . . . . . . . . . . . . 8

2.6 Grafo RDF representando mais propriedades do Palácio Gustavo Capanema. . . . . . 9

2.7 Código RDF do grafo exibido na Figura 2.6. . . . . . . . . . . . . . . . . 9

2.8 Código Resource Description Framework Schema (RDF-S) que define o vocabulário usado na Figura 2.7. . . . . . . . . . . . . . . . . . . . . . 10

2.9 Exemplo de consulta SPARQL Protocol And RDF Query Language (SPARQL), considerando o código RDF da Figura 2.7 . . . . . . . . . . . . . . . . 11

2.10 O crescimento da rede Linked Data de maio de 2007 a março de 2009 [Bizer e Health,

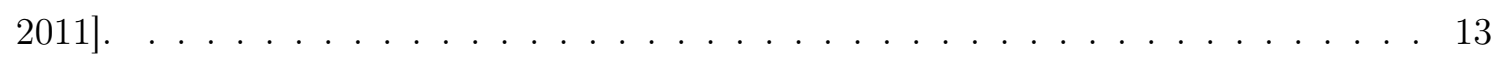

2.11 A rede Linked Data em Setembro de 2011 [Bizer e Health, 2011]. . . . . . . . . . . . 14

2.12 Formas de publicação na rede Linked Data (figura traduzida de [Bizer e Health, 2011]). 15

2.13 Exemplo de um código do Wikipedia e seu respectivo infobox. Figura extraída de

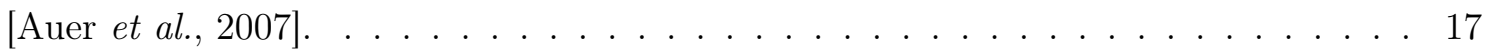

2.14 Arquitetura do sistema Sesame. Figura extraída de [Broekstra et al., 2002]. . . . . 18

3.1 Exemplo de clusterização hierárquica usando diagramas de Venn. . . . . . . . . . . . 19

3.2 Exemplo de um dendrograma. . . . . . . . . . . . . . . . . . . . . 20

3.3 Passo a passo da árvore construída a partir das instâncias C, D, A e B (nesta ordem) usando os valores de similaridade da Tabela 3.1. . . . . . . . . . . . . . . . 22

3.4 Árvore resultante construída a partir das instâncias A, B, C e D (nesta ordem) usando

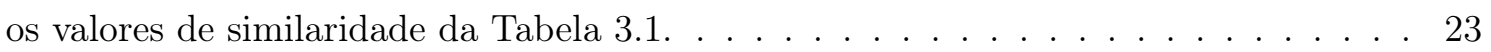

3.5 Ilustração do funcionamento do Algoritmo $4 . \ldots \ldots$. . . . . . . . . . . . . . 24

3.6 Resultado da aplicação do Algoritmo 4 à árvore da Figura 3.4. . . . . . . . . . . . . . 24

3.7 Árvore produzida com as instâncias $A, B, C$ e $D$ considerando os valores de similaridades na Tabela 3.1 e as tags na Tabela 3.2 . . . . . . . . . . . . . . . 25

3.8 Árvore resultante após a inserção da instância E. Na figura, as arestas grossas representam o caminho percorrido pela instância. . . . . . . . . . . . . . . . 25 




3.10 Exemplo de um repositório RDF usando o vocabulário exibido na Figura 3.9. . . . 27

3.11 Exemplo de um grafo RDF. . . . . . . . . . . . . . . . . . . . 33

3.12 Sobreposição dos grafos $G_{c}(i, j)=G(i) \cap G(j)$. Figura extraída de [Montes-y Gómez et al.,

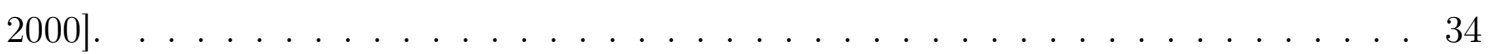

4.1 Módulos do sistema ArquiTag, com suas entradas e saídas. . . . . . . . . . . . . 38

4.2 Modelo RDF original do banco de dados. . . . . . . . . . . . . . . . 38

4.3 Código RDF-S que corresponde ao modelo da Figura 4.2 . . . . . . . . . . . . . . 39

4.4 Código RDF, armazenado em um arquivo individual, resultante da conversão dos dados da Tabela 1.1. . . . . . . . . . . . . . . . . . . . . . . . 40

4.5 Módulos do sistema ArquiTag com suas entradas e saídas estendido. Para a avaliação 90\% das instâncias são utilizadas para construir a árvore de similaridade, e os 10\% restantes são utilizadas para as recomendações. . . . . . . . . . . . . . . . . . 41

4.6 Modelo estendido do Arquigrafia. . . . . . . . . . . . . . . . . . . . . . . 44

4.7 Seleção no DBpedia das instâncias que correspondem aos valores literais da propriedade Autor no Arquigrafia. . . . . . . . . . . . . . . . . . . . . 45

4.8 Atribuição às referências no DBpedia através da propriedade Autor. . . . . . . . . . . 46

4.9 Importação das instâncias do DBpedia e dos modelos que a definem, através da propriedade Autor. . . . . . . . . . . . . . . . . . 46

4.10 Seleção no DBpedia das instâncias que correspondem aos valores literais da propriedade temEstiloArtistico no Arquigrafia. . . . . . . . . . . . . . . . . . 47

4.11 Atribuição às referências no DBpedia através da propriedade temEstiloArtistico. . . . 47

4.12 Importação das instâncias do DBpedia e dos modelos que a definem, através da propriedade temEstiloArtistico. . . . . . . . . . . . . . . . . . . 48

5.1 Medidas de precisão, com desvio-padrão, para os modelos da Tabela 5.1 com diferentes combinações de $[\alpha, \beta, \gamma]$ considerando o conjunto completo de tags. Os valores entre parenteses indicam o número médio de tags recomendadas por experimento. .

5.2 Medidas de cobertura, com desvio-padrão, para os modelos da Tabela 5.1 com diferentes combinações de $[\alpha, \beta, \gamma]$ considerando o conjunto completo de tags. Os valores entre parenteses indicam o número médio de tags recomendadas por experimento. . . 53

5.3 Número de ocorrências por tag. Note que somente 100 tags ocorrem mais do que 20 vezes nas instâncias do Arquigrafia. . . . . . . . . . . . . . . . . 53

5.4 Medidas de precisão para os modelos da Tabela 5.1 com diferentes combinações de $[\alpha, \beta, \gamma]$ considerando somente as 10 tags mais populares. . . . . . . . . . . . 54

5.5 Medidas de cobertura para os modelos da Tabela 5.1 com diferentes combinações de $[\alpha, \beta, \gamma]$ considerando somente as 10 tags mais populares. . . . . . . . . . . 54

5.6 Medidas de precisão da tag Estrutura . . . . . . . . . . . . . . . . . . . . . . . . . . . . . 55

5.7 Medidas da precisão da tag Residência. . . . . . . . . . . . . . . . . . . 55 


\section{Lista de Tabelas}

1.1 Propriedades definidas no vocabulário Arquigrafia cujas valores referem-se à imagem do Palácio Gustavo Capanema (Figura 1.1) . . . . . . . . . . . . . . . . 3

1.2 Tags associadas à imagem ilustrada na Figura $1.1 \ldots \ldots \ldots$

1.3 Instância adicionada ao banco de dados Arquigrafia. . . . . . . . . . . . . . . . 3

2.1 Resultado da consulta realizada pelo SPARQL da Figura 2.9. . . . . . . . . . . . 11

2.2 Sub-linguagens da OWL. . . . . . . . . . . . . . . . . . . . . . . . . . . . . . 12

3.1 Exemplo de similaridade para um conjunto de instâncias. . . . . . . . . . . . . . 22

3.2 Exemplo de conjuntos de tags associados ao conjunto de instâncias $\{A, B, C, D\}$. . 25

4.1 Triplas do registro mostrado na Tabela 1.1. . . . . . . . . . . . . . . . . . 38

4.2 Exemplos de descrições de algumas instâncias do Arquigrafia. . . . . . . . . . . . . . . 43

4.3 Termos extraídos da propriedade Descrição do Arquigrafia. . . . . . . . . . . . . . . . 43

4.4 Estilos artísticos inferidos a partir da Data da obra . . . . . . . . . . . . . . . . . 45

5.1 Modelos do Arquigrafia. . . . . . . . . . . . . . . . . . . 51

5.2 As 10 tags mais populares no Arquigrafia e o número total de vezes que elas ocorrem. 53 


\section{Lista de Símbolos}

API

Application Programming Interface

HTML

HyperText Markup Language

HTTP

HyperText Transfer Protocol

OWL

Web Ontology Language

RDF

Resource Description Framework

\section{RDF-S}

Resource Description Framework Schema

\section{SOAP}

Simple Object Access Protocol

\section{SPARQL}

SPARQL Protocol And RDF Query Language

\section{URI}

Uniform Resource Identifier

\section{URL}

Uniform Resource Locator

\section{W3C}

World Wide Web Consortium

XML

eXtended Markup Language

\section{XML-S}

eXtended Markup Language Schema 


\section{Capítulo 1}

\section{Introdução}

A Web contém uma imensurável quantidade de informação. Essa informação está interconectada e encontra-se distribuída na forma de páginas, imagens, vídeos, documentos, entre outros. Em outras palavras, a Web pode ser comparada a um enorme grafo, em que os nós deste grafo representam os recursos (documentos, páginas, imagens, etc) e os arcos representam os links (ou relacionamento) entre eles. A forma dinâmica com que são adicionados novos arcos e nós a esse grafo caracteriza a Web como uma grande rede de informação desestruturada. Logo, compartilhar e recuperar determinada informação pode ser difícil [Xu et al., 2006].

Páginas, imagens e vídeos são exemplos do que é denominado um recurso Web. Um recurso é, por definição, qualquer entidade que tenha uma identificação [Breitman et al., 2007]. Um recurso pode ser uma entidade digital (tal como documentos, imagens eletrônicas etc.) [Koivunen e Miller, 2001], uma entidade física (por exemplo, um livro identificado pelo seu ISBN - International Standard Book Number), ou ainda uma coleção de outros recursos [Breitman et al., 2007]. No caso de um recurso $W e b$, sua identificação é o Uniform Resource Identifier (URI), uma sequência de caracteres que tem por função identificar um recurso na Web através de um endereço eletrônico [Breitman et al., 2007].

Numa tentativa de estruturar a informação na Web, os recursos podem ser descritos através de um conjunto de propriedades e seus valores, definidos de acordo com um vocabulário controlado, i.e., um conjunto restrito e previamente conhecido de termos definidos pelo projetista de um sistema Web. O uso de um banco de dados para armazenar informações da Web é usualmente associado à denominada Deep Web ou Hidden Web [Hogan et al., 2011]. Deep Web refere-se à informação armazenada em banco de dados e que só pode ser acessada através de uma interface, usualmente por uma página Web [Hogan et al., 2011]. Tal informação é dificil de ser acessada, pois seu acesso é realizado quase que unicamente através da interface programada por um especialista que conhece o esquema de armazenamento do banco de dados - caracterizando um sistema fechado.

Uma outra forma de armazenar os recursos Web é com o uso da Web Semântica. Web Semântica é o uso de uma linguagem formal para representar o conhecimento conceitual de um determinado domínio de conhecimento presente na Web de forma estruturada e compreensível. Para descrever os recursos são adotadas linguagens específicas, e as descrições, por outro lado, não são armazenadas num banco de dados, permanecendo acessíveis independente de uma interface - caracterizando um sistema aberto. Dessa forma, a Web Semântica busca tornar a Deep web mais acessível, contando que os recursos sejam descritos com uma linguagem descritiva padrão [Hogan et al., 2011] disponível na Web para ser amplamente compartilhada.

Há ainda uma outra forma de estruturar a Web: através da associação de tags aos recursos Web. Tags são anotações de texto simples, atribuídas a um recurso Web e que não necessariamente estão relacionadas a um vocabulário controlado. Geralmente, uma tag busca descrever alguma característica do recurso Web associado.

Por exemplo, a Figura 1.1 mostra a imagem de um edifício catalogado no sistema Arquigrafia ${ }^{1}$, um recurso Web cujo URI é "http://www.arquigrafia.org.br/photo/1220" e suas respectivas tags. O projeto Arquigrafia tem como finalidade catalogar e descrever imagens de projetos arquitetônicos, tais como edifícios, parques ou praças, através de um sistema Web de banco de dados. Cada imagem catalogada possui um conjunto de valores para as propriedades que as descrevem, dados pelo

\footnotetext{
${ }^{1}$ http://arquigrafia.org.br
} 
fornecedor da imagem. As propriedades definidas para descrever uma imagem no sistema Arquigrafia são exibidas na Tabela $1.1 \mathrm{com}$ um exemplo de valores dados ao Palácio Gustavo Capanema (Figura 1.1). As propriedades Nome, Descrição, Imagem, Autor, Autor da Imagem, Data da obra, Estado, Cidade, Bairro e Endereço fazem parte de um vocabulário controlado, enquanto que as tags associadas a cada imagem fazem parte de um vocabulário aberto.

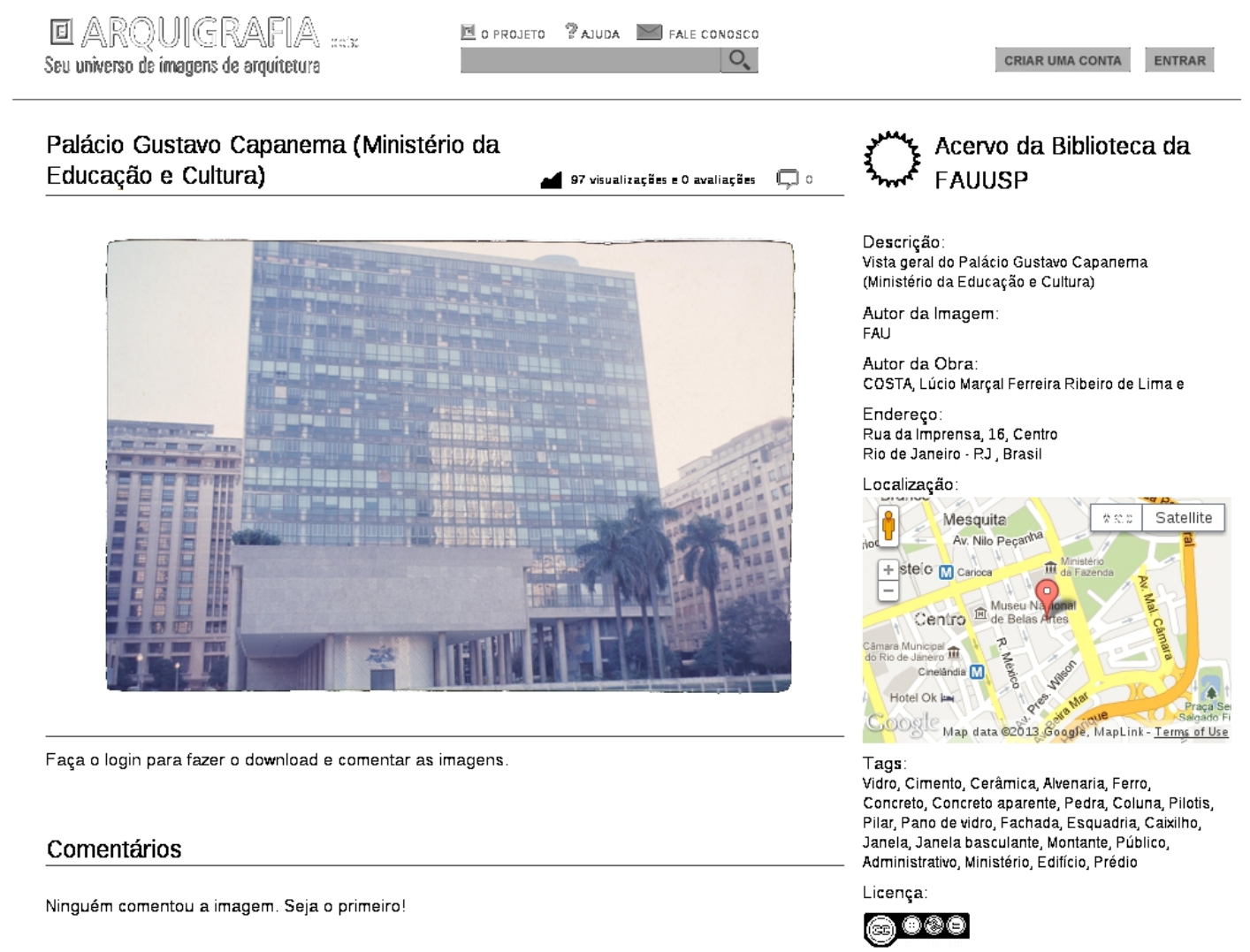

Figura 1.1: Exemplo de um recurso Web do sistema Arquigrafia. A URI definida para este recurso é "http://www.arquigrafia.org.br/photo/1220".

Tags podem ser usadas para a construção de uma ferramenta de recuperação da informação. O uso de tags permite ao usuário do sistema recuperar o recurso previamente marcado por ele, além de possibilitar a descoberta de novos recursos também marcados por outros usuários [Xu et al., 2006]. Em geral, para que a atribuição de tags a recursos Web funcione, a suposição aceita é de que, apesar da ausência de um vocabulário, existe um senso comum por parte dos usuários na interpretação do significado de determinada tag [Aurnhammer et al., 2006]. Diversos sites na Web adotam o uso de tags para descrever recursos, tais como, por exemplo, o Flickr ${ }^{2}$ (anotações de imagens) e o Del.icio.us ${ }^{3}$ (anotações de páginas Web).

Dada a atual importância das tags na Web, o objetivo deste trabalho é a criação de um sistema que possa recomendar ou predizer tags para um novo recurso Web baseado na similaridade deste novo recurso com os demais já existentes no sistema. Por exemplo, se for adicionada ao sistema Arquigrafia a instância descrita na Tabela 1.3, e esta for considerada similar à instância descrita na Tabela 1.1, o resultado da recomendação deverá ser um sub-conjunto das tags apresentadas na Tabela 1.2 .

Mais formalmente, o problema de recomendação de tags é: dado um conjunto $C$ de tuplas $\langle r, T\rangle$ onde $r$ é um recurso e $T$ é um conjunto de tags, a recomendação de tags consiste em prever o conjunto de tags $T^{\prime}$ para um novo recurso $r^{\prime}$ acrescentado em $C$ [Heymann et al., 2008].

\footnotetext{
${ }^{2}$ http://www.flickr.com

${ }^{3}$ https://delicious.com/
} 
Tabela 1.1: Propriedades definidas no vocabulário Arquigrafia cujas valores referem-se à imagem do Palácio Gustavo Capanema (Figura 1.1)

\begin{tabular}{|r|l|}
\hline Propriedade & Valor \\
\hline \hline Id: & 1220 \\
Nome: & Palácio Gustavo Capanema (Ministério da Educação e Cul- \\
tura) \\
Descrição: & Vista geral do Palácio Gustavo Capanema (Ministério da \\
& Educação e Cultura) \\
Imagem: & http://www.arquigrafia.org.br/photo/img-show/1220.jpeg \\
Autor do projeto: & COSTA, Lúcio Marçal Ferreira Ribeiro de Lima e \\
Autor da imagem: & FAU \\
Data da obra: & $1936-07-31$ \\
Estado: & RJ \\
Cidade: & Rio de Janeiro \\
Bairro: & Centro \\
Endereço: & Rua da Imprensa, 16
\end{tabular}

Tabela 1.2: Tags associadas à imagem ilustrada na Figura 1.1

Vidro, Cimento, Cerâmica, Alvenaria, Ferro, Concreto, Concreto aparente, Pedra, Coluna, Pilotis, Pilar, Pano de vidro, Fachada, Esquadria, Caixilho, Janela, Janela basculante, Montante, Público, Administrativo, Ministério, Edíficio, Prédio

O objetivo deste trabalho é a construção de um sistema de recomendação de tags para o sistema Arquigrafia, denominado ArquiTag, que representa as instâncias do Arquigrafia, e seus respectivos valores, na linguagem RDF da Semântica Web e usa essa representação, taxonômica e relacional, para a construção de uma árvore de similaridade com marcações das tags. Essa árvore é então utilizada para a recomendação de tags para novas instâncias do Arquigrafia. O sistema ArquiTag é analisado utilizando diferentes modelos do banco de dados Arquigrafia incluindo uma taxonômia e referências a instâncias na Web Semântica, mais especificamente, ao repositório Linked Data do DBpedia [Auer et al., 2007].

A organização do texto segue o seguinte formato: o Capítulo 2 introduz a Web Semântica, as linguagens utilizadas para a descrição de recursos e o Linked Data; o Capítulo 3 apresenta a métrica de similaridade e descreve o algoritmo utilizado para a recomendação de tags; o Capítulo 4 descreve o sistema ArquiTag, apresenta o modelo original do banco de dados RDF do Arquigrafia, um

Tabela 1.3: Instância adicionada ao banco de dados Arquigrafia.

\begin{tabular}{|r|l|}
\hline Propriedade & Valor \\
\hline \hline Id: & 1397 \\
Nome: & Teatro Municipal do Rio de Janeiro \\
Descrição: & Vista para o Teatro Municipal do Palácio Gustavo Capa- \\
& nema \\
Imagem: & http://www.arquigrafia.org.br/photo/img-show/1397.jpeg \\
Autor: & Lúcio Costa, Oscar Niemeyer e Affonso Eduardo Reidy \\
Autor da imagem: & CHENKER, Débora \\
Data da obra: & 1936-08-17 \\
Estado: & Rio de Janeiro \\
Cidade: & Rio de Janeiro \\
Bairro: & Centro \\
Endereço: & Rua da Imprensa, 16 \\
\hline
\end{tabular}


modelo estendido taxonômico e como são feitas referências ao Linked Data da DBpedia; o Capítulo 5 apresenta uma análise do experimento; e o Capítulo 6 contém as conclusões. 


\section{Capítulo 2}

\section{Web Semântica}

Web Semântica é o uso de uma linguagem formal para representar o conhecimento conceitual de um determinado domínio de conhecimento presente na Web de uma forma estruturada e compreensível. Na prática, a Web Semântica refere-se ao uso de linguagens de descrição (description logic) para estruturar determinadas informações, tornando explícito seu significado. Uma vez que a informação esteja explicitamente descrita, é possível aplicar ferramentas computacionais de inferência lógica, como as ferramentas Sesame [Broekstra et al., 2002] e Jena [McBride, 2001].

A Figura 2.1 exibe as diferentes camadas de expressividade existentes na Web Semântica.

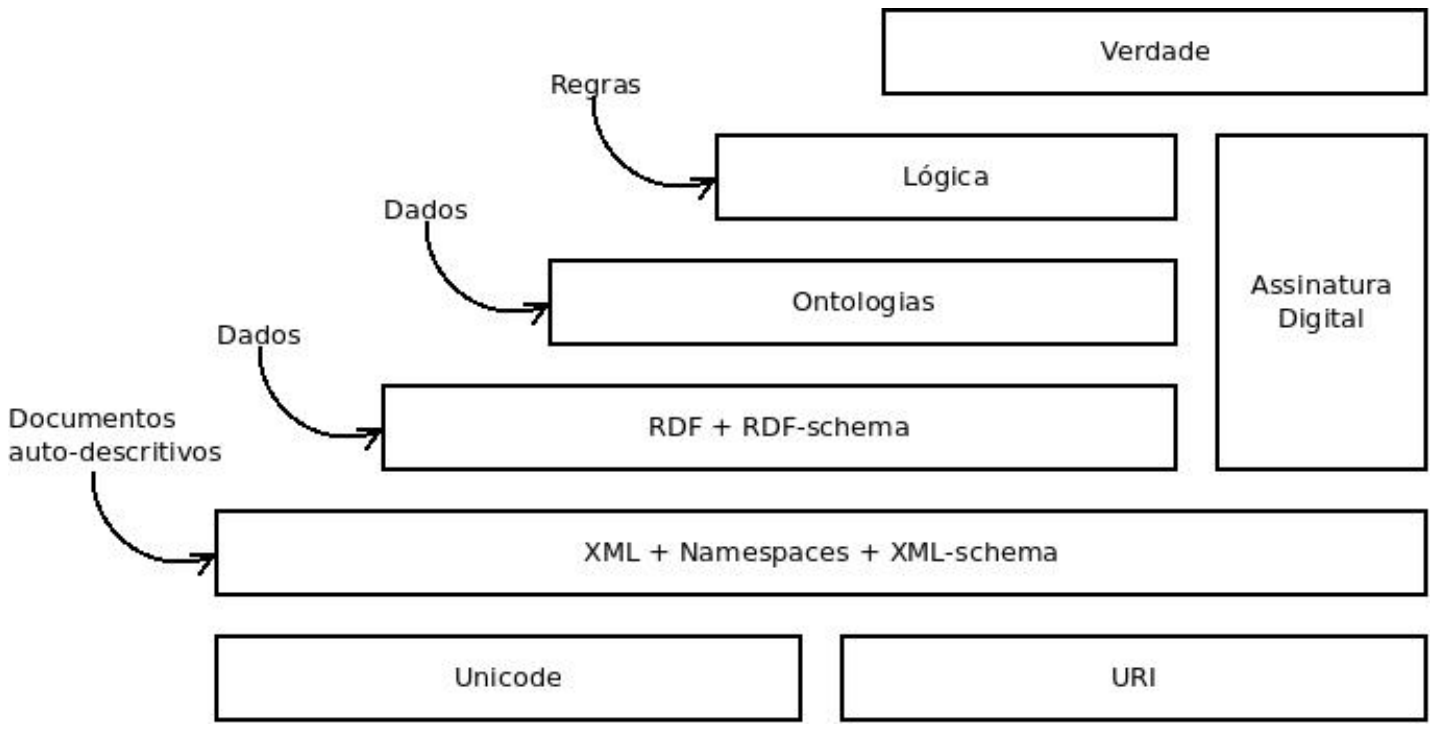

Figura 2.1: Camadas da Web Semântica (Figura traduzida de [Koivunen e Miller, 2001]).

Na Figura 2.1, as camadas mais baixas definem a codificação e o acesso às informações na Web. O uso da codificação Unicode possibilita o uso de caracteres internacionais na representação dos recursos [Koivunen e Miller, 2001], e o Uniform Resource Identifier (URI), similar ao Uniform Resource Locator (URL), permite associar um identificador único e global ao recurso. A diferença entre URL e URI esta no fato de que o URL identifica um documento na Web, enquanto o URI pode identificar um recurso, seja um documento Web ou não [Koivunen e Miller, 2001].

A Figura 2.1 exibe também as linguagens de descrição que compõem a semântica Web. São elas: eXtended Markup Language (XML), Resource Description Framework (RDF) e OWL. A linguagem XML é a base para as demais linguagens de descrições, pois possibilita a criação de documentos auto-descritivos. As demais (RDF e OWL) são voltadas à descrição de recursos e com diferentes níveis de expressividade (essas diferenças serão comentadas mais adiante).

As camadas de "lógica", "prova" e "verdade" na Figura 2.1 indicam as camadas de raciocínio lógico sobre o conteúdo descrito nas camadas inferiores. A "verdade" corresponde ao resultado da "prova" que, por sua vez, é o resultado de inferências lógicas que dependem das regras impostas ao domínio descrito [Koivunen e Miller, 2001]. Por fim, a camada de "assinatura digital" corresponde à assinatura associada aos documentos da Web e pode influenciar na confiabilidade das descrições 
utilizadas.

\subsection{Linguagens da Web Semântica}

\subsection{1 eXtended Markup Language (XML)}

O XML é uma linguagem de marcação de propósito geral, designada para descrever documentos estruturados [Breitman et al., 2007]. Porém, diferentemente da linguagem HyperText Markup Language (HTML), a glsxml não é destinada à exibição de dados num navegador.

A linguagem XML permite ao autor do documento especificar suas próprias marcações. Enquanto o HTML possui marcações fixas para parágrafos, cabeçalhos, cores, posicionamento, etc, o XML dá liberdade para que essas marcações sejam especificadas de acordo com a necessidade. Essa característica permite usar o XML para descrever a semântica de qualquer conteúdo, dando melhorias significativas em processos de recuperação e disseminação da informação [Almeida, 2002]. Assim, é possível descrever qualquer informação para transmissão, processamento ou armazenamento deste por um programa [Almeida, 2002].

De acordo com as especificações dos objetivos da linguagem, um documento XML [Bray et al., 2008]:

- deve ser de fácil criação;

- deve ser diretamente utilizado através da Internet;

- pode suportar uma grande variedade de aplicações;

- deve facilitar a implementação de programas que o interprete;

- deve ser legível para um humano;

- deve ter um design formal e conciso.

Um exemplo de documento XML é exibido na Figura 2.2.

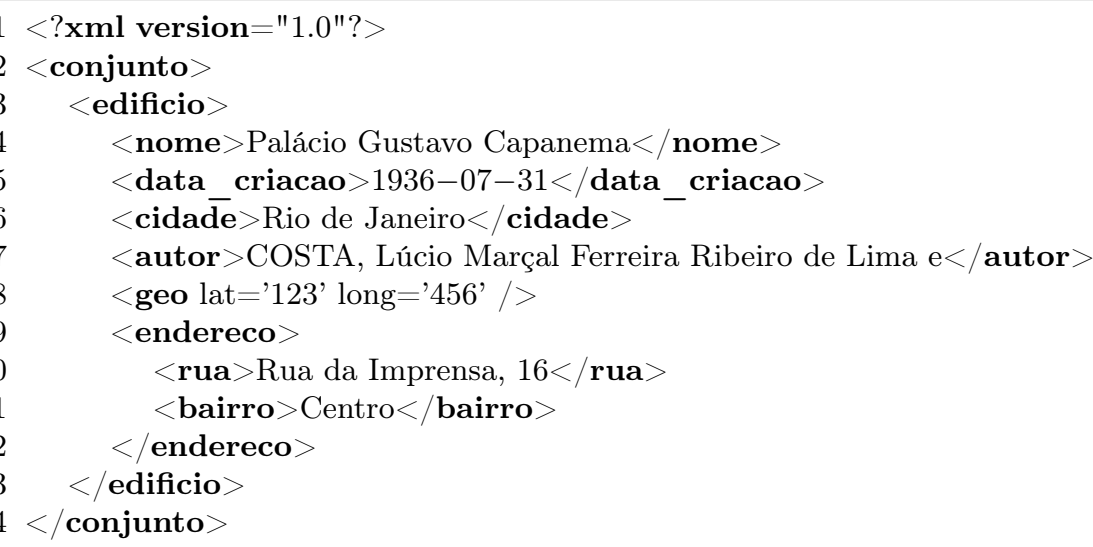

Figura 2.2: Exemplo de documento XML.

No XML, uma marcação consiste de seu início, seu conteúdo e seu fim. Por exemplo, na linha 4, os elementos " $<$ nome $>$ " e " $</$ nome $>$ " correspondem, respectivamente, ao início e fim de uma marcação e o elemento "Palácio Gustavo Capanema" corresponde ao seu conteúdo. Uma marcação também pode ter como conteúdo outras marcações, como é o caso de "<endereco $>$ " e "<edificio $>$ " no exemplo, ou pode não ter conteúdo, como é o caso de "<geo $>$ " na linha 8 (nesse caso chamada de elemento vazio). Além disso, as marcações podem conter atributos no formato propriedade="valor", como mostra a linha 8 [Bray et al., 2008, Breitman et al., 2007].

Para que se mantenha conciso, um documento XML deve cumprir com algumas regras, entre as quais: toda marcação deve ter início e fim, todas as marcações deve estar aninhadas e o documento como um todo deve estar contido em uma única marcação [Bray et al., 2008, Breitman et al., 2007]. 
A linguagem XML é flexível. Um determinado grupo de pessoas pode, por exemplo, utilizar-se de um mesmo padrão de marcação XML para descrever um documento e compartilhar essa informação através da internet entre suas aplicações. Entende-se por padrão de marcação um conjunto explícito de declarações que permitam validar um documento XML como pertencente ou não a esse padrão. Para isso utiliza-se a linguagem XML-S. O XML-S define uma classe de documentos XML permitindo a definição de tipos de dados simples (como string ou decimal) e complexos para cada elemento [Fallside e Walmsley, 2004]. A Figura 2.3 exibe o código para a validação do código XML da Figura 2.2.

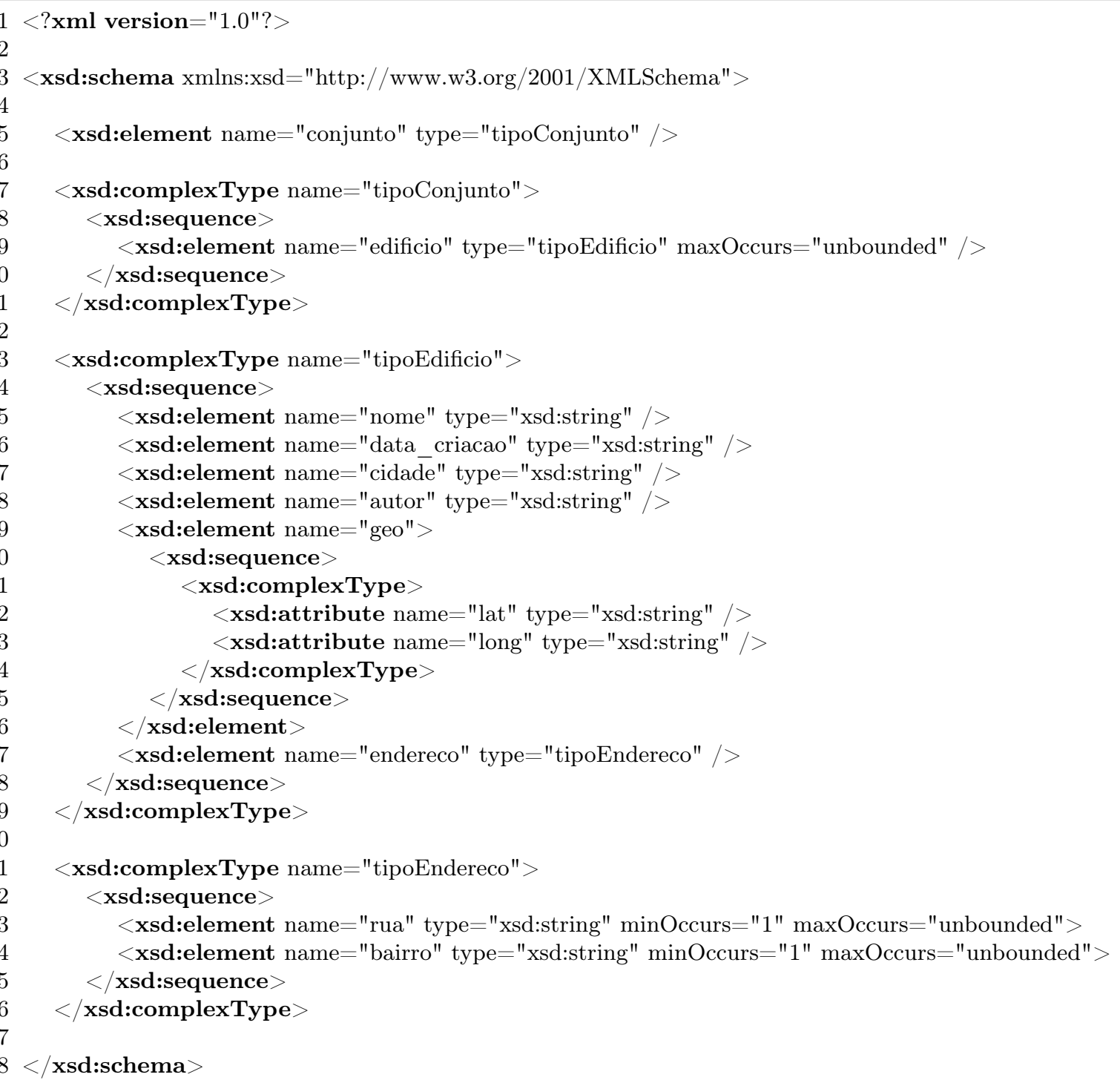

Figura 2.3: Código XML-S que valida o código XML apresentado na Figura 2.2.

O código XML-S exibido na Figura 2.3 classifica o documento XML apresentado na Figura 2.2. No código, usa-se a instrução "xsd:element" para especificar um elemento no documento XML. Por exemplo, a linha 15 define o elemento "conjunto" cujo tipo é "tipoConjunto", o qual é definido logo depois como uma sequéncia, de tamanho indefinido ("unbounded"), de elementos do tipo "edificio". Cada edifício, por sua vez, possuí elementos de "nome", "data_criacao", "cidade", "autor" e assim por diante, e cada um desses elementos possuí um tipo, nesse caso tipos mais simples tais como "xsd:string". Como um mesmo arquivo XML-S pode utilizar diversas definições de tipos disponibilizados na Web, utiliza-se o conceito de namespaces (linha 3 do código da Figura 2.3).

Um namespace define uma referência para uma coleção de tipos e declarações, os quais serão referenciados por um prefixo ao longo do documento [Fallside e Walmsley, 2004]. Na Figura 2.3, é de- 
finido o prefixo "xsd" cujas definições são encontradas em "http://www.w3.org/2001/XMLSchema". A utilização de namespaces é útil para que haja a distinção entre as definições utilizadas no documento [Fallside e Walmsley, 2004]. Por exemplo, na linha 15 é especificado que o elemento "nome" é do tipo "xsd:string", cuja definição deve ser encontrada no endereço do namespace "xsd".

\subsubsection{Resource Description Framework (RDF)}

Embora o XML possibilite a descrição de recursos na Web, como saber, por exemplo, se dois arquivos XML distintos estão se referindo ao mesmo recurso? Ou ainda, como saber se uma marcação "nome" em um arquivo XML corresponde à mesma semântica da marcação "nome" em um outro arquivo XML? A utilização do XML-S e de namespaces auxilia na definição da estrutura de um arquivo XML. No entanto, o XML ainda é muito flexível e não possui nenhuma formalidade na descrição da informação.

O RDF é um conjunto de conceitos cuja finalidade é descrever recursos na Web [Manola e Miller, 2004] e, diferentemente do XML, possui uma forma explícita para a descrição de recursos e informações.

Um documento RDF define um conjunto de triplas na forma $t=\langle s, p, o\rangle$, onde [Klyne e Carroll, 2004]:

- $s$, ou sujeito, é um recurso;

- $p$, ou predicado, é uma propriedade de $s$;

- $o$, ou objeto, é o valor da propriedade $p$ para o recurso $s$.

Uma tripla RDF representa um grafo como exibido na Figura 2.4.

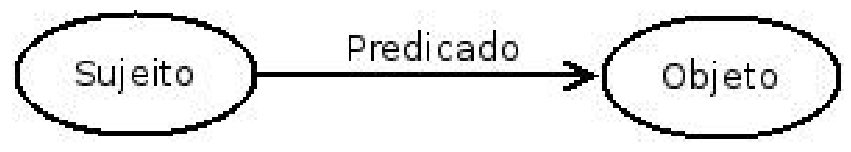

Figura 2.4: $\mathrm{O}$ grafo de uma tripla RDF.

Na Figura 2.4, a seta representa o predicado e parte do sujeito em direção ao objeto. O sujeito é o recurso Web que se deseja descrever, o predicado é alguma propriedade deste sujeito e o objeto é o valor do predicado para esse sujeito (que pode ser uma cadeia de caracteres ou um outro recurso). Por exemplo, para a frase "Palácio Gustavo Capanema fica na cidade de Rio de Janeiro" constrói-se o grafo ilustrado na Figura 2.5.

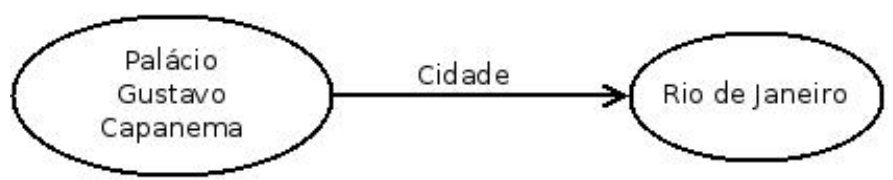

Figura 2.5: Grafo RDF que representa a frase "Palácio Gustavo Capanema fica na cidade de Rio de Janeiro".

Na Figura 2.5, "Palácio Gustavo Capanema", um edifício, reside na cidade do Rio de Janeiro, uma cidade. Se esses conceitos foram descritos em arquivos RDF identificados por uma URI, poderão ser localizados na rede. Logo, por exemplo, é possível estender as propriedades de "Palácio Gustavo Capanema" num grafo RDF. A Figura 2.6 exibe um grafo mais completo.

Os endereços URI exibidos na Figura 2.6 para as propriedades "cidade" e "autor" (e seus respectivos valores) são exemplos e representam referências a recursos Web que contém maiores informações sobre esses recursos. As únicas exceções são os valores para as propriedades "nome" e "data_criacao", os quais são valores literais.

O RDF, como linguagem, pode ser escrito utilizando-se de um conjunto de marcações XML específicas para descrever os recursos, denominada RDF/XML [Manola e Miller, 2004] ${ }^{1}$, a qual é

\footnotetext{
${ }^{1}$ Há outras linguagens para definir e estruturar as triplas RDF, tais como Turtle (http://www.w3.org/TR/turtle/), N3 (http://www.w3.org/TeamSubmission/n3/) e N-Triples (http://www.w3.org/2001/sw/RDFCore/ntriples/)
} 




Figura 2.6: Grafo RDF representando mais propriedades do Palácio Gustavo Capanema.

utilizada neste trabalho. Por simplicidade, "RDF" e "RDF/XML" nesse texto serão usados como sinônimos. O código RDF da Figura 2.6 é exibido na Figura 2.7.

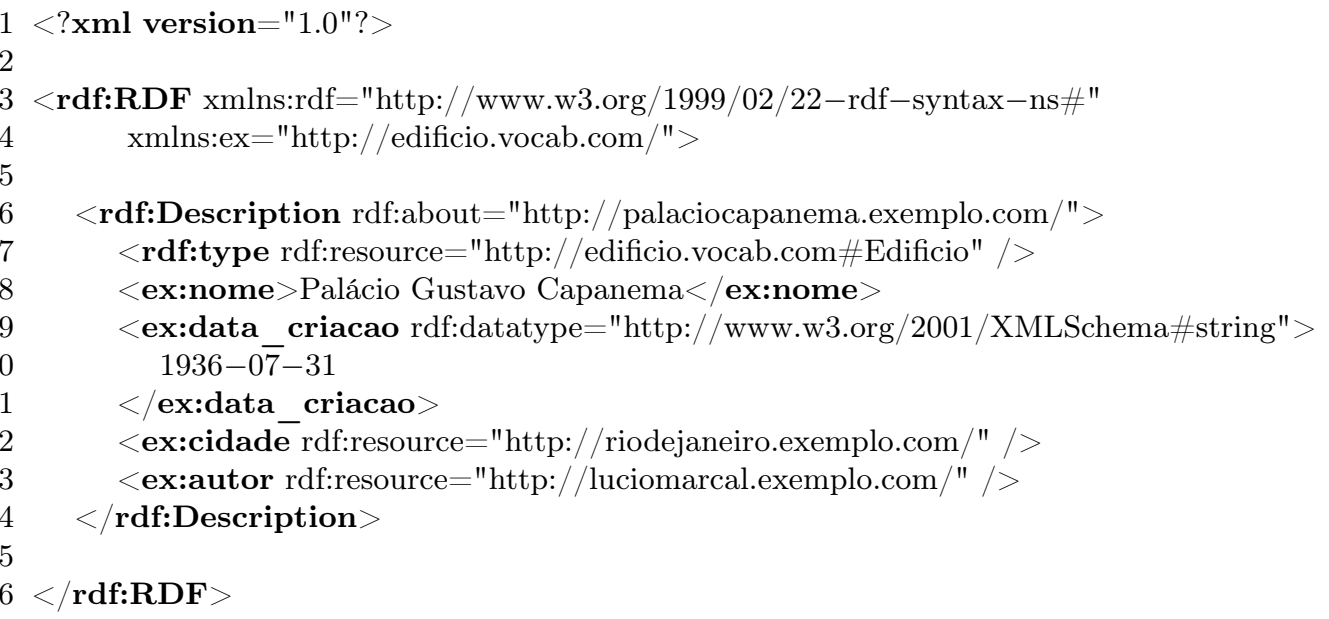

Figura 2.7: Código RDF do grafo exibido na Figura 2.6.

Na Figura 2.7, a marcação "rdf:Description" (na linha 6) define o recurso que será descrito. Entre as linhas 8 e 13 são definidas as propriedades do recurso. Duas dessas propriedades, linhas 12 e 13, referenciam um outro recurso na Web. As demais, linhas 8 e 11, possuem um conjunto de caracteres como valor. Note que a propriedade "data_criacao" conta com a definição do tipo do dado [Beckett, 2004].

Nas linhas 3 e 4 são definidos os namespaces utilizados nesse documento RDF. Assim como na linguagem XML, um namespace em RDF tem o objetivo de distinguir definições de marcações utilizadas no documento. Porém, no contexto da linguagem RDF, esse recebe o nome de vocabulário RDF [Breitman et al., 2007].

O RDF não dispõe de mecanismos para descrever as propriedades e termos utilizados num recurso qualquer. Um vocabulário RDF permite a definição de classes, propriedades e hirarquias, através da linguagem RDF-S. O RDF-S é uma extensão semântica do RDF [Brickley e Guha, 2004] que possibilita a descrição de grupos (ou classes) de recursos relacionados e as relações entre eles. Por exemplo, a linha 6 no código RDF 2.7 especifica que o recurso sendo descrito é do tipo "Pessoa" cuja definição encontra-se no vocabulário especificado pela URI "http://pessoa.vocabulario.com". O RDF-S que define esse vocabulário é exibido na Figura 2.8.

O código RDF-S acima define o vocabulário usado para descrever a instância no código RDF da Figura 2.7. Entre as linhas 3 e 4 estão definidos os vocabulários usados no documento (note que a linguagem RDF-S define a si mesma através do vocabulário especificado na linha 3). A classe "Edi- 


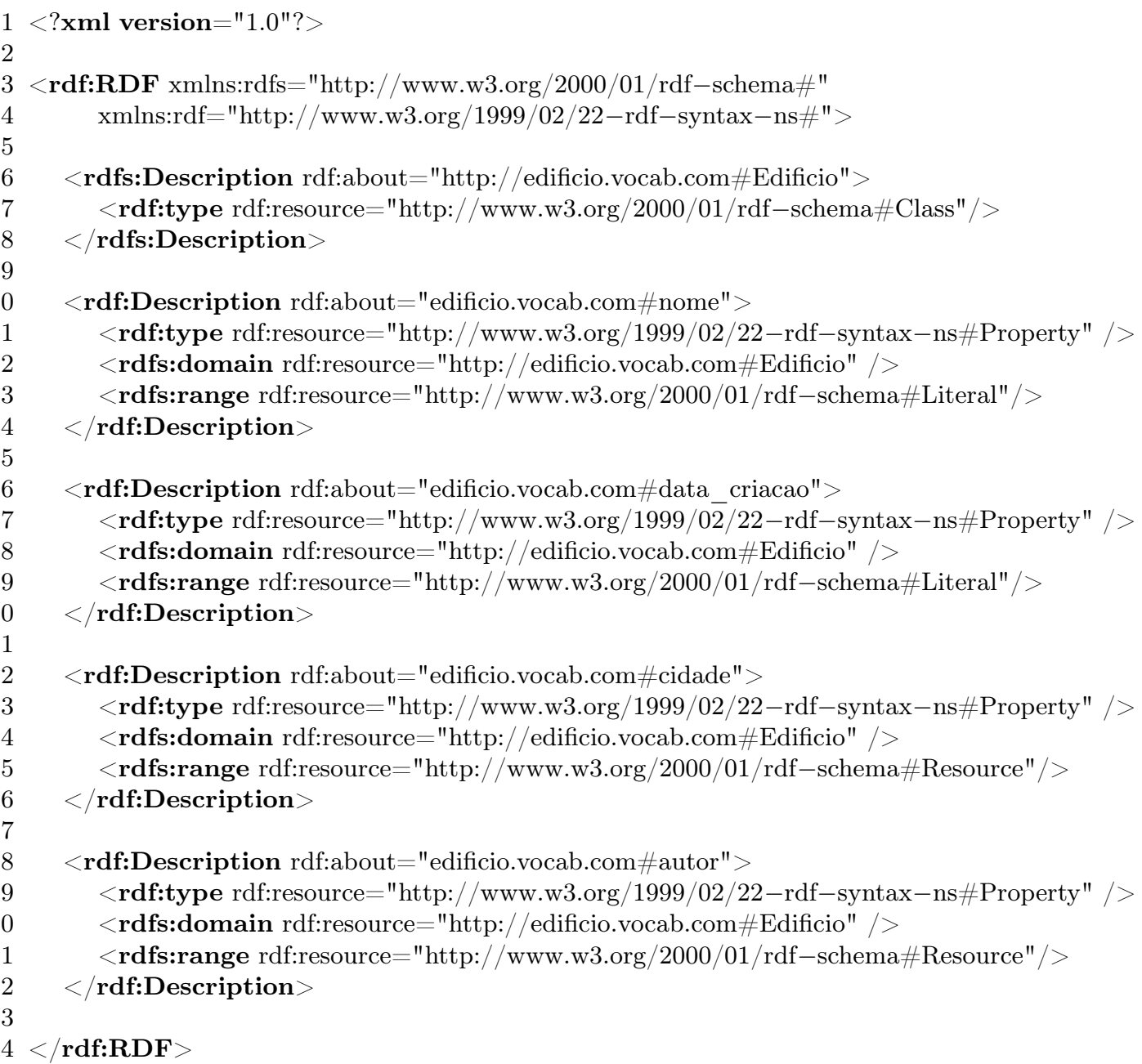

Figura 2.8: Código RDF-S que define o vocabulário usado na Figura 2.7.

ficio" é definida na linha 6. Uma classe, em RDF-S, é qualquer recurso cuja propriedade "rdf:type" tem valor igual a "rdfs:Class" [Breitman et al., 2007, Brickley e Guha, 2004]. Entre as linhas 10 e 28 são definidas as propriedades. Uma propriedade, em RDF-S, é qualquer recurso cujo valor atribuído a "rdf:type" tem valor igual a "rdfs:Property" [Breitman et al., 2007, Brickley e Guha, 2004]. Na definição de uma propriedade, "rdfs:domain" e "rdfs:range" especificam, respectivamente, a qual classe essa propriedade é aplicada e a qual classe pertence seu valor. No código, as propriedades "nome" e "data_criacao" têm, como valor de "rdfs:range", a classe de literais ("rdfs:Literal"), a qual define como valor qualquer sequência de caracteres. E as propriedades "cidade" e "autor" possuem, para a propriedade "rdfs:range", o valor "rdfs:Resoruce". Por definição, toda classe RDF é subclasse da classe "rdf:Resource", significando que qualquer recurso pode ser dado como valor para as propriedades "cidade" e "autor" [Brickley e Guha, 2004, Hayes, 2004, Manola e Miller, 2004].

Dado um vocabulário que define uma classe $C$, uma instância ou indivíduo de $C$ é qualquer recurso cujo valor para a propriedade "rdf:type" seja igual a $C$ [Breitman et al., 2007, Brickley e Guha, 2004, Manola e Miller, 2004]. Dessa forma, por exemplo, o indivíduo "Palácio Gustavo Capanema" descrito na Figura 2.7 é uma instância da classe "Edificio" definida no código RDF-S 2.8.

As descrições de um vocabulário em RDF-S são similares às definições de classe em linguagens orientadas a objetos. Na perspectiva de uma linguagem orientada a objetos, uma classe define as diversas propriedades para os objetos que esta classifica. Analogamente, em um vocabulário RDF são encontradas as definições de classes e propriedades em termos das classes dos recursos a que eles se aplicam [Brickley e Guha, 2004]. 


\section{SPARQL Protocol And RDF Query Language (SPARQL)}

O SPARQL é uma linguagem utilizada para a realização de buscas em triplas RDF [Clark et al., 2008, Prud'hommeaux e Seaborne, 2008]. Considerando o código RDF exibido na Figura 2.7, um exemplo de código SPARQL para efetuar uma busca é dado pela Figura 2.9.



Figura 2.9: Exemplo de consulta SPARQL, considerando o código RDF da Figura 2.7.

Na Figura 2.9, o comando PREFIX (linhas 1 e 2) estabelece quais são os namespaces e vocabulários utilizados na busca. O comando SELECT (linha 4) seleciona um conjunto de variáveis (nesse caso, a variável ?s), as quais conterão o resultado da busca. E o comando WHERE (linha 5) estabelece o padrão de triplas que deve ser buscado no grafo RDF. Esse padrão está descrito na linhas 6 e 7, e busca por todos os projetos que são edifícios e estão localizados na cidade do Rio de Janeiro. O resultado dessa consulta é um conjunto de URIs que identificam os recursos (retornados pela variável ?s) que correspondem com a busca. Esse resultado é exibido na Tabela 2.1 e corresponde a instância da Figura 2.7.

Tabela 2.1: Resultado da consulta realizada pelo SPARQL da Figura 2.9.

\begin{tabular}{|l|}
\hline ?s \\
\hline \hline http://palaciocapanema.exemplo.com/ \\
\hline
\end{tabular}

Em geral, é possível enviar comandos em SPARQL para repositórios RDF disponíveis na Web, tais como o repositório DBpedia discutido mais a frente. Muitos desses repositórios disponibilizam um serviço Web, identificado por um URI, que processam e respondem às consultas SPARQL enviadas.

\subsubsection{Web Ontology Language (OWL)}

O OWL é uma linguagem que permite a definição de classes, propriedades e a descrição de indivíduos [McGuinness e van Harmelen, 2004, Smith et al., 2004]. É definida como um vocabulário, assim como RDF e RDF-S, porém possui maior poder de expressividade.

O vocabulário OWL contém conceitualizações que facilitam a interpretação do conteúdo por um computador [Breitman et al., 2007], permitindo um maior nível de descrições nas classes e propriedades [Breitman et al., 2007, McGuinness e van Harmelen, 2004]. Uma classe em OWL pode conter propriedades que definem a relação entre classes, tais como união, disjunção, restrições, equivalências, interseç̧ões e complementos. A linguagem OWL permite definir propriedades que possam conter características tais como transitividade, simetria, inversa, funcional e inversa funcional.

A expressividade da linguagem OWL é organizada em três sub-linguagens, mostradas na Tabela 2.2 [Breitman et al., 2007, McGuinness e van Harmelen, 2004].

Embora a linguagem OWL esteja muito associada à visão da Web Semântica, a sua adoção é difícil e exige um nível considerado de compreensão para que seja utilizada [Hausenblas, 2009a]. Assim, por ser mais simples e permitir uma ampla adoção, os esforços para descrever recursos na Web Semântica estão mais concentrados na linguagem RDF. Esses esforços e a adoção de princípios para a publicação de dados em RDF são conhecidos como Linked Data. 
Tabela 2.2: Sub-linguagens da OWL.

\begin{tabular}{|l|l|}
\hline Sub-linguagem OWL & Descrição \\
\hline \hline OWL Lite & $\begin{array}{l}\text { Oferece hierarquia de classes e propriedades e um conjunto } \\
\text { de regras limitado. }\end{array}$ \\
\hline OWL DL & $\begin{array}{l}\text { Onde DL é o acrônimo para Description Logic. O nível de } \\
\text { expressividade é maior que o oferecido pela OWL Lite, porém } \\
\text { é limitado à decidibilidade do problema, de modo que possa } \\
\text { ser computável. }\end{array}$ \\
\hline OWL Full & $\begin{array}{l}\text { É a linguagem sem limitações, porém ignora a questões de } \\
\text { decidibilidade. }\end{array}$ \\
\hline
\end{tabular}

\section{$2.2 \quad$ Linked Data}

O Linked Data é uma série de boas práticas para estruturar e conectar os dados na Web [Hausenblas, 2009a]. Essa série de boas práticas cria e alimenta uma enorme rede semântica, conectando recursos de diferentes lugares na Web.

Tecnicamente, Linked Data refere-se à publicação de recursos na Web em um formato padrão para que sejam interpretados por computadores, com descrições explicitamente definidas. Esses recursos devem possuir links para recursos externos e, eventualmente, os recursos externos devem ter links para outros recursos [Bizer et al., 2009].

Em contraste com a visão da web semântica sobre níveis de ontologia e inferência, o Linked Data refere-se puramente à publicação de dados em RDF. Essa simplificação facilita a publicação dos dados e permite uma ampla adoção da tecnologia [Hausenblas, 2009a]. Através do uso do RDF, a rede Linked Data é o grafo formado por diversos recursos descritos e espalhados pela Web [Bizer et al., 2009].

Tim Berners-Lee, um dos pesquisadores junto ao World Wide Web Consortium (W3C) do projeto Linked Data, escreveu os quatro princípios do Linked Data [Berners-Lee, 2009, Bizer et al., 2009, Hausenblas, 2009a]. Segundo ele, desrespeitar esses princípios não afeta a rede, mas fará com que a oportunidade de torná-la interconectada seja perdida [Berners-Lee, 2009]. São eles:

1. Usar URI como nome para os recursos;

2. Usar HyperText Transfer Protocol (HTTP) URIs para que os recursos possam ser acessados;

3. Ao acessar um recurso Web, este deve providenciar informações úteis utilizando os padrões (RDF e RDF-S, por exemplo);

4. Incluir links para outros URIs a fim de habilitar a descoberta de novos recursos Web.

O primeiro princípio refere-se à identificação de um recurso, que deve ser através de seu URI. O segundo princípio aponta para o uso do protocolo HTTP para o acesso aos recursos. O HTTP é atualmente um protocolo altamente difundido, e por isso ele é utilizado. O terceiro princípio sustenta o uso do RDF como a linguagem de descrição padrão. E o último princípio sugere que o recurso acessado deve ter links para outros recursos, de forma a tornar a rede mais interconectada.

O projeto mais visível é o projeto Linked Open Data [Bizer e Health, 2011, Bizer et al., 2009]. Em 2007, inicialmente, o projeto Linked Open Data contava apenas com o grupo envolvido na pesquisa. O objetivo do projeto era identificar dados na Web que pudessem ser compartilhados (livres), convertê-los para RDF de acordo com os princípios do Linked Data e publicá-los na Web [Bizer e Health, 2011, Bizer et al., 2009]. Desde o início, o projeto esteve aberto a qualquer publicação segundo os princípios do Linked Data [Bizer e Health, 2011]. Esse foi um fator determinante no crescimento do Linked Data na Web, criando uma rede de triplas RDF. A Figura 2.10 exibe o crescimento dessa rede ${ }^{2}$. A figura é apenas um indicativo do quanto a rede cresceu com o passar do

\footnotetext{
${ }^{2}$ Essas figuras encontram-se disponíveis em http://lod-cloud.net/
} 
tempo, ela mostra um grafo onde os nós representam conjuntos de triplas RDF (um repositório) e os arcos representam a existência de links entre os repositórios. Quanto maior o nó do grafo, maior é a quantidade de triplas RDF contidas naquele repositório, e quanto mais espesso o arco, maior a quantidade de links entre eles.
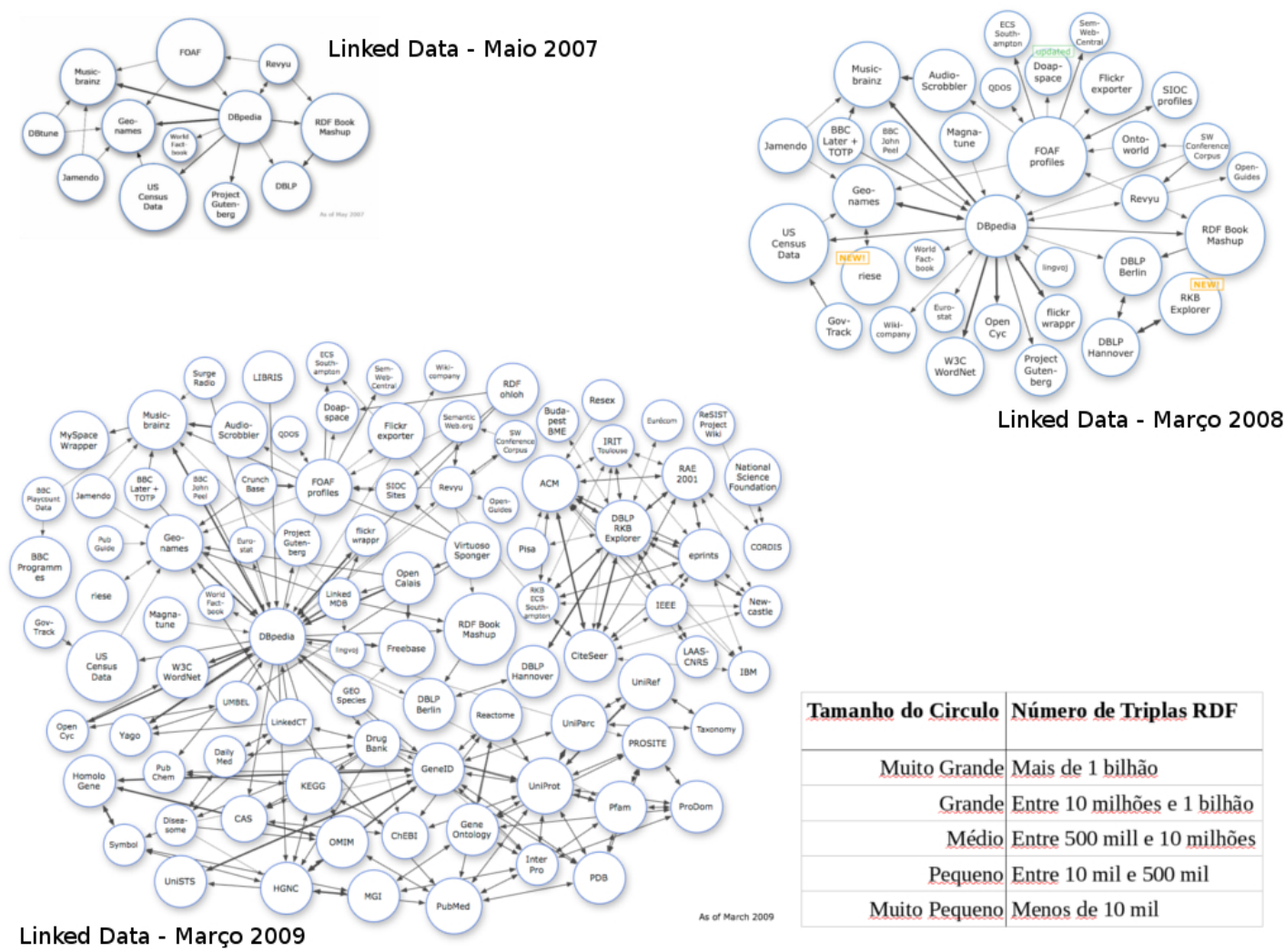

Figura 2.10: O crescimento da rede Linked Data de maio de 2007 a março de 2009 [Bizer e Health, 2011].

Diversas organizações adotaram o Linked Data como forma de publicar dados. O resultado, como mostra a Figura 2.10, é um grafo contendo informações sobre diversos tópicos, tais como localizações geográficas, pessoas, companhias, livros, publicações científicas, filmes, músicas, televisão e muito mais [Hausenblas, 2009a]. A Figura 2.11 exibe o tamanho da rede Linked Data em Setembro de 2011.

O Linked Data pode ser visto como uma camada adicional na Web, e possui algumas das mesmas características dos documentos HTML, além de caracteríticas adicionais, tais como [Bizer e Health, 2011]:

- os dados são genéricos e podem conter todo tipo de informação;

- qualquer pessoa pode publicar dados na rede;

- os dados podem representar informações contraditórias;

- a existência de links entre os recursos;

- as publicações de dados não são limitadas aos vocabulários pré-existentes, i.e., os desenvolvedores podem criar novos vocabulários;

- o dado é auto-descritivo. Se alguma aplicação, enquanto consumindo dados no Linked Data, encontrar alguma informação descrita com o uso de um vocabulário não familiar, basta que a aplicação acesse o URI que define o vocabulário em questão para identificar os termos e suas definições; 


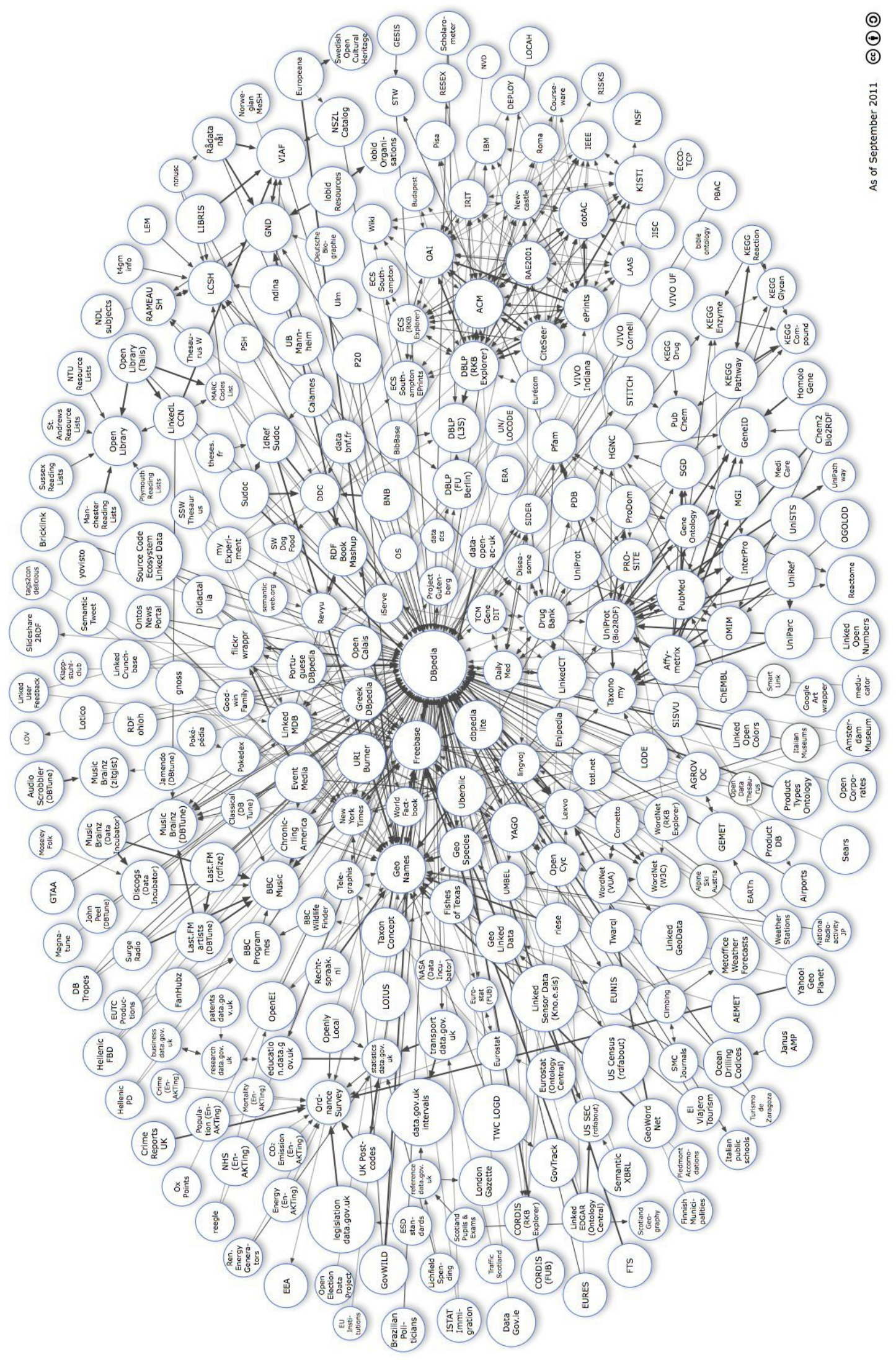

Figura 2.11: A rede Linked Data em Setembro de 2011 [Bizer e Health, 2011]. 
- o uso do padrão HTTP para o acesso e do padrão RDF para a descrição dos dados possibilitam mais facilmente o acesso à informação do que aquele feito por alguma Application Programming Interface (API) na Web.

\subsubsection{Publicação e Consumo}

O uso da rede Linked Data pode ser identificado basicamente através de duas formas: publicação e consumo. A publicação de dados na rede Linked Data refere-se a estruturação e descrição de um conjunto de dados em RDF, tornando-os disponíveis na rede [Hausenblas, 2009b]. E o consumo refere-se a descoberta de dados na rede e o acesso a eles [Hausenblas, 2009b].

A publicação de dados no Linked Data requer a adoção da estrutura dessa rede [Bizer e Health, 2011], bem como a adoção dos princípios básicos listados por Berners-Lee [Berners-Lee, 2009]. É importante notar que a adoção desses princípios e tecnologia não significa o abandono dos gerenciadores e tecnologias já existentes, mas sim a adição de uma nova camada técnica conectada ao Linked Data [Bizer e Health, 2011].

Há diversas formas para se efetuar a publicação no Linked Data [Bizer e Health, 2011]. A Figura 2.12 apresenta algumas delas e divide a publicação em três etapas:

1. Preparação dos dados;

2. Armazenamento dos dados;

3. Publicação dos dados.

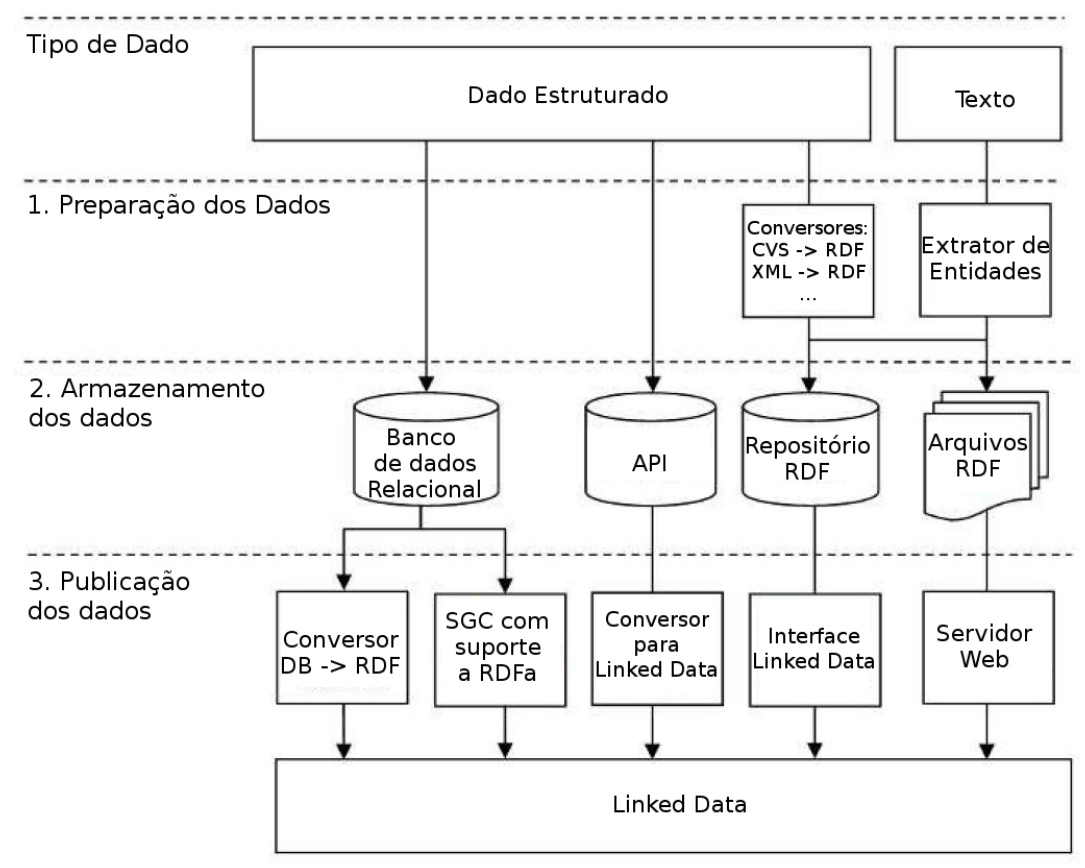

Figura 2.12: Formas de publicação na rede Linked Data (figura traduzida de [Bizer e Health, 2011]).

A preparação dos dados consiste na conversão da informação, estruturada ou não (tipo texto), para a linguagem RDF. Após a extração, o armazenamento pode ser realizado por um repositório RDF ou através de arquivos de texto RDF. Note que nem todo dado necessita ser convertido para RDF, podendo permanecer em um banco de dados ou com um acesso restrito a uma API. Para finalmente tornar os dados públicos, existem diversas opções entre as que estão presentes na Figura 2.12 [Bizer e Health, 2011]:

- A publicação pode ser realizada diretamente do banco de dados através de um conversor para a linguagem RDF; 
- A publicação pode ser realizada através de um Sistema Gerenciador de Conteúdo (como Drupal $^{3}$, por exemplo). Nesse caso, a informação é publicada no formato RDF-S, que é o uso de RDF diretamente num código HTML [Adida et al., 2012];

- Se o acesso à informação é realizado por uma API, a publicação pode ser feita por um conversor que transforma o resultado de uma consulta na linguagem RDF. Geralmente, esses conversores são customizados devido à grande heterogeneidade dessas APIs;

- Caso os arquivos RDF convertidos tenham sido armazenados em um repositório próprio, esse repositório já possui uma interface que permite o acesso aos recursos RDF;

- Ou os arquivos RDF podem simplesmente ser disponibilizados através de um servidor comum, como o Apache $^{4}$, por exemplo.

A escolha na forma de publicação dos dados depende muito da quantidade de dados a ser publicada e da frequência com que esses dados são alterados. Quantidades pequenas de dados com pouca atualização/alteração exigem pouco esforço e, eventualmente, podem ser convertidos para RDF manualmente [Bizer e Health, 2011]. Porém, dados em grandes quantidades e/ou com muitos períodos de atualização/alteração exigem métodos automatizados e/ou customizados de publicação [Bizer e Health, 2011].

Entende-se por "consumo" as etapas de descoberta, acesso e processamento de recursos Web [Hausenblas, 2009b]. Dado um endereço URI, o processo de descoberta refere-se à necessidade de buscar um recurso no Linked Data referente a esse URI. O acesso define o método com o qual o recurso será obtido, se através de uma consulta SPARQL ou pela obtenção de um arquivo RDF. E o processamento refere-se ao uso feito com os dados RDF obtidos. Tipicamente, o resultado do processamento é, novamente, a descoberta de um novo conjunto de endereços URI, os quais podem ser acessados e processados [Hausenblas, 2009b].

\subsubsection{O projeto DBpedia}

O projeto DBpedia ${ }^{5}$ disponibiliza na rede Linked Data mais de 1,95 milhões de informações sobre diversos tópicos, incluindo pessoas, lugares, álbuns de música e filmes, também com links para imagens, páginas, arquivos RDF externos, etc [Auer et al., 2007].

O objetivo do projeto DBpedia é a conversão dos dados da Wikipedia ${ }^{6}$ para o padrão RDF [Auer et al., 2007]. Como outras aplicações na Web, o Wikipedia tem sua busca limitada a palavras, o que ocasiona um acesso muito limitado à sua base de dados [Auer et al., 2007]. Com sua conversão para o formato RDF e publicação segundo os princípios do Linked Data, torna-se possível realizar buscas mais sofisticadas.

O conjunto de dados disponibilizado pela DBpedia é interligado com outros repositórios, como o Geonames ${ }^{7}$, MusicBrainz $^{8}$ e o WordNet $^{9}$ [Auer et al., 2007].

Os recursos da DBpedia são identificados pela URI "http://dbpedia.org/resource/<recurso>", em que "<recurso >" deve ser substituído pelo nome do recurso desejado. O acesso a um recurso pode ser feito através de pontos de acesso SPARQL, através do acesso diretamente ao recurso RDF ou ainda através de uma interface mais amigável proporcionada pelo acesso usando o navegador Web [Auer et al., 2007].

Os dados extraídos disponibilizados como recursos RDF pela DBpedia proveem das infobox, um vocabulário controlado pela Wikipedia para descrever sucintamente os recursos [Auer et al., 2007]. A Figura 2.13 (a) exibe um trecho de um código do Wikipedia que gera o infobox exibido na 2.13 (b).

\footnotetext{
${ }^{3}$ https://drupal.org/

${ }^{4}$ http://httpd.apache.org/

${ }^{5}$ http://dbpedia.org/

${ }^{6}$ http://www.wikipedia.org

${ }^{7}$ http://www.geonames.org/

${ }^{8}$ http://musicbrainz.org/

${ }^{9} \mathrm{http}: / /$ wordnet.princeton.edu/
} 


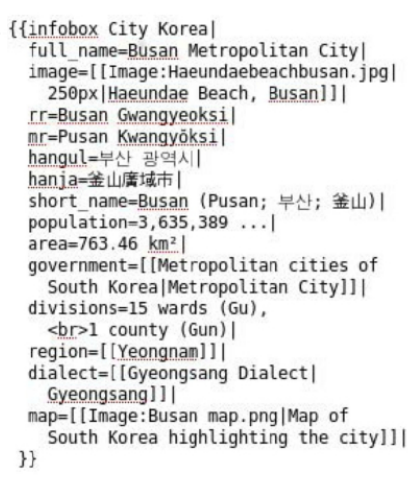

(a)

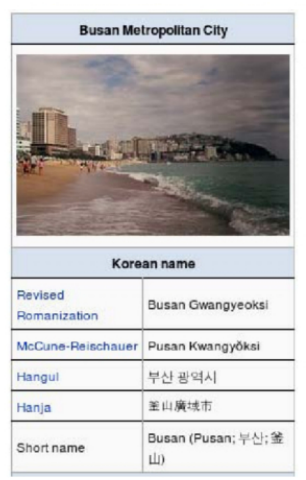

(b)

Figura 2.13: Exemplo de um código do Wikipedia e seu respectivo infobox. Figura extraída de [Auer et al., 2007].

O projeto DBpedia oferece diversos recursos na Web. Trata-se de um excelente ponto de partida para a obtenção de recursos e links para novos recursos na Web sobre praticamente qualquer tópico.

\subsubsection{Sesame}

Sesame $^{10}$ é um sistema que permite armazenar dados RDF ou RDF-S em repositórios, permitindo a subsequente busca de informações [Broekstra et al., 2002]. Ele possui uma arquitetura flexível, sendo possível criar extensões caso necessário. A Figura 2.14 exibe sua arquitetura.

Como mostra a figura, o Sesame possibilita o acesso aos repositório através da Web via protocolo HTTP ou Simple Object Access Protocol (SOAP). Por ser flexível, a arquitetura possibilita criar novos objetos para manipular protocolos que ainda não estejam implementados. A comunicação é então direcionada a um dos módulos que compõem o sistema Sesame. Esses módulos são listados abaixo:

Módulo Administrativo: Este módulo possibilita a inserção de novos dados RDF em um repositório do Sesame. Assim, para realizar inferências usando o Sesame, após fazer uma referência do repositório Sesame a um repositório externo no Linked Data, é preciso importar o modelo (ou parte dele) do repositório externo considerado (por exemplo, o DBpedia) para o repositório local. Para isso, dependendo do projeto em questão é preciso selecionar o vocabulário relevante. Esse módulo também permite a remoção dos dados do repositório.

Módulo de Busca: O módulo de busca do Sesame recebe um pedido de consulta em SPARQL e, comunicando-se com o repositório, retorna o resultado.

Módulo de Exportação: Este módulo acessa o repositório, converte e exporta os dados ali armazenados para o formato RDF/XML.

Na Figura 2.14, todos os módulos comunicam-se com o repositório através de uma camada de abstração, a qual permite abstrair o local onde os dados serão armazenados, tais como arquivos, banco de dados ou diretamente na memória.

\footnotetext{
${ }^{10}$ Disponível em http://www.openrdf.org/
} 


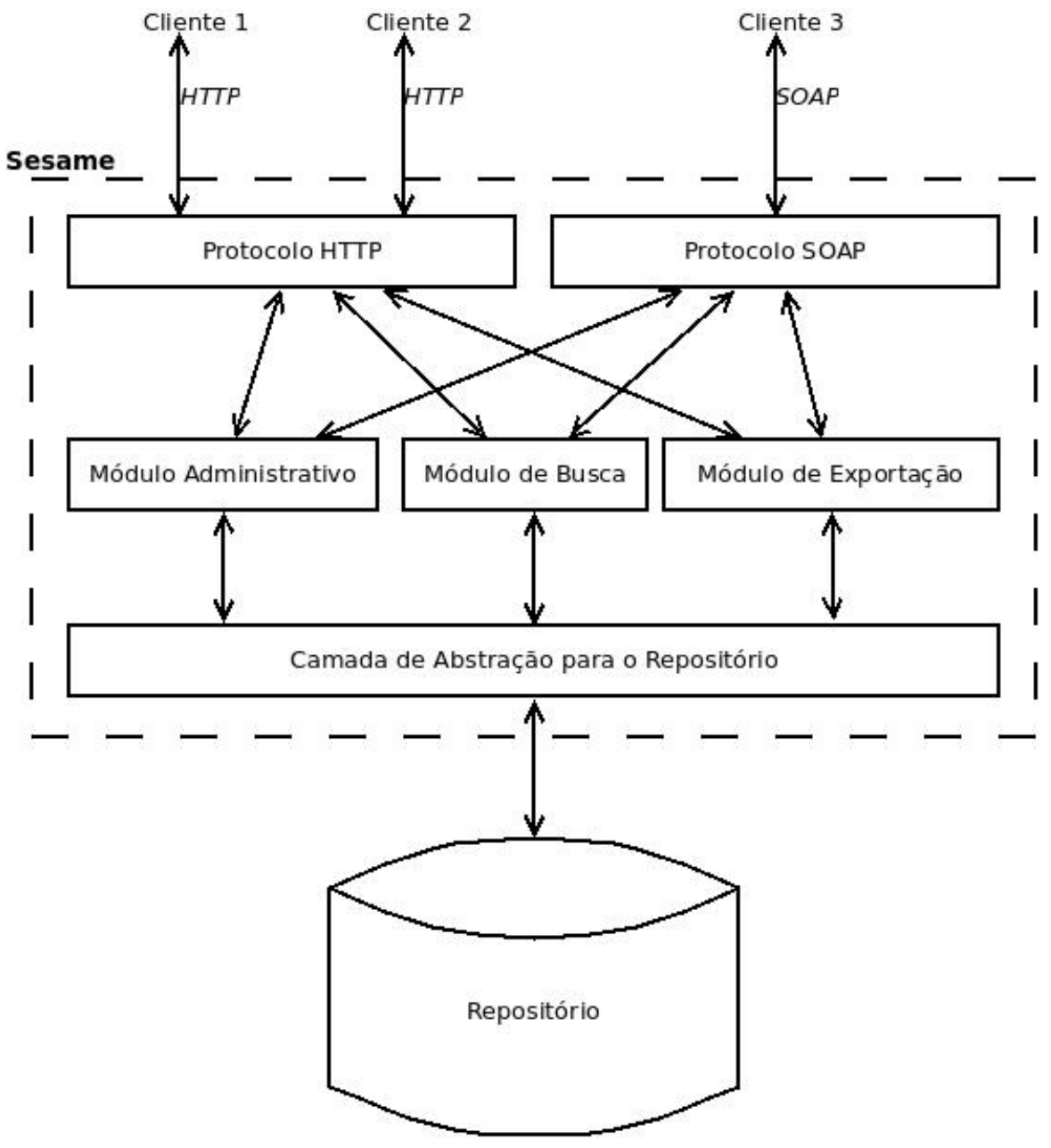

Figura 2.14: Arquitetura do sistema Sesame. Figura extraída de [Broekstra et al., 2002]. 


\section{Capítulo 3}

\section{Recomendação de tags}

Considerando um conjunto $C$ de tuplas $\langle r, T\rangle$, onde $r$ é um recurso Web (por exemplo, uma instância RDF) e $T$ um conjunto de tags, a recomendação de tags consiste em prever o conjunto de tags $T^{\prime}$ para um novo recurso Web $r^{\prime}$ acrescentado em $C$ [Heymann et al., 2008].

O processo de recomendação é realizado utilizando-se um algoritmo de agrupamento hierárquico, apresentado na Seção 3.1, e uma métrica de similaridade entre instâncias RDF, apresentada na Seção 3.2 .

\subsection{Agrupamento Hierárquico}

Agrupamento (ou clustering) é uma técnica que classifica, segundo algum critério, um conjunto de instâncias (ou elementos) em grupos (ou clusters) [Begelman et al., 2006, Grimnes et al., 2008, Manning e Schütze, 1999].

Agrupamento Hierárquico (Hierarcihcal Clustering) é uma técnica de clusterização onde um grupo (ou cluster) $C$ pode ser subdividido em outros dois grupos $\left\{c_{1}, c_{2}\right\}$, tal que $c_{1}, c_{2} \in C$ e $c_{1} \cap c_{2}=\emptyset$ [Witten e Frank, 2005]. Por exemplo, a Figura 3.1 mostra um exemplo de clusterização hierárquica usando diagramas de Venn. Nela, os pontos $A$ e $B$ formam o grupo $\{A, B\}$, os pontos $D$ e $E$ formam o grupo $\{D, E\}$. Por sua vez, $C$ forma o grupo $\{C,\{A, B\}\}$. Finalmente, os grupos formando um único agrupamento.

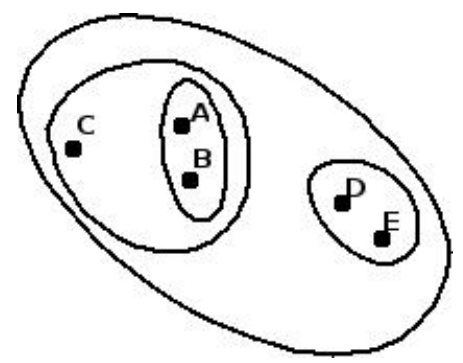

Figura 3.1: Exemplo de clusterização hierárquica usando diagramas de Venn.

O critério utilizado para a classificação hierárquica é uma métrica de similaridade ou distância aplicada aos elementos do domínio [Witten e Frank, 2005]. No exemplo da Figura 3.1, a métrica utilizada é a distância Euclidiana entre os pontos $A, B, C, D$ e $E$.

Usualmente, a representação de um agrupamento hierárquica é realizada através de um dendrograma [Hastie et al., 2001, Manning e Schütze, 1999, Witten e Frank, 2005]. Um dendrograma representa um diagrama similar a uma representação de árvore binária, onde cada nó representa um agrupamento. A Figura 3.2 mostra um exemplo de dendrograma cuja classificação é equivalente à mostrada na Figura 3.1.

Na Figura 3.2, cada nó da árvore representa um agrupamento. Os nós-folha representam um grupo de uma única instância, cada nó interno representa o agrupamento de dois nós-filhos, e o nó-raiz representa todo o conjunto de instâncias [Hastie et al., 2001].

Considerando um número $n$ fixo de instâncias, o agrupamento hierárquico é geralmente realizado através dos algoritmos Aglomerativo ou Divisivo [Hastie et al., 2001, Manning e Schütze, 1999, Witten e Frank, 2005], discutidos a seguir. 


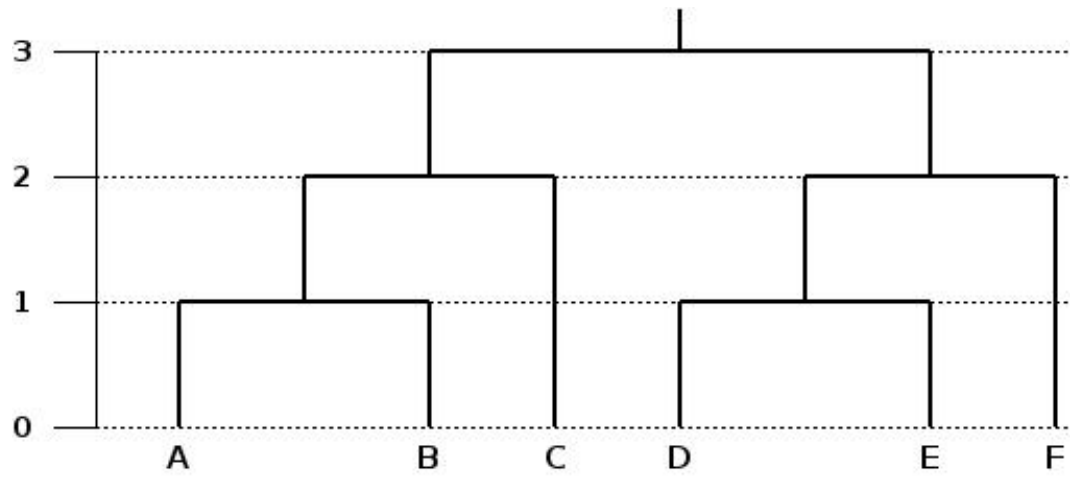

Figura 3.2: Exemplo de um dendrograma.

Algoritmo Aglomerativo Trata-se de um método bottom-up de agrupamento, onde a cada iteração, os grupos mais similares são unificados [Manning e Schütze, 1999, Witten e Frank, 2005]. O algoritmo desse método é exibido no Algoritmo 1 [Manning e Schütze, 1999]. Dado um conjunto $S$ com $n$ instâncias, inicialmente cada instância é considerada um grupo $c_{i}$ isolado (linha 2). Em cada iteração, através de uma métrica de similaridade, obtém-se os grupos mais similares (linha 7), que são agrupados em $C_{j}$ (linha 8 ) e adicionados ao conjunto $C$ (linha 9). Esse processo se repete até que todas as instâncias contidas em $S$ estejam sob um único grupo contido em $C$ (condição da linha 6) [Manning e Schütze, 1999, Witten e Frank, 2005].



Algoritmo Divisivo: Trata-se de um método top-down onde inicialmente um conjunto $S$ de instâncias está inteiramente contido em um único grupo [Manning e Schütze, 1999, Witten e Frank, 2005]. O algoritmo desse método é exibido no Algoritmo 2 [Manning e Schütze, 1999]. Inicialmente, todas as instâncias pertencem a um único grupo em $C$ 1. Em cada iteração determina-se qual é o elemento $c_{u} \in C$ menos coerente (linha 4) e esse é dividido em dois (linha 5) [Manning e Schütze, 1999, Witten e Frank, 2005]. Esse processo se repete até que todos os elementos tenham sido agrupados (linha 3).

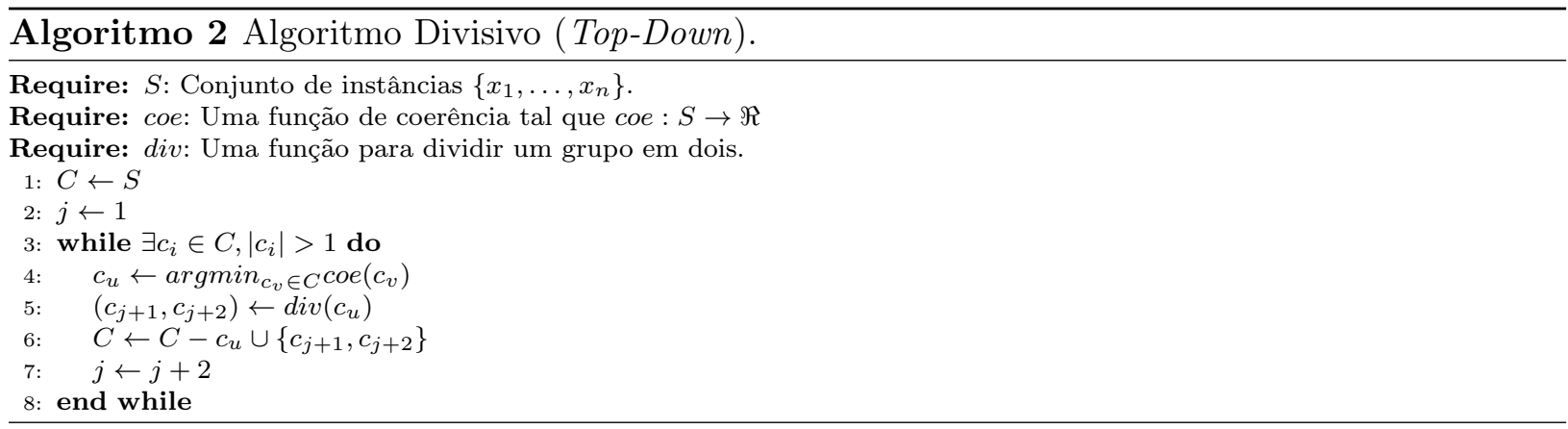

Os algoritmos Aglomerativo e Divisivo possuem um único inconveniente: são aplicados a um 
número $n$ fixo de instâncias. Como a recomendação de tags neste trabalho é realizada para um conjunto crescente de instâncias, é necessário que o algoritmo de agrupamento crie a estrutura de um modo incremental [Witten e Frank, 2005], ou seja, a partir de um grupo inicialmente vazio as instâncias são adicionadas uma por uma na estrutura a medida que vão aparecendo. Por isso, baseado no algoritmo aglomerativo (Algoritmo 1), foi criado um algoritmo que realiza esse procedimento, exibido em Algoritmo 3.

Nesse algoritmo, todo nó da árvore é um grupo definido pela tupla $<s, i, C_{1}, C_{2}, C_{p}>$, onde $C_{1}$ e $C_{2}$ são nós-filhos, $C_{p}$ o nó-pai, $s$ a máxima similaridade entre $C_{1}$ e $C_{2}$, e $i$ a instância armazenada. A função maxSim, presente no algoritmo 3, é definida no espaço $\max \operatorname{Sim}: C \times C \rightarrow[0,1]$ e é calculada de acordo com a expressão 3.1. Em outras palavras, a similaridade entre dois grupos $C_{i}$ e $C_{j}$ é a máxima similaridade entre todas as instâncias contidas em $C_{i}$ e $C_{j}$ [Manning e Schütze, 1999], onde sim é a métrica de similaridade discutida na próxima seção.

$$
\max \operatorname{Sim}\left(C_{i}, C_{j}\right)=\max \left\{\operatorname{sim}(i, j) \mid \forall i \in C_{1} \text { e } \forall j \in C_{2}\right\}
$$



No Algoritmo 3, ao inserir uma nova instância, é criado um novo grupo que a conterá (linha 1). Depois, verifica-se se o nó raiz não é nulo 3. Caso seja, o grupo criado passa a ser o nó raiz (linha 4). Caso contrário, inicia-se a descida pela árvore (linha 8 a 21). A descida na árvore só acontece se o nó apontado pela variável aux não for folha e se o resultado para a máxima similaridade entre aux e a nova instância sendo inserida for maior que o valor de similaridade armazenado em aux (linha 8), isto é, se a nova instância for similar aos nós-filhos de aux. Se for, determina-se qual deles é o mais similar a nova instância (linhas 9 e 10). Isso determina a direção da descida na árvore (linha 14 a 20). Durante a descida na árvore, é possível que, mesmo sendo mais similar a um dos nós-filhos de $a u x$, a nova instância também seja muito similar ao outro nó-filho. Quando isso acontece, o valor 
da similaridade armazenado em aux é atualizado (linha 12). Ao fim da iteração, a nova instância é adicionada e as referências para o nó-pai são atualizadas (linha 22 a 34)

Como exemplo, considere o conjunto de instâncias $\{A, B, C, D, E, F\}$. A Figura 3.3 mostra a construção da árvore, sendo inseridas, nessa ordem, as instâncias C, D, A e B cujas similaridades são mostradas na Tabela 3.1. Ao inserir a instância C (Figura 3.3.a), a árvore se encontra vazia e, portanto, esse passa a ser o nó-raiz da árvore. Ao inserir D (Figura 3.3.b), é criado o grupo $\{C, D\}$. O nó que define o grupo contém a similaridade entre os nós-filhos. A instância A, ao ser inserida, é comparada com as instâncias $\mathrm{C}(\operatorname{sim}(A, C)=0,4)$ e $\mathrm{D}(\operatorname{sim}(A, D)=0,5)$, porém a instância $\mathrm{A}$ não é similar às instâncias $\mathrm{C}$ e $\mathrm{D}$ para continuar descendo a árvore $(\max \{\operatorname{sim}(A, C)=$ $0,4, \operatorname{sim}(A, D)=0,5\}<\operatorname{sim}(C, D))$, sendo inserida um nível acima (Figura 3.3.c). Finalmente, a instância B é mais similar ao grupo $\{C, D\}$ do que ao grupo $\{A\}$ e portanto, é inserido abaixo de A e acima do grupo $\{C, D\}$ (Figura 3.3.d). Note que, na Figura 3.3.d, o valor da similaridade no nó raiz foi atualizado para $\operatorname{sim}(B, A)$, pois $\operatorname{sim}(B, A)>\max \{\operatorname{sim}(A, C)=0,4, \operatorname{sim}(A, D)=0,5\}$ (linha 12 do Algoritmo 3).

Tabela 3.1: Exemplo de similaridade para um conjunto de instâncias.

\begin{tabular}{|c||cccc|}
\hline & A & B & C & D \\
\hline \hline $\mathrm{A}$ & 1 & 0,6 & 0,4 & 0,5 \\
$\mathrm{~B}$ & 0,6 & 1 & 0,5 & 0,7 \\
$\mathrm{C}$ & 0,4 & 0,5 & 1 & 0,8 \\
$\mathrm{D}$ & 0,5 & 0,7 & 0,8 & 1 \\
\hline
\end{tabular}
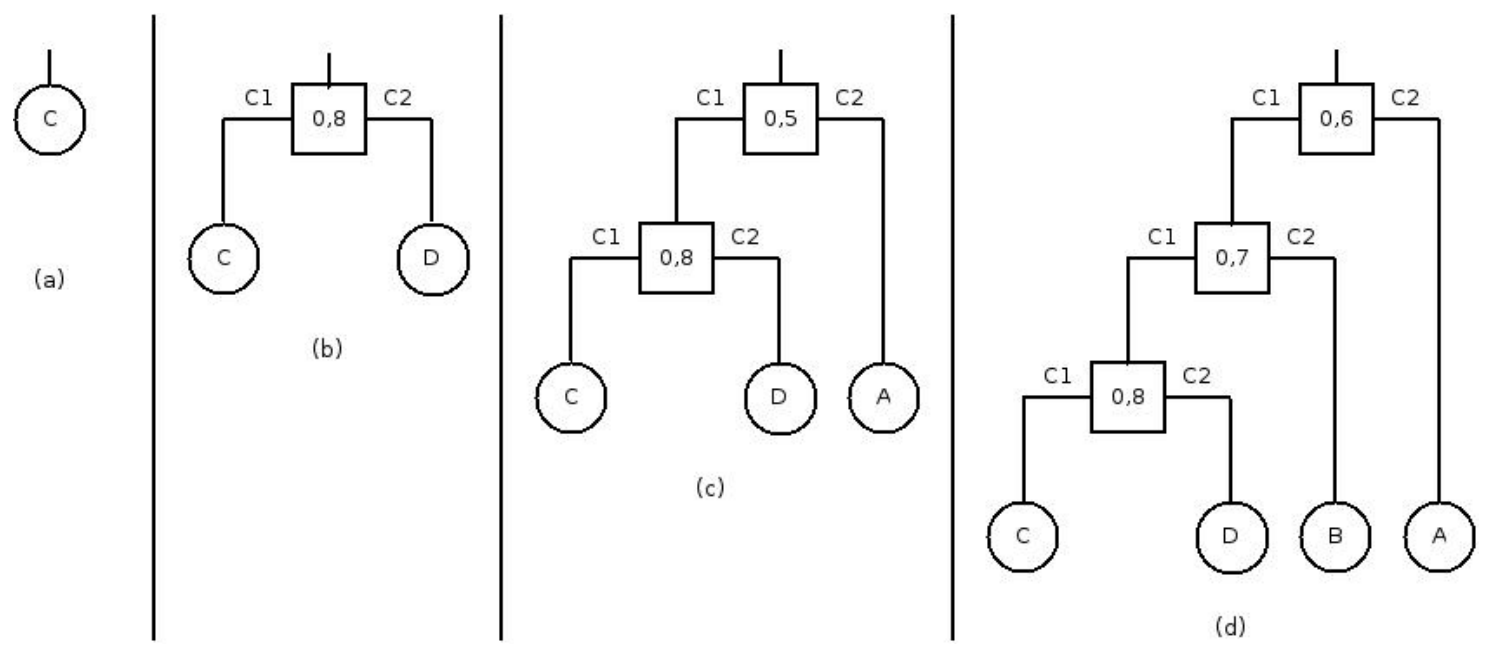

Figura 3.3: Passo a passo da árvore construída a partir das instâncias C, D, A e B (nesta ordem) usando os valores de similaridade da Tabela 3.1 .

É característica da árvore resultante que, para todo nó $n$, o valor de similaridade armazenado nos nós-filhos é sempre maior que o valor armazenado em $n$. Essa característica é esperada, uma vez que deseja-se agrupar as instâncias mais similares. No entanto, dependendo da ordem de inserção das instâncias na estrutura, essa característica pode ser violada. Por exemplo, considere a ordem de inserção A, B, C e D. A árvore resultante é exibida na Figura 3.4. Nessa caso, note-se a violação dessa característica, apontada na figura. Quando essa característica é violada e detectada, é executado um algoritmo de correção. Esse algoritmo é mostrado em Algoritmo 4.

O Algoritmo 4 realiza a troca entre um nó e seu nó-pai. A Figura 3.5 exibe a forma com que o algoritmo funciona. Uma vez detectado o nó cujo valor de similaridade é menor que o valor armazenado em seu nó-pai (Figura 3.5.a), calcula-se os valores de similaridade $s_{1}=\max \operatorname{Sim}(B, C)$ e $s_{2}=\max \operatorname{Sim}(A, C)$ como mostrado na Figura 3.5.b (linhas 12, 13, 26 e 27). O valor que obtiver maior similaridade (na figura, o valor de $s_{2}$ ) passa a ser o novo nó-filho do nó-pai, e são trocadas 


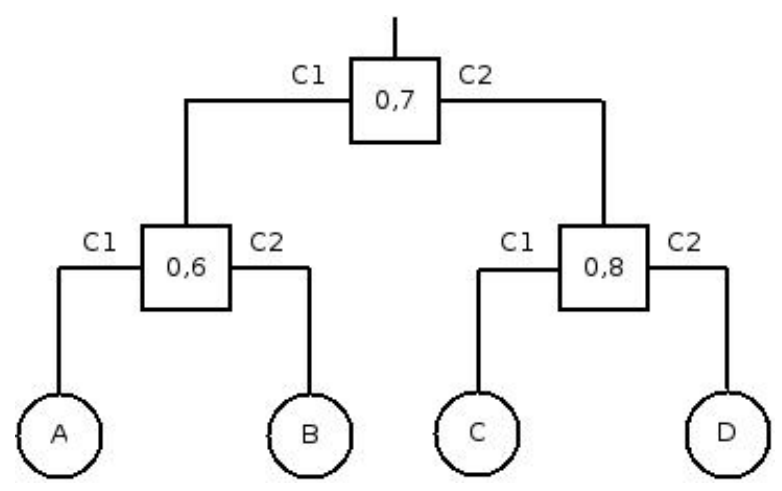

Figura 3.4: Árvore resultante construída a partir das instâncias A, B, C e D (nesta ordem) usando os valores de similaridade da Tabela 3.1.

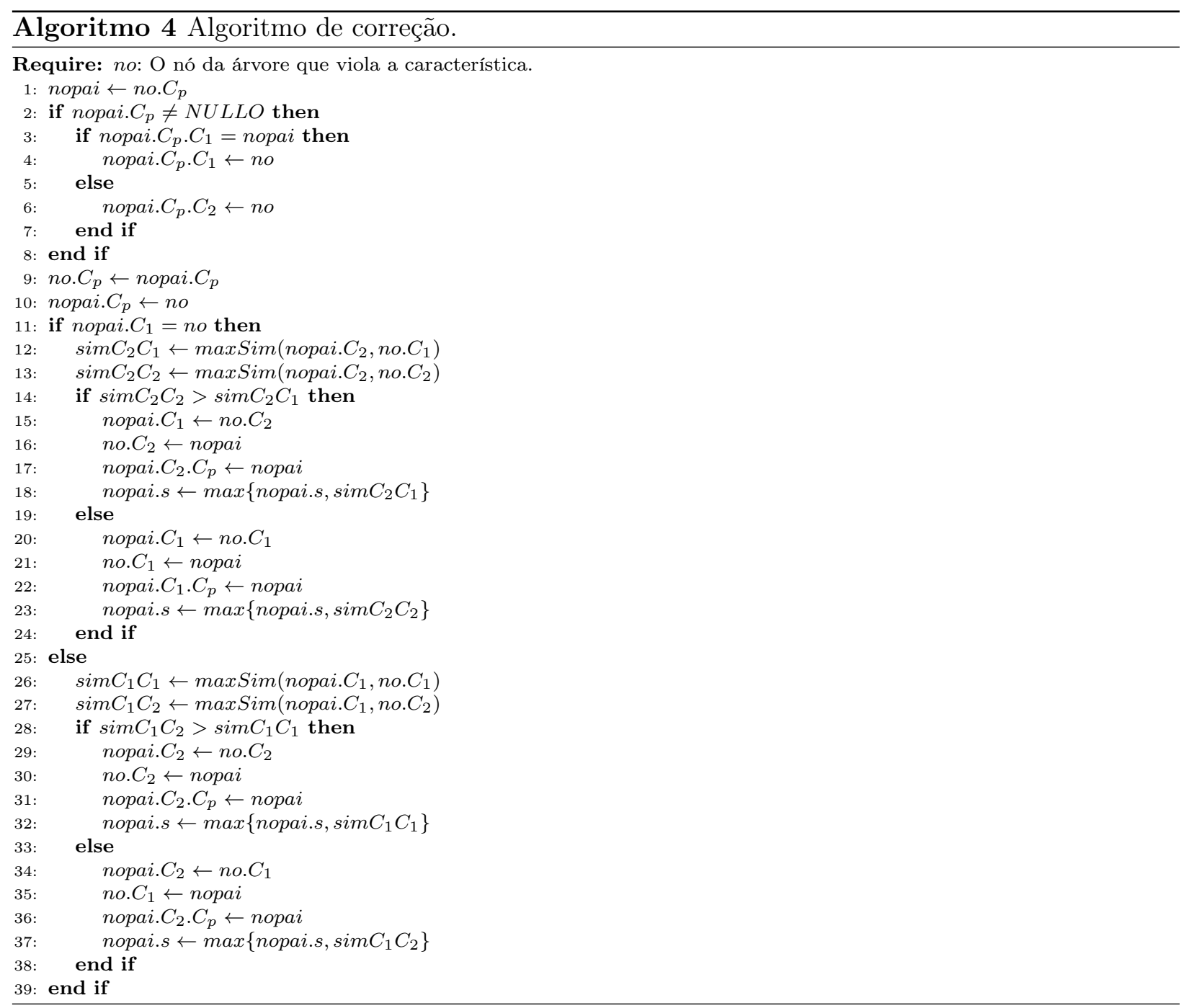

as posições do nó com seu nó-pai (ver Figura 3.5.c) (linha 28 a 38 e 14 a 24), obtendo a árvore resultante mostrada na Figura 3.5.d.

Aplicando o Algoritmo 4 à árvore produzida na Figura 3.4, a árvore resultando é mostrada na Figura 3.6. Note que a árvore resultante exibida na Figura 3.6 é a mesma exibida na Figura 3.3.d. Combinando os Algoritmos 3 e 4, a árvore resultante é independe da ordem de inserção das instâncias. 


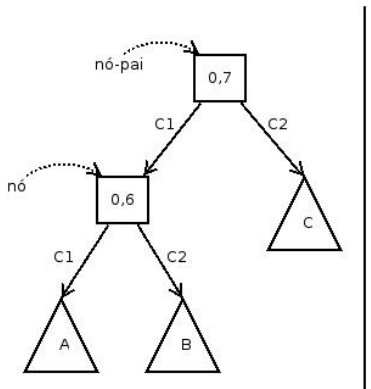

(a)

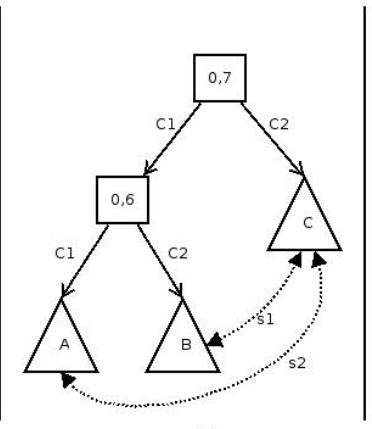



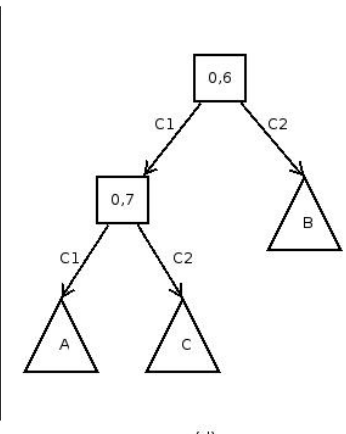

(d)

Figura 3.5: Ilustração do funcionamento do Algoritmo 4.

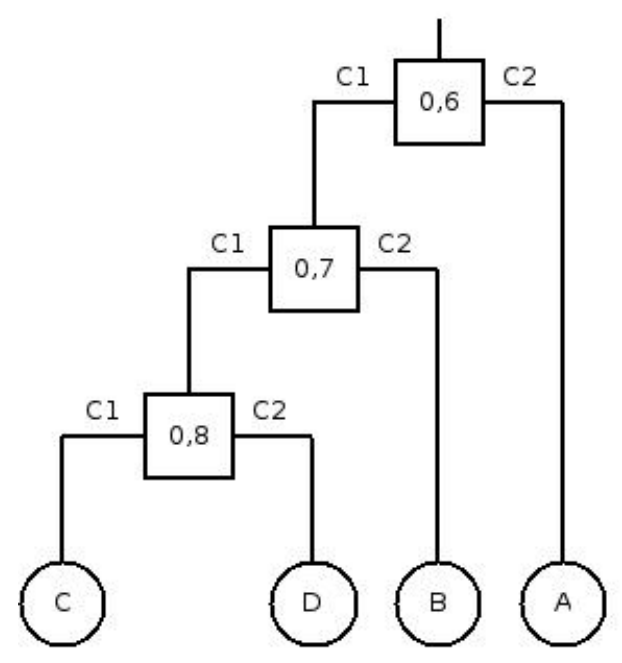

Figura 3.6: Resultado da aplicação do Algoritmo 4 à árvore da Figura 3.4.

\subsubsection{Usando agrupamento hierárquico para predizer tags}

A estrutura do agrupamento hierárquico descrita na seção anterior foi adaptada para realizar a recomendação de tags. A recomendação de tags é definida da seguinte forma: dado um conjunto $C$ de tuplas $\langle r, T\rangle$ onde $r$ é um recurso e $T$ é um conjunto de tags, o problema consiste em prever o conjunto de tags $T$ para um novo recurso acrescentado em $C$ [Heymann et al., 2008].

Para que a estrutura possa recomendar tags a um recurso qualquer, parte-se do pressuposto de que recursos similares possuem tags similares [Oliveira et al., 2008, Sood et al., 2007]. Considerando que cada recurso agrupado é associado a um conjunto de tags, espera-se que dois recursos agrupadas sob um mesmo nó (portanto com um alto grau de similaridade) possuam conjuntos de tags com grande intersecção.

Assim, os nós internos do agrupamento criado pelo Algoritmo 3 foram modificados para que contenham, além do valor $s$ da similaridade, um conjunto de $T$ de tags de forma que $T$ é definido como a interseção entre os conjuntos de tags dos seus nós-filhos. Por exemplo, considere o conjunto de instâncias $\{A, B, C, D\}$, os valores de similaridade para estas instâncias exibidos na Tabela 3.1, e que cada instância pertencente a esse conjunto possua o conjunto de tags mostrado na Tabela 3.2.

O agrupamento produzido a partir dos valores de similaridade mostrados na Tabela 3.1 e das tags exibidas na Tabela 3.2 produz como resultado a árvore de similaridade exibida na Figura 3.7. Nela, os nós internos possuem um conjunto de tags resultante da intersecção dos conjuntos de tags de seus nós-filhos.

A recomendação de tags só pode ser realizada se já houver uma árvore de similaridade criada a partir de um conjunto de instâncias com tags pré-definidas. A partir daí, qualquer nova instância 


\begin{tabular}{|r||l|}
\hline Instância & Tags \\
\hline $\mathrm{A}$ & $t_{1}, t_{2}, t_{3}$ \\
$\mathrm{~B}$ & $t_{4}, t_{5}$ \\
$\mathrm{C}$ & $t_{1}, t_{5}$ \\
$\mathrm{D}$ & $t_{1}, t_{4}, t_{5}$ \\
\hline
\end{tabular}

Tabela 3.2: Exemplo de conjuntos de tags associados ao conjunto de instâncias $\{A, B, C, D\}$.

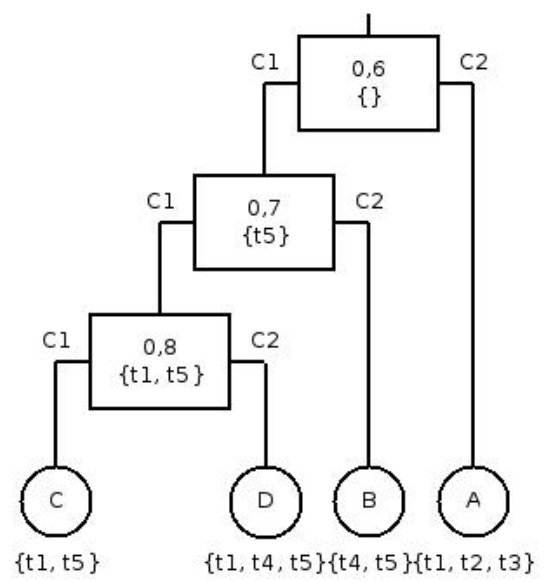

Figura 3.7: Árvore produzida com as instâncias $A, B, C$ e $D$ considerando os valores de similaridades na Tabela 3.1 e as tags na Tabela 3.2 .

inserida nesse conjunto poderá ter suas tags recomendadas pelo sistema.

A nova instância a ser adicionada na árvore de similaridade será posicionada ao lado do ramo mais similar, de acordo com o Algoritmo 3. Essa nova instância deverá receber como recomendações as tags contidas no caminho que percorreu desde o nó raiz até a sua devida posição na árvore. Por exemplo, suponha a adição de uma instância $E$ à estrutura exibida na Figura 3.7, com os seguintes valores de similaridade: $\operatorname{sim}(E, A)=0,3, \operatorname{sim}(E, B)=0,5, \operatorname{sim}(E, C)=0,6$ e $\operatorname{sim}(E, D)=0,9$. A nova instância $E$ será, portanto, inserida ao lado da instância $D$ e receberá, por recomendação, o conjunto de tags $\left\{t_{1}, t_{5}\right\}$. A Figura 3.8 exibe a árvore de similaridade resultante.



Figura 3.8: Árvore resultante após a inserção da instância E. Na figura, as arestas grossas representam o caminho percorrido pela instância.

Para verificar se as tags preditas pelo algoritmo estão corretas, o conjunto de instâncias considerado (as instâncias do Arquigrafia) é dividido em dois: o conjunto de treinamento e o conjunto 
de testes. O conjunto de treinamento é utilizado para criar o agrupamento hierárquico inicial. O conjunto de testes contém as novas instâncias a serem adicionadas a esse agrupamento. Para cada instância inserida, as tags preditas são comparadas com as tags originalmente atribuídas à instância e são anotados os erros e acertos. Os experimentos são abordados no Capítulo 5.

\subsection{Métrica de similaridade entre instâncias RDF}

Essa secão apresenta a métrica de similaridade utilizada nesse trabalho para a produção da árvore de similaridade. A métrica de similaridade utilizada é definida sobre o espaço de instâncias e é baseada no trabalho de Maeche e Zacharias [Maedche e Zacharias, 2002]. Mais adiante, ainda nesse capítulo, serão discutidas outras métricas.

Antes de prosseguir para definição da métrica, faz-se necessário apresentar as definições de vocabulário e repositório $\mathrm{RDF}$.

\section{- Vocabulário}

Um vocabulário é definido como uma tupla $V=\langle C, P, H$, prop $\rangle$, com $C \cap P=\emptyset$, onde:

- $C$ é um conjunto de classes ou conceitos;

- $P$ é um conjunto de propriedades;

- $H$ define uma hierarquia de classes (ou uma hierarquia taxonômica de classes), de forma que $H \subseteq C \times C$;

- prop é uma função $P \rightarrow C \times C$ que associa propriedades não-taxonômicas entre classes.

Note que o conjunto $H$ conta com a propriedade transitiva e acíclica entre as classes, isto é, se $H(A, B)$ e $H(B, C)$ estão definidos, então $H(A, C)$ está implícita. Além disso, dada uma propriedade $p \in P$ com função $\operatorname{prop}(p)=\left(c_{1}, c_{2}\right), c_{1}$ é chamado de domínio (dom) de $p$ e $c_{2}$ é chamado de alcance (alc) de $p$. Finalmente, são chamados de atributos todas as propriedades cujo alcance sejam apenas valores literais $(\operatorname{alc}(\operatorname{prop}(p))=$ LITERAL $)$. Um valor literal é qualquer sequência de caracteres (string) incluindo números ou formatos de data [Brickley e Guha, 2004].

A Figura 3.9 mostra um exemplo de vocabulário RDF. De acordo com esse vocabulário, todo recurso possui um nome, um projeto arquitetônico, é construído em uma determinada cidade, por um determinado arquiteto e pode ser classificado através das sub-classes Arq_High-Tech e Arq_Moderna (ambos estilos de arquitetura).

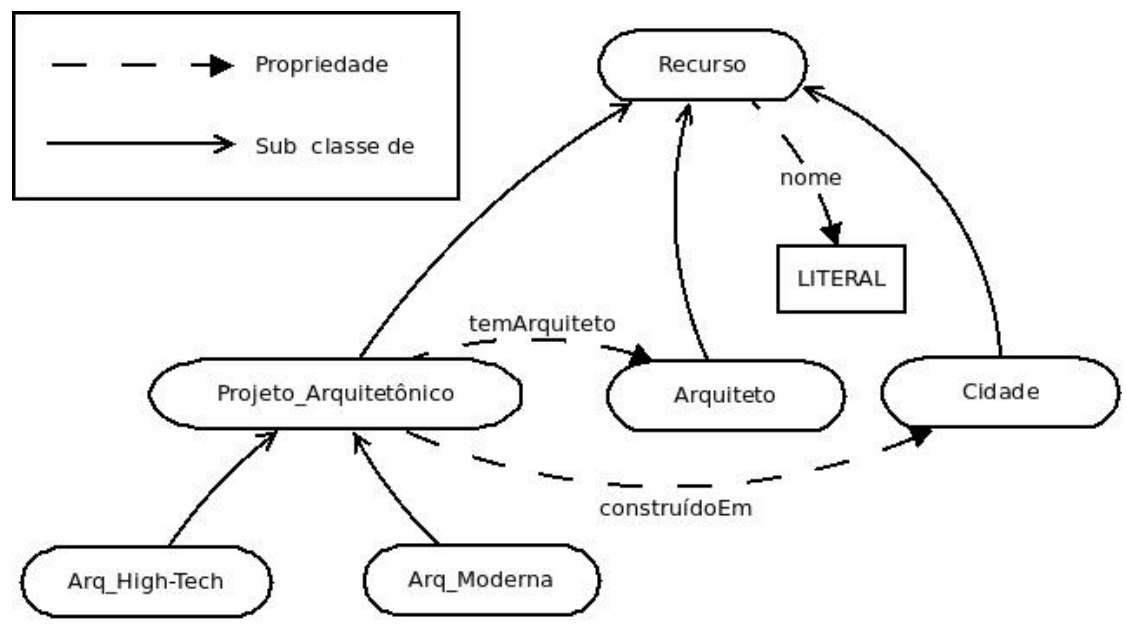

Figura 3.9: Exemplo de um vocabulário RDF.

Para simplificar a notação, denota-se por $p\left(c_{1}, c_{2}\right)$ ( $\left.\operatorname{com} c_{1}, c_{2} \in C\right)$ quando $\operatorname{prop}(p)=\left(c_{1}, c_{2}\right)$. Da mesma forma, a expressão $H\left(c_{1}, c_{2}\right)$ ( $\operatorname{com} c_{1}, c_{2} \in C$ ) significa que $c_{1}$ é uma sub-classe (ou sub-conceito) de $c_{2}$. 
A definição do vocabulário RDF mostrado na Figura 3.9 é listada a seguir:

- $C=\{$ Recurso, Projeto_Arquitetônico, Arquiteto, Cidade, Arquitetura_High-Tech, ... $\}$;

- $P=\{$ nome, temArquiteto, construídoEm $\} ;$

- $H=\{\{$ Projeto_Arquitetônico, Recurso $\},\{$ Arquiteto, Recurso $\},\{$ Cidade, Recurso $\}, \ldots\}$;

$-\operatorname{prop}($ nome $)=($ Recurso, LITERAL $)$,

$-\operatorname{prop}($ temArquiteto $)=($ Projeto_Arquitetônico, Arquiteto $)$

- $\operatorname{prop}($ construídoEm $)=($ Projeto_Arquitetônico, Cidade $)$

\section{- Repositório RDF}

Um repositório $\mathrm{RDF}$ é uma tupla $R=<V, I, L$, inst, instp $>$, onde:

- $V$ é um vocabulário;

- I é um conjunto de instâncias;

- $L$ é um conjunto de literais;

- inst é uma função $C \rightarrow 2^{I}$;

- instp é uma função $P \rightarrow 2^{I \times(I \cup L)}$.

A definição inst associa cada instância ao conjunto de classes que o define. Para simplificar, denota-se por $C(I)$ a expressão $\operatorname{inst}(C)=I$. A definição instp associa propriedades de uma instância a outra instância ou a um valor literal (textual). A Figura 3.10 exibe um exemplo de um repositório RDF usando o vocabulário exibido na Figura 3.9. Nela, os quadros brancos representam as classes presentes no vocabulário e os quadros cinzas as instâncias.

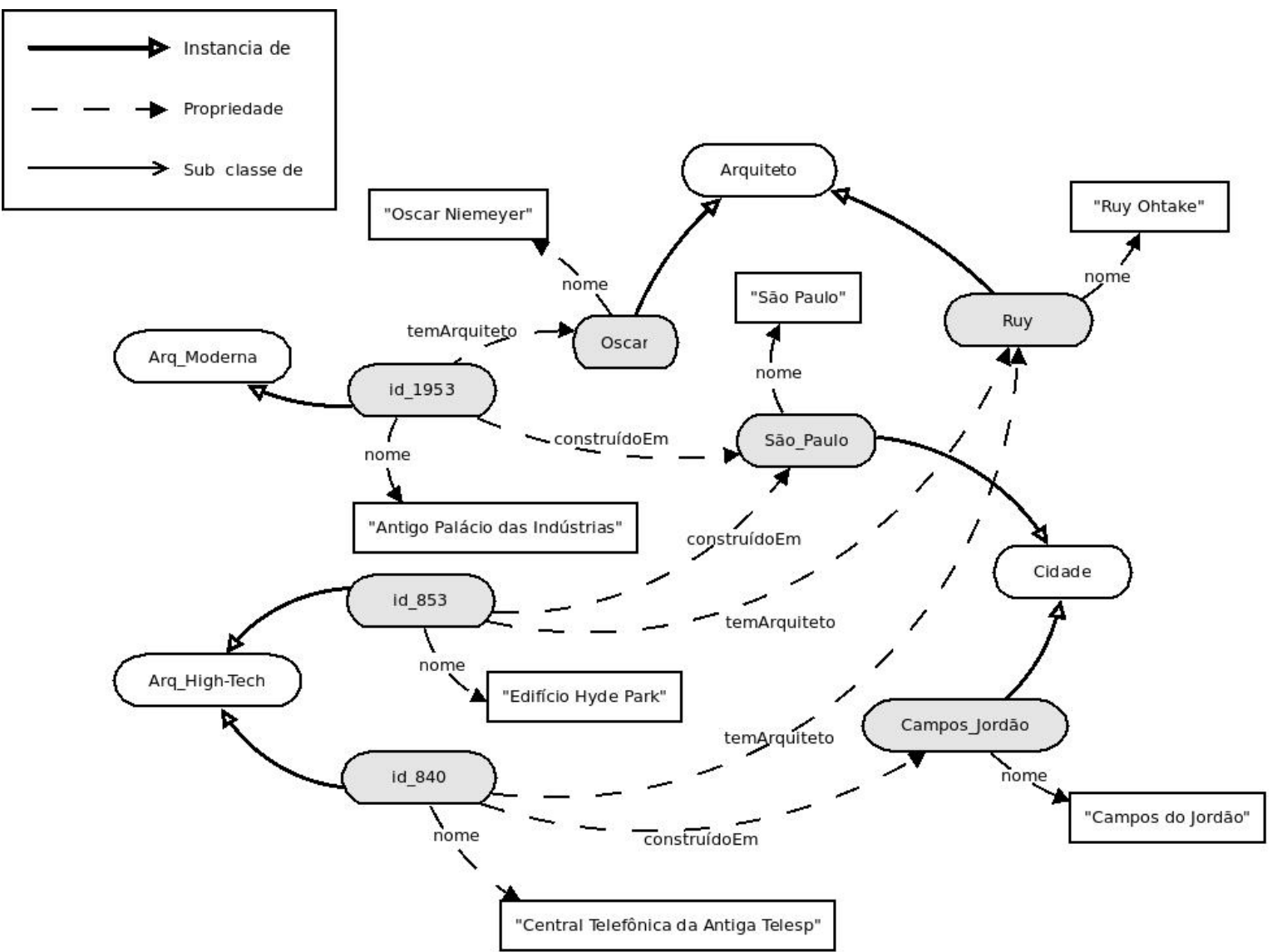

Figura 3.10: Exemplo de um repositório RDF usando o vocabulário exibido na Figura 3.9.

A definição do repositório RDF para o exemplo mostrado na Figura 3.10 é listada a seguir: 
- $V$ é o vocabulário definido na Figura 3.9;

- $I=\{$ Oscar, Ruy, São_Paulo,Campos_Jordão,id_1953,id_853,id_840 $\}$

- $L=\{$ "Oscar Niemeyer", "Ruy Ohtake", "São Paulo", "Campos do Jordão", ... $\}$

- inst(Arq_Moderna) $=\{$ id_1953 $\}$;

- inst(Arq_High-Tech) $=\{$ id_853,id_840 $\}$;

- inst(Arquiteto $)=\{$ Oscar, Ruy $\}$;

- inst $($ Cidade $)=\{$ São_Paulo, Campos_Jordão $\}$;

- instp(nome) $=\{($ Oscar, "Oscar Niemeyer"), (Ruy, "Ruy Ohtake"), .. $\}$

- instp $($ temArquiteto $)=\{($ id_1953, Oscar $),($ id_853, Ruy $),($ id_840, Ruy $)\}$

- instp (construídoEm) $=\left\{(\right.$ id_1953, São_Paulo $),\left(i d \_840\right.$, Campos_Jordão $\left.), \ldots\right\}$

A métrica é definida sobre o espaço $I$ de instâncias. Para toda instância $i$ e $j \in I$, a métrica atende às seguintes propriedades:

1. $\operatorname{sim}(i, j) \geq 0$ (positividade);

2. $\operatorname{sim}(i, j)=\operatorname{sim}(j, i)$ (comutatividade);

3. $\operatorname{sim}(i, j)=1$ se, e somente se, $i=j$ (maximidade).

Das propriedades acima, nota-se que a métrica $\operatorname{sim}(i, j)$ é definida no intervalo $[0,1]$ e, quanto mais próximo de 1 é o valor da similaridade entre $i$ e $j$, mais similares são as instâncias $i$ e $j$.

Dadas duas instâncias $i$ e $j \in I$, a métrica de similaridade é calculada através dos seguintes critérios [Maedche e Zacharias, 2002]:

- Similaridade Taxonômica (ST): Computa a similaridade entre as instâncias $i$ e $j$ considerando as classes e superclasses que os definem;

- Similaridade Relacional (SR): Computa a similaridade entre $i$ e $j$ considerando o relacionamento dessas instâncias com as demais através das suas propriedades;

- Similaridade Literal (SL): Computa a similaridade entre $i$ e $j$ considerando as propriedades cujo alcance é um literal (cadeias de caracteres).

Cada um dos critérios acima tem como resultado um valor no intervalo [0,1]. A similaridade entre as instâncias $i$ e $j$ é definida através da expressão:

$$
\operatorname{sim}(i, j)=\frac{\alpha \times S T(i, j)+\beta \times S R(i, j)+\gamma \times S L(i, j)}{\alpha+\beta+\gamma},
$$

onde $\alpha, \beta$ e $\gamma \in \mathbb{R}$ são os pesos associados a cada uma das medidas de similaridade, de forma que $\alpha+\beta+\gamma>0$.

\subsubsection{Similaridade Taxonômica}

Dada duas instâncias $i$ e $j$, a similaridade taxonômica mede o quanto essas instâncias são similares considerando as classes (e classes ancestrais) que as definem. Quanto mais classes em comum houver entre essas duas instâncias, maior é a sua similaridade taxonômica. Dadas duas instâncias $i, j \in I$, a similaridade taxonômica (ST) é definida pela expressão:

$$
S T(i, j)= \begin{cases}\frac{E C(C(i), C(j))}{2} & \text { se } i \neq j, \\ 1 & \text { caso contrário. }\end{cases}
$$

Na expressão, $C(i)$ refere-se à classe que define a instância $i$. Por sua vez, a expressão Equivalência de Conceito $(E C)$ é definida pela expressão: 


$$
E C\left(c_{i}, c_{j}\right)=\frac{\left|C A\left(c_{i}\right) \cap C A\left(c_{j}\right)\right|}{\left|C A\left(c_{i}\right) \cup C A\left(c_{j}\right)\right|}
$$

onde as Classes Ancestrais $(C A)$ são obtidas através da expressão a seguir, que retorna, para uma classe $c$ qualquer, todas as superclasses que a definem.

$$
C A(c)= \begin{cases}\{c\} \cup C A\left(c^{\prime}\right) & \text { se } \exists c^{\prime} \in C \text { e } \exists\left(c, c^{\prime}\right) \in H \\ \{c\} & \text { caso contrário. }\end{cases}
$$

Como exemplo, considere as instâncias "id_1953" e "id_853" exibidas na Figura 3.10. A similaridade taxonômica entre elas é igual a:

$$
\begin{aligned}
S T(\text { id_1953,id_853) }= & \\
= & \frac{E C(\text { Arq_Moderna, Arq_High-Tech })}{2} \\
& =\frac{\mid C A(\text { Arq_Moderna }) \cap C A(\text { Arq_High-Tech }) \mid}{\mid C A(\text { Arq_Moderna }) \cup C A(\text { Arq_High-Tech }) \mid} \times \frac{1}{2}
\end{aligned}
$$

Onde, $C A$ (Arq_Moderna) e $C A($ Arq_High-Tech) são, respectivamente, iguais a:

$$
\begin{gathered}
C A(\text { Arq_Moderna })=\{\text { Arq_Moderna, Projeto_Arquitetônico, Recurso }\} \\
C A(\text { Arq_High-Tech })=\{\text { Arq_High-Tech, Projeto_Arquitetônico, Recurso }\}
\end{gathered}
$$

Substituindo esses valores na Equação 3.6:

$$
S T\left(\text { id_1953,id_853) }=\frac{2}{4} \times \frac{1}{2}=0,25\right.
$$

Assim, a similaridade taxonomica entre as instâncias "id_1953" e "id__853" é de 0,25.

\subsubsection{Similaridade Literal}

Nem todas as propriedades definidas em um vocabulário são associadas a uma instância. Nesse caso são associadas a valores literais. Chamam-se Atributos o conjunto de propriedades cujo alcance pertence à classe Literal. Então, seja $A \subseteq P$ o conjunto dos atributos, $A$ é definido pela expressão:

$$
A=\{p \mid p \in P \text { e } \operatorname{alc}(p)=\text { LITERAL }\}
$$

A Similaridade Literal $(S L)$ entre duas instâncias $i$ e $j$ é definida pela expressão:

$$
S L(i, j)=\frac{\sum_{a \in A C(i, j)} S A(i, j, a)}{|A C i, j|} .
$$

Similar às definições da similaridade relacional, a similaridade literal é realizada considerando somente atributos em comum existentes entre as duas instâncias $i$ e $j$. Os Atributos em Comum $(A C)$ são obtidos através da expressão.

$$
A C(i, j)=A I(i) \cap A I(j)
$$

onde os Atributos de uma Instância $(A I)$ são obtidos pela expressão 3.13:

$$
A I(i)=\{a \mid a \in A \text { e } \operatorname{dom}(a) \in C A(i)\} .
$$

Finalmente, a similaridade entre $i$ e $j$ através do atributo $a(S A)$, é dada pela expressão: 


$$
S A(i, j, a)= \begin{cases}0 & \text { se } V A(i, a)=\emptyset \text { ou } V A(j, a)=\emptyset, \\ \frac{\sum_{x \in V A(i, a)} \max \{l \operatorname{sim}(x, y) \mid \forall y \in V A(j, a)\}}{|V A(i, a)|} & \text { se }|V A(i, a)| \geq|V A(j, a)|, \\ \frac{\sum_{x \in V A(j, a)} \max \{\operatorname{lsim}(x, y) \mid \forall y \in V A(i, a)\}}{|V A(j, a)|} & \text { caso contrário, }\end{cases}
$$

onde o Valor do Atributo ( $V A)$ é definido como:

$$
V A(i, a)=\{x \mid x \in L \text { e } \operatorname{prop}(a)=(C(i), L)\}
$$

Na Expressão 3.14, lsim é definida como lsim : $L \times L \rightarrow[0,1]$. Dessa forma, essa função pode variar de acordo com o tipo de dado a ser comparado. Para este trabalho os tipos de dados não são diferenciados, e lsim é definida como sendo a distância de Levenshtein [Levenshtein, 1966] ${ }^{1}$. Usualmente as operações de inserão e deleção tem custo 1, e a operação de substituição tem custo 2 [Levenshtein, 1966, Marzal e Vidal, 1993, Yujian e Bo, 2007].

Portanto, a função $l$ sim é definida como:

$$
\operatorname{lsim}(x, y)=1-\frac{\text { Levenshtein }(x, y)}{|x|+|y|},
$$

onde, dada a string $x,|x|$ representa o número de caracteres que a compõe.

Como exemplo, considere novamente as instâncias "id_1953" e "id_853" exibidas na Figura 3.10. A similaridade literal entre elas é igual a:

$$
S L\left(\text { id_1953, id_853) }=\frac{\sum_{a \in A C\left(\mathrm{id} \_1953, \mathrm{id} \_853\right)} S A\left(\mathrm{id} \_1953, \mathrm{id} \_853, a\right)}{\left|A C\left(\mathrm{id} \_1953, \mathrm{id} \_853\right)\right|} .\right.
$$

Os atributos em comum entre as instâncias "id_1953" e "id_853" são iguais a:

$$
A C(\text { id_1953,id_853) }=A I(\text { id_1953 }) \cap A I(\text { id_853 })=\{\text { nome }\} .
$$

Assim, a similaridade literal entre as instâncias "id_1953" e "id_853" é dada por:

$$
S L\left(\text { id_1953,id_853) }=\frac{S A(\text { id__1953, id_853, nome })}{1},\right.
$$

onde $S A$ (id_1953,id_853, nome) é igual a:

$$
\begin{aligned}
& S A(\text { id_1953,id_853,nome })= \\
& \qquad \operatorname{lsim}(\text { "Antigo Palácio das Indústrias", "Edifício Hyde Park") }=0.51 \text {. }
\end{aligned}
$$

Finalmente, a similaridade literal entre as instâncias "id_1953" e "id_853" resulta em 0,51.

\subsubsection{Similaridade Relacional}

Se duas instâncias quaisquer possuem, através de uma mesma propriedade $p$, uma conexão com uma mesma terceira instância, então estas duas instâncias são mais similares se comparadas a outras duas que possuem conexões com instâncias diferentes através de $p$ [Maedche e Zacharias, 2002]. Por exemplo, na Figura 3.9, projetos arquitetonicos que tem o mesmo arquiteto são mais similares se comparados a projetos com arquitetos diferentes.

Dadas duas instâncias $i$ e $j$, a Similaridade Relacional $(S R)$ é definida através da expressão:

$$
S R(i, j)=\frac{\sum_{p \in P C S(i, j)} S P(i, j, p)+\sum_{p \in P C E(i, j)} S P(i, j, p)}{|P C S(i, j)|+|P C E(i, j)|} .
$$

\footnotetext{
${ }^{1}$ A distância de Levenshtein é o menor número de inserções, deleções ou substituições capaz de transformar uma string $s_{1}$ em outra $s_{2}$ [Levenshtein, 1966, Marzal e Vidal, 1993, Yujian e Bo, 2007]
} 
A Expressão 3.21 considera somente as propriedades comuns entre $i$ e $j$, pois as propriedades diferentes já são consideradas no cálculo da Similaridade Taxonômica [Maedche e Zacharias, 2002].

Para as instâncias $i$ e $j$, a similaridade relacional é calculada considerando propriedades comuns de entrada e saída, ou seja, propriedades onde $i$ e $j$ são considerados domínio e alcance. Essas propriedades são obtidas através das expressões $P C S(i, j)$ (Propriedades Comuns de Saída) e $P C E(i, j)$ (Propriedades Comuns de Entrada), definidas pelas Expressões 3.22 e 3.23 respectivamente.

$$
\begin{gathered}
P C S(i, j)=P S(i) \cap P S(j) . \\
P C E(i, j)=P E(i) \cap P E(j) .
\end{gathered}
$$

As Propriedades de Saída $(P S)$ e as Propriedades de Entrada $(P E)$ são definidas como:

$$
\begin{gathered}
P S(i)=\{p \mid p \in P \text { e } \operatorname{dom}(p) \in C A(C(i)) \text { e } \operatorname{alc}(p) \neq L I T E R A L\}, \\
P E(i)=\{p \mid p \in P \text { e } \operatorname{alc}(p) \in C A(C(i))\} .
\end{gathered}
$$

Nas Expressões 3.24 e 3.25, a propriedade $p$ a ser obtida deve estar definida como alcance ou domínio de alguma classe ancestral de $i$. Se $p$ é uma propriedade que tem como alcance uma classe ancestral de $C(i)$, então por herança a classe $C(i)$ também pode ser referenciada por $p$. Note que o alcance de $p$, em $P S(i)$, não pode pertencer à classe Literal.

Finalmente, a similaridade entre $i$ e $j$ através da propriedade $p$ é dada pela Expressão 3.26 a seguir, denominada $S P$.

$$
S P(i, j, p)= \begin{cases}0 & \text { se }|I A(i, p)|=0 \text { ou }|I A(j, p)|=0, \\ \frac{\sum_{k \in I A(i, p)} \max \{\operatorname{sim}(k, l) \mid \forall l \in I A(j, p)\}}{|I A(i, p)|} & \text { se }|I A(i, p)| \geq|I A(j, p)|, \\ \frac{\sum_{k \in I A(j, p)} \max \{\operatorname{sim}(k, l) \mid \forall l \in I A(i, p)\}}{|I A(j, p)|} & \text { caso contrário, }\end{cases}
$$

onde a Instância Associada $(I A)$ a $i$ através de $p$ é definida pela expressão:

$$
I A(i, p)=\{j \mid j \in I \text { e }(P(i, j) \text { ou } P(j, i))\} .
$$

Como o RDF permite a associação a várias instâncias através de uma mesma propriedade, um conjunto de instâncias pode ser retornado pela expressão acima.

Convém ressaltar que para evitar que o processo recursivo na Expressão 3.26 se torne infinito, é definido um valor de máxima profundidade. Ao alcançar essa profundidade, a média aritmética entre a similaridade taxonômica e a similaridade literal é retornada [Maedche e Zacharias, 2002].

Como exemplo, considere novamente as instâncias "id_1953" e "id__853" exibidas na Figura 3.10. A similaridade relacional entre essas instâncias é igual a:

$$
\begin{aligned}
& S R(\text { id_1953,id_853) }= \\
& =\frac{\sum_{p \in P C S\left(\mathrm{id} \_1953, \mathrm{id} \_853\right)} S P\left(\mathrm{id} \_1953, \mathrm{id} \_853, \mathrm{p}\right)+\sum_{p \in P C E\left(\mathrm{id} \_1953, \mathrm{id} \_853\right)} S P\left(\mathrm{id} \_1953, \mathrm{id} \_853, \mathrm{p}\right)}{\left|P C S\left(\mathrm{id} \_1953, \mathrm{id} \_853\right)\right|+\mid P C E(\text { id_1953, id_853) }} .
\end{aligned}
$$

Uma vez que, neste exemplo, PCE(id_1953, id_853) resulta num conjunto vazio, a expressão 3.28 é igual a:

$$
S R\left(\text { id_1953, id_853) }=\frac{\sum_{p \in P C S\left(\mathrm{id} \_1953, \mathrm{id} \_853\right)} S P\left(\mathrm{id} \_1953, \mathrm{id} \_853, p\right)}{\left|P C S\left(\mathrm{id} \_1953, \mathrm{id} \_853\right)\right|} .\right.
$$


As propriedades de saída das instâncias "id_1953" e "id__853" são iguais a:

$$
\begin{gathered}
P S(\text { id_1953) }=\{\text { temArquiteto, construídoEm }\}, \\
P S(\text { id_853) }=\{\text { temArquiteto, construídoEm }\} .
\end{gathered}
$$

Logo, PCS(id_1953,id_853) é igual a:

$$
\text { PCS(id_1953,id_853) }=\{\text { temArquiteto, construídoEm }\} .
$$

Assim, a similaridade relacional entre as instâncias "id_1953" e "id_853" é calculada através da expressão:

$$
\begin{aligned}
& S R(\text { id_1953,id_853) }= \\
& \qquad \frac{S P(\text { id_1953, id_853,temArquiteto })+S P(\text { id__1953, id_853, construídoEm })}{2} .
\end{aligned}
$$

Como ambas as instâncias possuem a instância São_Paulo como valor da propriedade construídoEm, o valor obtido para a expressão $S P($ id_1953, id_853, construídoEm) é igual a 1. Porém, para a propriedade temArquiteto tem-se:

$$
S P(\text { id_1953,id_853, temArquiteto })=\operatorname{sim}(\text { Oscar }, \text { Ruy })=0,5 .
$$

Finalmente, a similaridade relacional entre as instâncias "id_1953" e "id_853" é igual a:

$$
S R\left(\text { id_1953,id_853) }=\frac{1+0,5}{2}=0,75 .\right.
$$

Portanto, a similaridade resultante obtida para as instâncias "id_1953" e "id_853" é (considerando $\alpha, \beta$ e $\gamma$ iguais a 1$)$ :

$$
\operatorname{sim}\left(\text { id_1953,id_853) }=\frac{0,25+0,75+0,51}{3}=0,503 .\right.
$$

\subsection{Outras métricas de similaridade entre instâncias RDF}

A métrica explicada na seção anterior foi utilizada neste trabalho porque compreende três medidas de similaridade diferentes: taxonômica, relacional e literal. No entanto, há outras métricas de similaridade entre instâncias RDF e duas serão discutidas nesta seção.

\subsubsection{Métrica baseada na distância de vetores}

Esse método é uma adaptação da tradicional comparação de vetores com o objetivo de comparar instâncias RDF [Grimnes et al., 2008]. Dados uma instância $i$ e um grafo RDF $G$, define-se os nós alcançáveis a partir de $i$ utilizando a expressão [Grimnes et al., 2008]:

$$
\text { alcancavel }(i, G)=\{o \mid<i, p, o>\in G\} \cup\{j \mid j \in \operatorname{alcancavel}(o, G)\} .
$$

O vetor para uma instância $i$ é definido como [Grimnes et al., 2008]:

$$
V(i)=\{\text { menorCaminho }(i, x, G) \mid x \in \operatorname{alcancavel}(i, G)\},
$$

onde menorCaminho $(i, x, G)$ é o caminho mais curto do nó $i$ até o nó $x$ no grafo $G$, e caminho é definido como o número de arestas entre os dois nós (ou seja, o número de propriedades). Por exemplo, o vetor para o nó "http://exemplo/joao" do grafo mostrado na Figura 3.11, é dado por: 


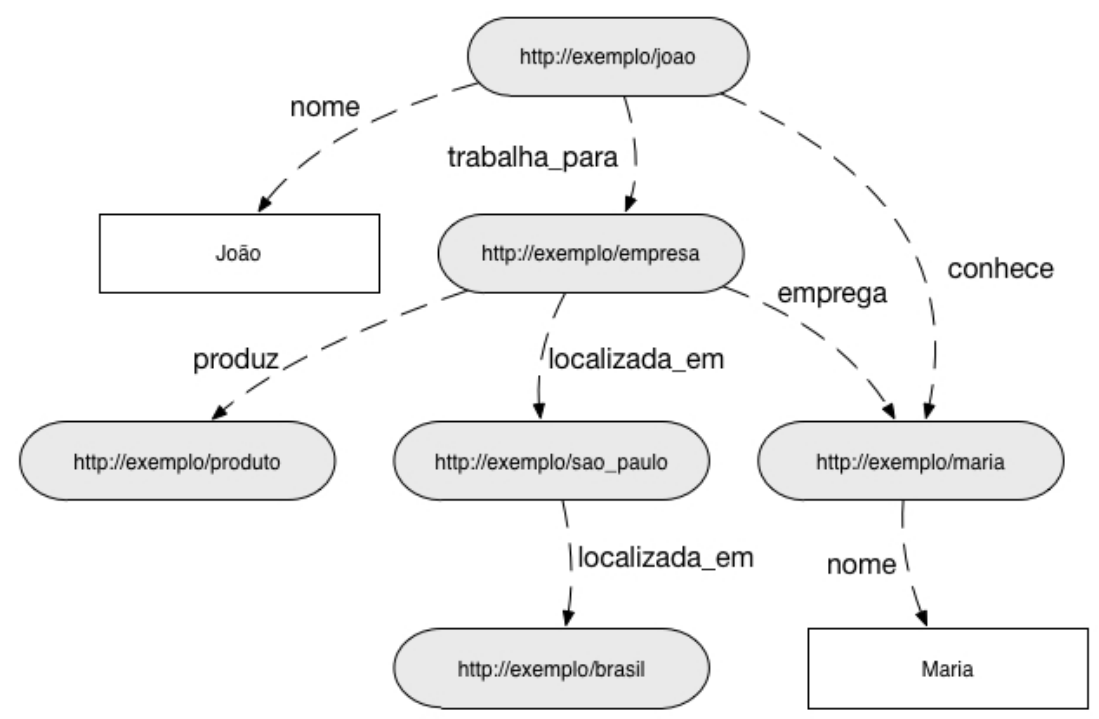

Figura 3.11: Exemplo de um grafo RDF.

$$
\begin{array}{r}
V(\text { http }: / / \text { exemplo/joao })=\{\text { nome }, \text { trabalha_para,conhece,trabalha_para } \rightarrow \text { produz }, \\
\text { trabalha_para } \rightarrow \text { localizada_em,trabalha_para} \rightarrow \text { emprega }, \\
\text { trabalha_para } \rightarrow \text { localizada_em } \rightarrow \text { localizada_m } \\
\text { conhece } \rightarrow \text { nome }\} .
\end{array}
$$

Note que o caminho trabalha_para $\rightarrow$ emprega $\rightarrow$ nome não foi incluído porque o recurso "http://exemplo/maria" pode ser alcançado por um caminho menor, através da propriedade conhece. $\mathrm{O}$ vetor $V$ resultante da expressão 3.38 é composto por todos os caminhos possíveis no grafo $G$ a partir de uma instância $i$. Obviamente o número de arestas que compõem esses caminhos devem ser limitados. Assim, dadas duas instâncias $i$ e $j$, e um vetor $V$ de propriedades, a similaridade é dada pela expressão [Grimnes et al., 2008]:

$$
\operatorname{sim} V(i, j, V)=\frac{1}{|V|} \sum_{v \in V} \frac{2 *\left|i_{v} \cap j_{v}\right|}{\left|i_{v}\right|+\left|j_{v}\right|},
$$

onde $i_{v}$ e $j_{v}$ representam os nós alcançáveis a partir do caminho representado em $v$. Essa expressão resultará em um valor no intervalo $[0,1]$, onde 1 significa que as instâncias $i$ e $j$ compartilham as mesmas propriedades.

Esse método possui alguns problemas. Por considerar apenas as arestas do grafo formado pelos recursos RDF (i.e. as propriedades dos recursos), as classes que definem as instâncias, bem como os valores literais, são ignorados. Se, por exemplo, duas instâncias compartilham similaridades apenas em seus valores literais ou nas classes que as define, essa métrica não será capaz de detectá-las.

\subsubsection{Métrica baseada em grafos}

Nessa métrica, a comparação entre duas instâncias é realizada comparando-se o grafo RDF em que se encontram. Inicialmente, dadas duas instâncias $i$ e $j$, é extraído um conjunto de instâncias relacionadas a $i$ e a $j$. Esse conjunto é extraído de maneira recursiva até um dado limite $l$ [Grimnes et al., 2008].

Dessa forma, para as instâncias $i$ e $j$, e considerando $G(i)$ e $G(j)$ os seus respectivos grafos extraídos, a similaridade consiste em [Montes-y Gómez et al., 2000]:

1. Obter a sobreposição de seus grafos;

2. Calcular a similaridade entre os dois grafos de forma relativa à sua sobreposição. 
A sobreposição $G_{c}(i, j)=G(i) \cap G(j)$ é dada pela intersecção do conjunto de nós e arestas de $G(i)$ e $G(j)$. Como exemplo, a Figura 3.12 ilutra os grafos $G(i)$ e $G(j)$ e mostra o resultado $G_{c}$ da sobreposição.
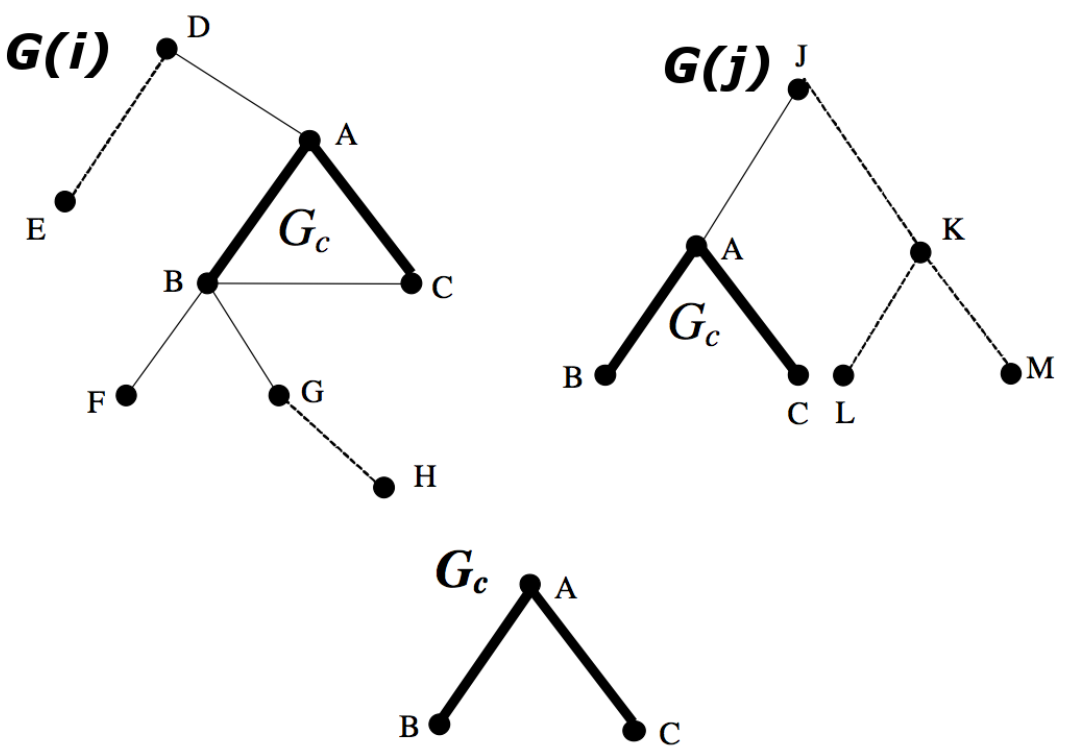

Figura 3.12: Sobreposição dos grafos $G_{c}(i, j)=G(i) \cap G(j)$. Figura extraída de [Montes-y Gómez et al., 2000].

O cálculo da similaridade entre $G(i)$ e $G(j)$ é feito com base na sobreposição $G_{c}$, entre o quão similar são os nós e as relações existentes entre eles [Montes-y Gómez et al., 2000].

A similaridade entre os nós do grafo $\left(S_{n}\right)$ expressa quão similares são os nós $G(i)$ e $G(j)$, e é calculada pela expressão abaixo [Montes-y Gómez et al., 2000]:

$$
s_{n}(i, j)=\frac{2 \times n\left(G_{c}\right)}{n(G(i))+n(G(j))},
$$

onde $n(G)$ é o número de nós do grafo $G$.

A similaridade relacional $s_{r}$ entre $G(i)$ e $G(j)$ expressa o quão são similares considerando-se as arestas desses grafos. É calculada através da seguinte expressão [Montes-y Gómez et al., 2000]:

$$
s_{r}(i, j)=\frac{2 \times m\left(G_{c}\right)}{m_{G_{c}}(G(i))+m_{G_{c}}(G(j))},
$$

onde $m\left(G_{c}\right)$ é o número de arestas do grafo $G_{c}$, e $m_{G_{c}}(G)$ é o número de arestas na vizinhança imediata do grafo $G_{c}$ no grafo $G$. A vizinhança imediata de $G_{c} \subseteq G$ consiste das arestas com ao menos uma terminação em $G$.

Finalmente, para essa métrica, a similaridade é calculada com a expressão [Montes-y Gómez et al., 2000]:

$$
s(i, j)=s_{n}(i, j) \times\left(a+(1-a) \times s_{r}(i, j)\right)
$$

onde $a$ é calculada com a expressão [Montes-y Gómez et al., 2000]:

$$
a=\frac{2 \times n\left(G_{c}\right)}{2 \times n\left(G_{c}\right)+m_{G_{c}}(G(i))+m_{G_{c}}(G(j))}
$$

Assim como as demais métricas, $s(i, j)$ resulta em um valor no intervalo $[0,1]$ e indica o quão similares são as instâncias $i$ e $j$. 
Embora essa métrica avalie as instâncias considerando a estrutura do grafo RDF, ela também não considera os vocabulários que as definem e ignoram os valores literais que podem haver nas instâncias RDF. 


\section{Capítulo 4}

\section{O Sistema ArquiTag}

ArquiTag é um sistema de recomendação de tags para as imagens do banco de dados Arquigrafia. O sistema ArquiTag pode recomendar tags para novas imagens no banco de dados usando as informações do Arquigrafia com a adição de instâncias do Linked Data da DBpedia relacionadas a essas instâncias. O ArquiTag é composto por 4 módulos:

1. Conversor RDF. Converte a base de dados do Arquigrafia para o formato RDF, gerando um conjunto de documentos RDF, chamado de Linked Data do Arquigrafia e adicionando referências a recursos externos no Linked Data da DBpedia. Nessa fase também é construída uma tabela com as tags pré-definidas para as instâncias (i.e. que foram marcadas anteriormente por visitantes do Arquigrafia);

2. Explorador. Acessa as instâncias (internas e externas ao Arquigrafia) referenciadas pelo conversor e cria um repositório local com as novas instâncias exploradas no DBpedia;

3. Treinamento. Treina uma árvore de similaridade com o repositório criado e a tabela de tags e faz a marcação dos nós da árvore com as tags pré-definidas por classes de similaridade;

4. Recomendação de tags. Realiza a recomendação de tags, usando a árvore criada, para as novas instâncias.

A Figura 4.1 ilustra o processo do ArquiTag em termos de entradas e saídas de seus módulos. O conversor RDF recebe um conjunto de instâncias do Arquigrafia e as converte para o repositório Linked Data do Arquigrafia (LD Arquigrafia). Ele também constrói uma tabela com as tags prédefinidas para cada instância do Arquigrafia. A adição de referências a recursos no DBpedia, para alguns termos selecionados é feita manualmente. Em seguida, o explorador usa o LD Arquigrafia para explorar no DBpedia as instâncias referenciadas, e as armazena em um segundo repositório contendo também o LD Arquigrafia. O próximo passo, denominado treinamento, utiliza as instâncias do Arquigrafia contidas nesse repositório para criar uma árvore de similaridade, usando a tabela de tags pré-definidas, a qual será utilizada no último módulo para recomendar tags para as novas instâncias do Arquigrafia. pré-definidas.

O sistema ArquiTag foi desenvolvido em Java versão $1.7^{1}$, e utiliza a biblioteca Sesame (ver Capítulo 2, Seção 2.2.3) versão 2.7.32 para a criação, acesso e manipulação de arquivos RDF. As próximas seções explicam em mais detalhes cada módulo do sistema ArquiTag.

\subsection{Módulo Conversor RDF}

O Conversor RDF obtém dados do banco de dados Arquigrafia e os converte ao formato RDF. Essa conversão é necessária porque os registros contidos no Arquigrafia irão, posteriormente, referenciar instâncias externas contidas no Linked Data DBpedia e uma vez que essas instâncias são descritas em RDF, os registros do Arquigrafia também devem ser convertidos para esse formato. Além disso, a métrica de similaridade utilizada só pode ser aplicada a instâncias descritas em RDF.

\footnotetext{
${ }^{1}$ Disponível em http://www.oracle.com/technetwork/pt/java/javase/downloads/index.html

${ }^{2}$ Disponível em http://www.openrdf.org/
} 




Figura 4.1: Módulos do sistema ArquiTag, com suas entradas e saídas.

Nessa etapa é importante definir um modelo dos dados. O modelo original do banco de dados Arquigrafia que contém as propriedades Nome, Descrição, Cidade, Estado, Autor e Data da obra, pode ser visto como um modelo de triplas RDF conforme ilustrado na Figura 4.2, e descrito diretamente na linguagem RDF-S (Figura 4.3).

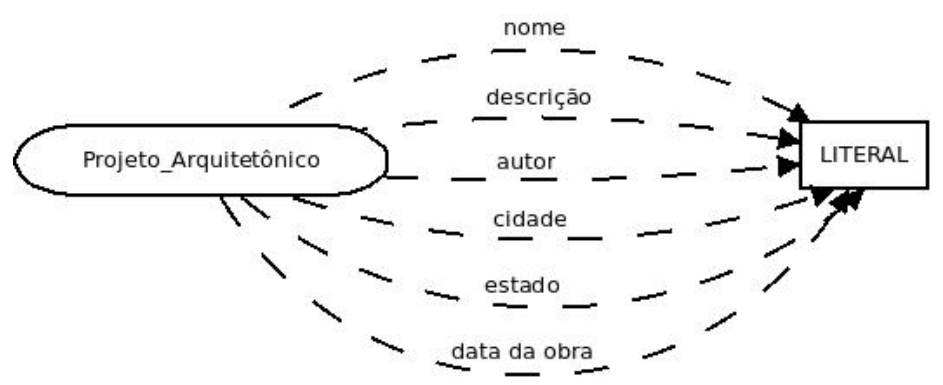

Figura 4.2: Modelo RDF original do banco de dados.

Para a conversão, os dados do banco de dados devem ser convertidos no formato de triplas. Por exemplo, para o registro mostrado na Tabela 1.1, que segue o modelo RDF da Figura 4.2, são criadas as triplas mostradas na Tabela 4.1.

Tabela 4.1: Triplas do registro mostrado na Tabela 1.1.

\begin{tabular}{|c|c|c|}
\hline Sujeito & Predicado & Objeto \\
\hline imagem_1220 & Nome & $\begin{array}{l}\text { Palácio Gustavo Capanema (Ministério da Educação e } \\
\text { Cultura) }\end{array}$ \\
\hline imagem_1220 & Descrição & $\begin{array}{l}\text { Vista geral do Palácio Gustavo Capanema (Ministério } \\
\text { da Educação e Cultura) }\end{array}$ \\
\hline imagem_1220 & Autor & COSTA, Lúcio Marçal Ferreira Ribeiro de Lima e \\
\hline imagem_1220 & Estado & RJ \\
\hline imagem_1220 & Cidade & Rio de Janeiro \\
\hline imagem_1220 & Data da obra & 1936-07-31 \\
\hline
\end{tabular}

Com o modelo da Figura 4.2 e as triplas RDF mostradas na Tabela 4.1, cada registro do banco de dados passa a ser descrito como uma instância em RDF, com as propriedades do modelo e seus respectivos valores. Para realizar a conversão, usa-se a classe Repository da biblioteca Sesame, responsável pela geração, manipulação e armazenamento de um conjunto de triplas RDF. As triplas da Tabela 4.1 são enviadas para um objeto da classe Repository através do método add(subject, property, object) e então gravadas em um arquivo RDF. Por exemplo, as triplas RDF da Tabela 4.1 resultam no código da Figura 4.4.

O modelo RDF da Figura 4.2 pode ser melhorado, porém esse modelo simples, extraído dire- 


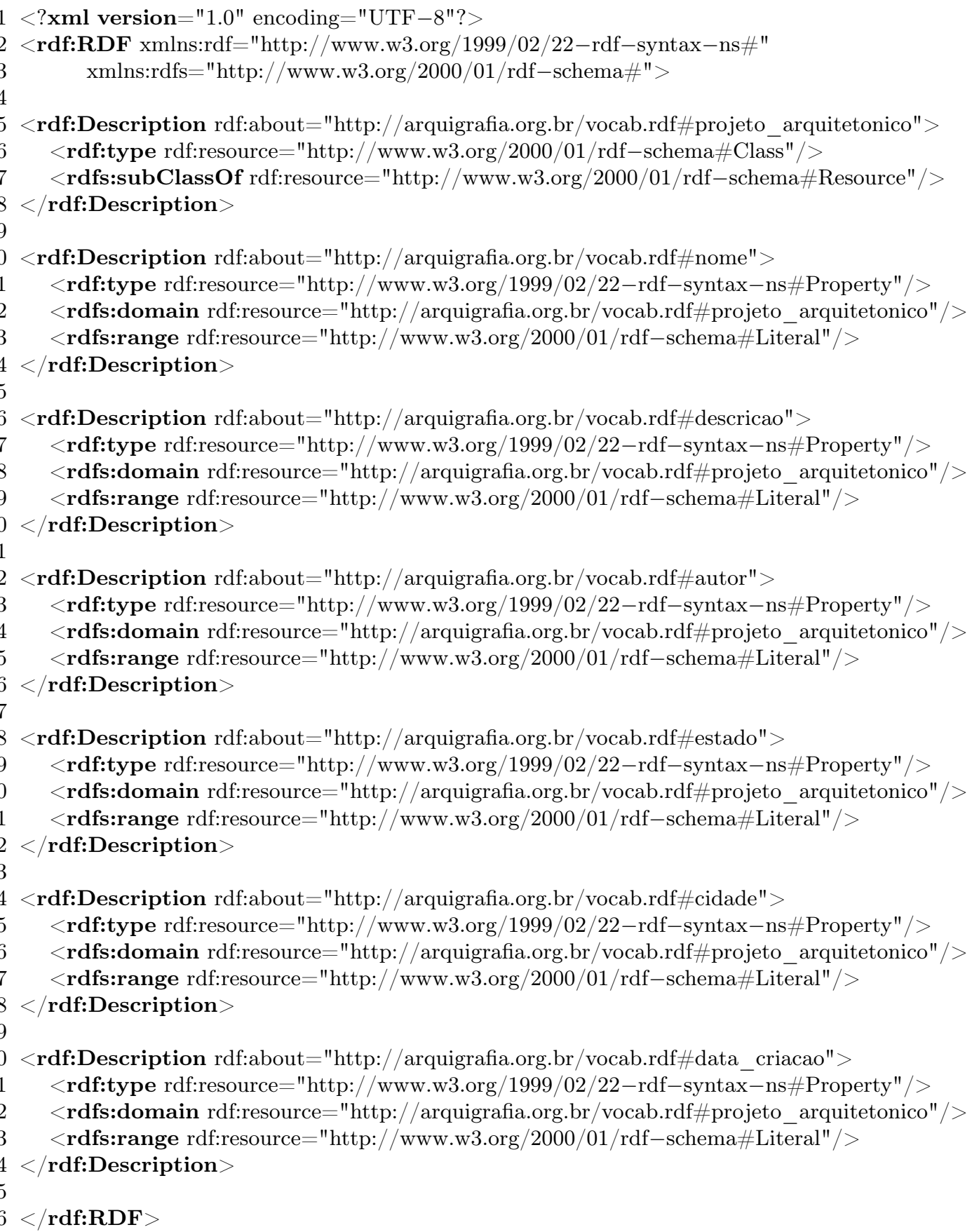

Figura 4.3: Código RDF-S que corresponde ao modelo da Figura 4.2.

tamente do banco de dados do Arquigrafia (Figura 4.2), é suficiente para a descrição do sistema ArquiTag apresentada nesse capítulo. Modelos mais complexos podem servir para fazer outros tipos de referências para o LD da DBpedia. Isso será explorado na Seção 4.6, ainda nesse capítulo.

O módulo Conversor recebe, como entrada, um modelo descrito em RDF-S (tal qual o exibido na Figura 4.2), e um arquivo em XML contendo os registros do banco de dados.

No momento da conversão é possível fazer com que o valor de algumas propriedades das instâncias referenciem recursos do DBpedia. Isso é feito, por exemplo, substituindo o valor "Oscar Niemeyer" para a propriedade Autor pela URI "http://dbpedia.org/resource/Oscar_Niemeyer", do DBpedia. Outros tipos de referências ao DBpedia são explicadas no próximo capítulo. Fazer referências não basta, é preciso também selecionar partes do modelo do DBpedia para serem importadas para o repositório local (pelo módulo Explorador). 




Figura 4.4: Código RDF, armazenado em um arquivo individual, resultante da conversão dos dados da Tabela 1.1.

Além das conversões para RDF dos registros contidos no banco de dados, o conversor também é encarregado de obter as tags pré-definidas para cada registro e criar um arquivo que associa cada instância a suas respectivas tags. Este arquivo resultante, denominado Tabela de Tags, é um arquivo texto onde cada linha contém a identificação da instância convertida e uma sequência de tags pré-definidas.

Finalmente, o conversor devolve um grupo de arquivos RDF, um para cada registro contido no banco de dados (com a adição de referências ao DBpedia), e o arquivo correspondente à Tabela de Tags.

\subsection{Módulo Explorador}

A partir de um conjunto de arquivos RDF dados como entrada, o módulo Explorador, através dos valores das propriedades de cada instância, realiza a busca no LD DBpedia pelas instâncias referenciadas e as salva localmente. Para cada instância acessada no DBpedia, o Explorador verifica se esta possui outras referências. Se sim, essas novas referências são acessadas e esse processo prosegue até um determinado nível de profundidade. O nível de profundidade máximo considerado pelo explorador é 4 .

Assim como o conversor, o explorador também faz uso da biblioteca Sesame, tanto para o armazenamento das triplas RDF como para o acesso aos recursos no DBpedia. O Sesame, além da classe Repository, possui a classe Connection, que permite a conexão a algum ponto de acesso no Linked Data. O ponto de acesso é identificado por uma URI, a qual pode receber solicitações de busca na linguagem SPARQL. O ponto de acesso para a obtenção do DBpedia é identificado pela URI "http://dbpedia.org/sparql". Cada instância acessada no DBpedia é armazenada num objeto da classe Repository, juntamente com as instâncias do Arquigrafia.

Como resultado, o Explorador cria um único arquivo RDF-S contendo todas as instâncias do Arquigrafia, as instâncias acessadas no DBpedia, e os modelos que as definem. Esse arquivo único é chamado de LD_Arq_DBpedia. O uso deste módulo é importante para que nos módulos seguintes (Treinamento e Recomendação de Tags) não exista necessidade para acessar essas instâncias na Web, uma vez que erros de conexão podem acontecer e comprometer os resultados.

\subsection{Módulo Treinamento}

O treinamento é a etapa onde a árvore de similaridade é criada e que, posteriormente, será usada na recomendação de tags. O processo de criação da árvore foi discutido no Capítulo 3.

Esse módulo recebe como entrada o repositório, resultante da fase anterior, um arquivo texto cujas linhas identificam as instâncias a serem inseridas na árvore de similaridade, um segundo arquivo de texto correspondendo à Tabela de tags (gerado pelo conversor), os parâmetros $[\alpha, \beta, \gamma]$ 
para a métrica de similaridade e o parâmetro que informa a máxima profundidade a ser utilizada na métrica da Similaridade Relacional. Opcionalmente, esse módulo aceita também como entrada um arquivo de cache contendo valores de similaridades previamente calculados.

Nessa etapa usa-se a classe Repository do Sesame para realizar buscas no repositório RDF-S local, i.e., no arquivo LD_Arq_DBpedia. Por causa da métrica de similaridade, o método de busca do Sesame é invocado diversas vezes, utilizando a linguagem SPARQL.

Como a métrica de similaridade exige tempo para ser calculada, e o processo de criação da árvore de similaridade pode exigir muitos cálculos a cada inserção de uma instância, o módulo de treinamento cria uma tabela para armazenar os valores das similaridades já calculados, chamada de Sim_cache. Essa tabela armazena os três valores de similaridade calculados para cada par de instâncias. O único parâmetro que afeta diretamente o valor da similaridade é o parâmetro de máxima profundidade associado a Similaridade Relacional.

Como resultado, esse módulo cria um arquivo XML contendo a árvore de similaridade e um arquivo contendo a tabela de similaridade armazenada previamente em cache. $\mathrm{O}$ arquivo de cache pode ser reutilizado para treinar outro conjunto de instâncias, e para a recomendação de tags.

\subsection{Módulo Recomendação de tags}

Esse módulo recomenda tags para uma nova instância inserida na árvore de similaridade e recebe, como entrada, o arquivo XML da árvore de similaridade e um arquivo de texto cujas linhas identificam as instâncias para as quais serão recomendadas tags. Opcionalmente, o arquivo Sim_cache pode ser dado como entrada.

O módulo de recomendação de tags carrega a árvore de similaridade e as novas instâncias, usando o processo de inserção e recomendação discutido no Capítulo 3.

Como resultado, esse módulo produzirá um novo arquivo XML contendo a árvore de similaridade atualizada e um arquivo texto contendo as recomendações de tagas para cada nova instância que foi inserida.

\subsection{Avaliação}

Os quatro módulos discutidos anteriormente descrevem o sistema ArquiTag ilustrado na Figura 4.1. A Figura 4.5 estende o ArquiTag com um módulo de avaliação.

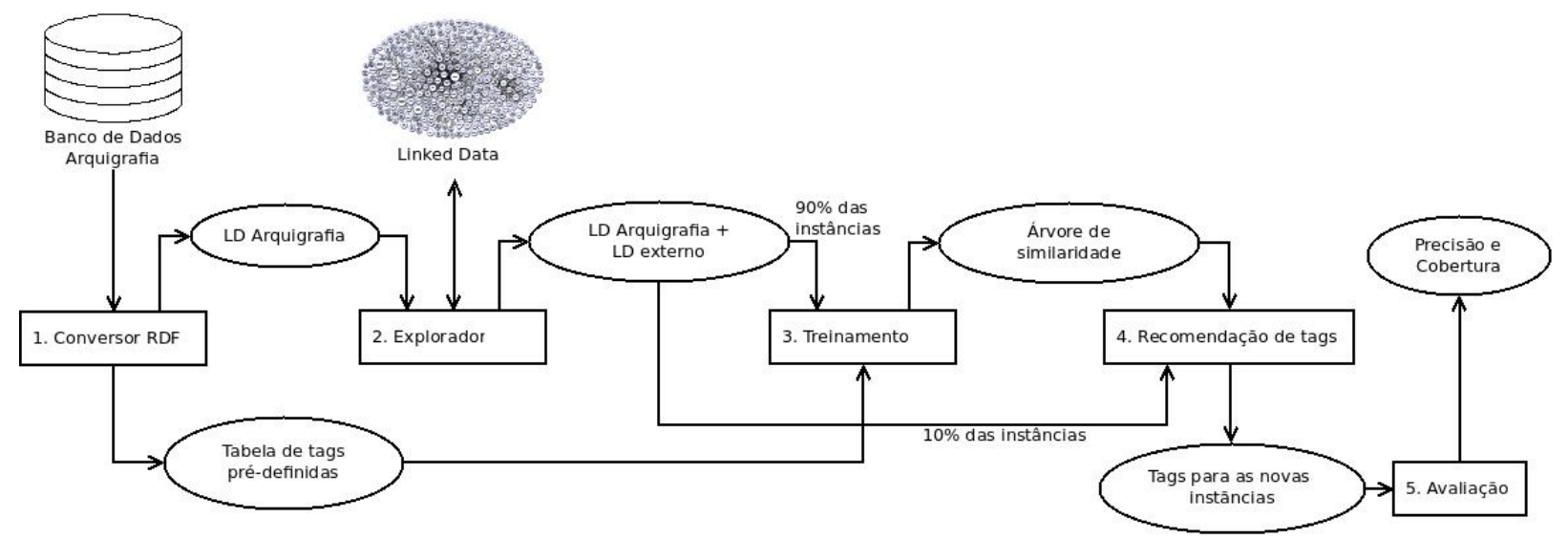

Figura 4.5: Módulos do sistema ArquiTag com suas entradas e saídas estendido. Para a avaliação 90\% das instâncias são utilizadas para construir a árvore de similaridade, e os 10\% restantes são utilizadas para as recomendações.

Para que seja possível avaliar o sistema ArquiTag, o total de instâncias do Arquigrafia foi dividido em dois conjuntos: o conjunto de treino e o conjunto de teste. O conjunto de treino contém 90\% das instâncias do Arquigrafia, e o conjunto de teste contém os $10 \%$ restantes. As instâncias de teste são utilizadas como novas instâncias às quais serão recomendadas tags. Ao final da etapa de recomendação, as tags recomendadas serão comparadas às tags previamente associadas às respectivas instâncias. Cada comparação entre essas tags é classificada em uma das categorias listadas 
abaixo:

Verdadeiro Positivo (VP) Tags preditas pelo sistema e que originalmente pertencem às instâncias.

Falso Positivo (FP) Tags preditas pelo sistema e que originalmente não pertencem às instâncias.

Verdadeiro Negativo (VN) Tags não preditas pelo sistema e que originalmente não pertencem às instâncias.

Falso Negativo (FN) Tags não preditas pelo sistema e que originalmente pertencem às instâncias.

Após a classificação, a avaliação é realizada através das medidas de Precisão e Cobertura, que são definidas abaixo pelas Expressões 4.1 e 4.2, respectivamente [Autayeu et al., 2009, Witten e Frank, 2005].

$$
\begin{aligned}
& P=\frac{|V P|}{|V P|+|F P|} \\
& C=\frac{|V P|}{|V P|+|F N|}
\end{aligned}
$$

A precisão (Expressão 4.1) é um valor no intervalo $[0,1]$ que indica a quantidade de correspondências corretas realizadas [Autayeu et al., 2009], e a cobertura (Expressão 4.2) é um valor no intervalo $[0,1]$ que indica a quantidade de correspondências encontradas [Autayeu et al., 2009].

Para a avaliação realizada nesse trabalho, que será descrita no Capítulo 5, foi aplicada a técnica da Validação Cruzada (Cross Validation) [Witten e Frank, 2005]. Essa técnica consiste em particionar o conjunto de instâncias do Arquigrafia em $n$ partes, de modo que cada partição seja usada em turnos pelo módulo de recomendação, enquanto as partições restantes são usadas pelo módulo de treinamento [Witten e Frank, 2005]. Neste trabalho, as instâncias foram particionadas em 10 $(n=10)$, e os módulos de treinamento, recomendação e avaliação (ver Figura 4.5) são repetidos 10 vezes alternando-se a partição destinada ao módulo de recomendação. Ao final das 10 repetições são obtidas as médias de precisão e cobertura calculadas para cada avaliação.

Nesse trabalho, modelos mais complexos foram propostos para descrever as instâncias do Arquigrafia, e as recomendações para cada um são avaliadas através das medidas de precisão e cobertura. Esse modelos são discutidos na próxima seção.

\subsection{Remodelando o Sistema Arquigrafia e criando referências para o Linked Data do DBpedia}

O modelo RDF do Arquigrafia mostrado na Figura 4.2 é um modelo simples, extraído diretamente do modelo original do banco de dados do Arquigrafia. Uma vez que nesse trabalho deseja-se criar formas mais ricas de relacionamentos entre o conteúdo do Arquigrafia e os recursos do DBpedia, foi necessário construir um modelo mais detalhado do conteúdo do Arquigrafia. Esse modelo é chamado de modelo estendido do Arquigrafia, e se baseia nas propriedades Descrição e Data da obra, a saber:

- No Arquigrafia, a propriedade Descrição contém várias informações importantes que podem contribuir para a similaridade literal, taxonômica e relacional entre duas instâncias (imagens) do Arquigrafia. Por exemplo, as instâncias 1212 e 1439 da Tabela 4.2 possuem os termos "Corredor" e "Auditório", respectivamente, que são dois tipos de ambiente existentes no interior de um espaço fechado de um projeto arquitetônico. Em outros casos pode-se identificar termos que descrevem os estilos artístico dos projetos, como por exemplo "Art Déco" e "Futurismo", presentes na descrição da instância 202, e "Brutalismo" na instância 165 (ver Tabela 4.2). As imagens podem ser consideradas similares se pertencem a um mesmo estilo artístico.

- A propriedade Data da obra do Arquigrafia pode ser usada para inferir o estilo artístico de uma imagem do Arquigrafia. Por exemplo, a instância de no 1220 tem valor para Data da obra igual a "1936-07-31", cujo ano pertence aos períodos [1920, 1960], [1920, 1940] e [1925, 1939] que 
correspondem, respectivamente, aos períodos de vigência dos estilos artísticos Modernismo, Bauhaus e Art Déco. Com isso, as imagens podem ser consideradas similares por pertencerem a um mesmo estilo artístico, mas de forma indireta, através de suas datas de construção.

Tabela 4.2: Exemplos de descrições de algumas instâncias do Arquigrafia.

\begin{tabular}{|l|l|l|l|}
\hline ID & Nome & Data da obra & Descrição \\
\hline \hline 165 & $\begin{array}{l}\text { Museu de Arte Moderna - } \\
\text { MAM }\end{array}$ & 1953 & $\begin{array}{l}\text { Obra de Affonso Reidy destaca- } \\
\text { se pela verdade estrutural ou bru- } \\
\text { talismo de sua concepção (utiliza } \\
\text { os materiais in bruto). Também } \\
\text { destaca-se a composição da sua es- } \\
\text { trutura, um peristilo moderno, e o } \\
\text { térreo livre }\end{array}$ \\
\hline 1212 & $\begin{array}{l}\text { Faculdade de Arquitetura e } \\
\text { Urbanismo da Universidade } \\
\text { de São Paulo }\end{array}$ & $\begin{array}{l}\text { Corredor das salas de aula da Facul- } \\
\text { dade de Arquitetura e Urbanismo da } \\
\text { Universidade de São Paulo }\end{array}$ \\
\hline 1220 & $\begin{array}{l}\text { Palácio Gustavo Capanema } \\
\text { (Ministério da Educação e } \\
\text { Cultura) }\end{array}$ & $31-07-1936$ & $\begin{array}{l}\text { Vista geral do Palácio Gustavo Ca- } \\
\text { panema (Ministério da Educação e } \\
\text { Cultura) }\end{array}$ \\
\hline 1439 & Tribunal de Contas & $20-08-1971$ & Auditório do Tribunal de Contas \\
\hline
\end{tabular}

A Tabela 4.3 exibe palavras extraídas da propriedade Descrição das imagens do Arquigrafia que podem ser usadas na construção do modelo estendido. A Tabela 4.4 lista estilos artísticos e seus períodos de maior vigência. Os estilos com asterisco são os que estão presentes na propriedade Descrição de alguma instância no Arquigrafia. Os demais, podem ser inferidos a partir da data da obra e da Tabela 4.4

Tabela 4.3: Termos extraídos da propriedade Descrição do Arquigrafia.

\begin{tabular}{|l|l|l|l|l|l|l|}
\hline art deco & ecletismo & estatua & lareira & ornamento & ponte & sala \\
auditório & elevador & futurismo & luterana & palco & portão & salão \\
basílica & entrada & hall & marquise & parque & praça & varanda \\
brutalismo & escada & janela & modernismo & passarela & quadra & \\
cobertura & escultura & jardim & monumento & pátio & rampa & \\
corredor & estacionamento & lago & neocolonial & piscina & rua & \\
\hline
\end{tabular}

\subsubsection{Modelo estendido do Arquigrafia}

Com base nos termos da Tabela 4.3, foi criado um novo modelo do Arquigrafia ilustrado na Figura 4.6. Nele, cada instância do Arquigrafia pode ser classificada em uma ou mais das subclasses que aparecem como folhas na estrutura taxonômica. Além disso, toda sub-classe herda as propriedades definidas a partir da classe Projeto Arquitetônico, que contém todas as propriedades do modelo original (Figura 4.2) mais duas novas propriedades: temEstiloArtístico e temUso (com valores público ou privado).

Na Figura 4.6, os conceitos denominados Projeto de Arte, Projeto de um Espaço, Espaço Aberto, Espaço Fechado, Acesso, Interior, Exterior e Projeto Arquitetônico foram criados para compor a taxonomia. Nessa Figura, cada Projeto Arquitetônico passa a ser classificado como Projeto de Arte ou Projeto de um Espaço. Caso seja um Projeto e Arte, será classificado como Monumento, Estátua, Escultura, Basílica ou Ornamento. Caso seja um Projeto de um Espaço, será classificada como Espaço Aberto, Espaço Fechado ou Acesso. Se for classificada como Espaço Aberto, poderá ainda ser classificada como Parque, Lago, Piscina, Quadra, Estacionamento, Jardim, Pátio, Praça ou Varanda. Se for classificada como Acesso, poderá ser classificada como Passarela, Entrada, Rua, Rampa, 




Figura 4.6: Modelo estendido do Arquigrafia.

Portão ou Ponte. Se for Espaço Fechado, poderá ser classificada como Interior ou Espaço Fechado. Em Interior, poderá ser classificada como Auditório, Sala, Elevador, Corredor, Lareira, Escola, Salão, Palco ou Hall. E finalmente, em Exterior poderá ser classificada como Janela, Cobertura ou Marquise.

A propriedade temEstiloArtístico é uma propriedade multivalorada, i.e., pode conter múltiplos valores. Dependendo da data da obra de um projeto arquitetônico, este pode pertencer a mais de um estilo artístico, como acontece com a instância ${ }^{\circ} 1220$ que pertence aos estilos Modernismo, Bauhaus e Art Déco. A representação de múltiplos valores associados a uma propriedade em RDF é feita repetindo-se a propriedade múltiplas vezes.

A propriedade temEstiloArtístico relaciona um projeto arquitetônico com um dos termos da coluna "Estilo Artístico" da Tabela 4.4. E a propriedade temUso relaciona o projeto arquitetônico com o seu tipo de uso que pode ser público ou privado. Essa propriedade está definida para a classe Projeto de um Espaço. O valor dessa propriedade foi atribuído a cada instância do Arquigrafia do tipo Projeto de um Espaço, de acordo com sua descrição.

\subsubsection{Referências feitas do modelo estendido do Arquigrafia para o DBpedia}

Para algumas propriedades selecionadas do modelo estendido foram feitas referências a recursos do DBpedia. Essas referências são feitas em três fases: seleção, atribuição e importação.Inicialmente, 
Tabela 4.4: Estilos artísticos inferidos a partir da Data da obra.

\begin{tabular}{|l|l||l|l|}
\hline Estilo Artístico & Período & Estilo Artístico & Período \\
\hline \hline Renascimento & {$[1400,1600]$} & Modernismo* & {$[1920,1960]$} \\
Maneirismo & {$[1550,1600]$} & Bauhaus & {$[1920,1940]$} \\
Barroco & {$[1600,1750]$} & Art Déco* & {$[1925,1939]$} \\
Neoclassicismo & {$[1750,1920]$} & Estilo Internacional & {$[1930,1970]$} \\
Pombalino & {$[1770,1850]$} & Brutalismo* & {$[1950,1960]$} \\
Neorromânico & {$[1840,1900]$} & Pós-modernismo & {$[1950,2010]$} \\
Ecletismo* & {$[1880,1920]$} & High-tech & {$[1970,2010]$} \\
Futurismo* & {$[1909,1916]$} & & \\
\hline
\end{tabular}

para cada instância do Arquigrafia são selecionadas as instâncias no DBpedia que correspondem aos valores literais atribuídos à propriedade considerada. Em seguida, esse valor é substituído pela respectiva URI (no módulo Conversor). Finalmente, o módulo Explorador é encarregado de importar as instâncias referenciadas juntamente com a parte do modelo DBpedia que as define e que são previamente selecionadas. Esse processo é descrito em detalhes para as referências feitas para as propriedades Autor e temEstiloArtistico.

\section{Propriedade Autor}

- Seleção e atribuição de referências ao Arquigrafia. Inicialmente são selecionadas as instâncias no DBpedia que correspondem aos valores literais atribuídos à propriedade $A u$ tor das instâncias do Arquigrafia. A Figura 4.7 (esquerda) mostra um exemplo para duas instâncias, Imagem_165 e Imagem_1212, cujos valores são Lucio Costa e Afonso Reidy, respectivamente. Na Figura 4.7 (direita), foram identificados no DBpedia os recursos http sobre os mesmos autores. Em seguida (Figura 4.8), a referência aos autores do DBpedia é realizada, substituindo-se o valor da propriedade Autor do Arquigrafia pela URI do respectivo autor (arquiteto) no DBpedia.

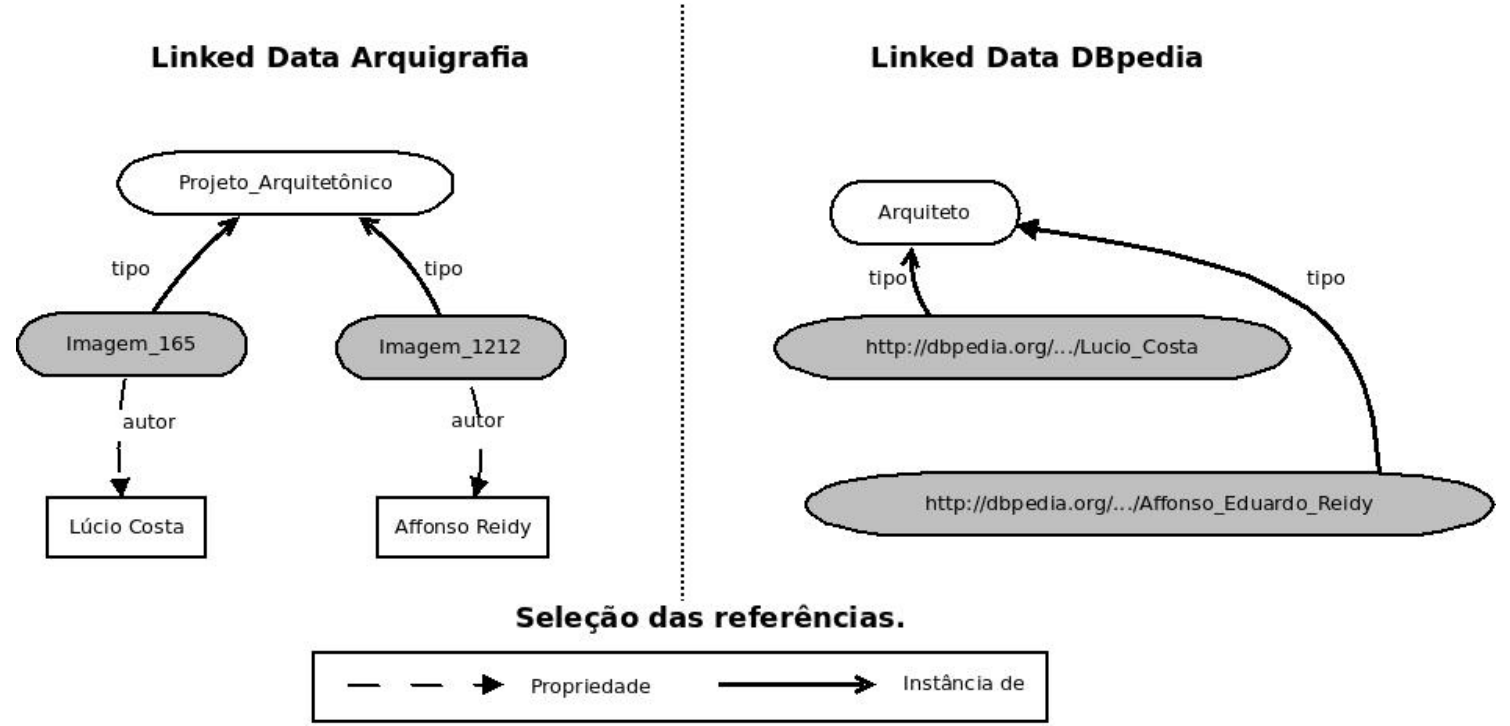

Figura 4.7: Seleção no DBpedia das instâncias que correspondem aos valores literais da propriedade Autor no Arquigrafia.

- Importação das instâncias e parte do modelo DBpedia. Ao acessar as instâncias referenciadas pela propriedade Autor no DBpedia, também são importados, pelo módulo Explorador, a classe Arquiteto e algumas de suas propriedades, a saber: Nome, temNacionalidade e temEstilo (do Arquiteto). Como as instâncias de Arquiteto relacionam-se com outras (através das propriedades temNacionalidade e temEstilo), as classes que as definem também devem 


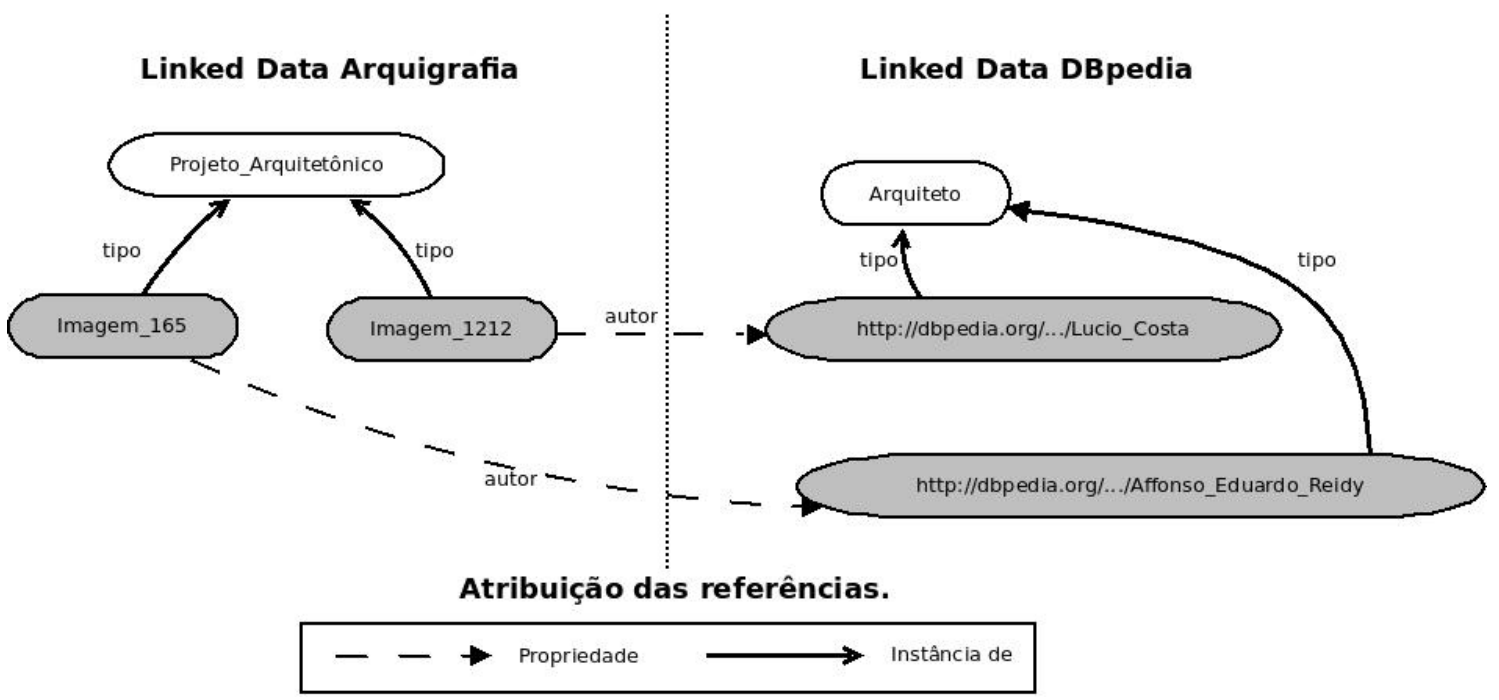

Figura 4.8: Atribuição às referências no DBpedia através da propriedade Autor.

ser importadas, i.e., País e Estilo Artístico. A Figura 4.9 exibe a propriedade Autor que relaciona o Projeto_Arquitetônico do Arquigrafia à classe Arquiteto no DBpedia e a parte do modelo DBpedia que é importada. Note que a classe Arquiteto é subclasse da classe mais geral Recurso_DBpedia, assim como as classes País e Estilo_Artístico. A classe Recurso_DBpedia possui a propriedade Nome, a qual por herança é definida também para todas as demais subclasses.

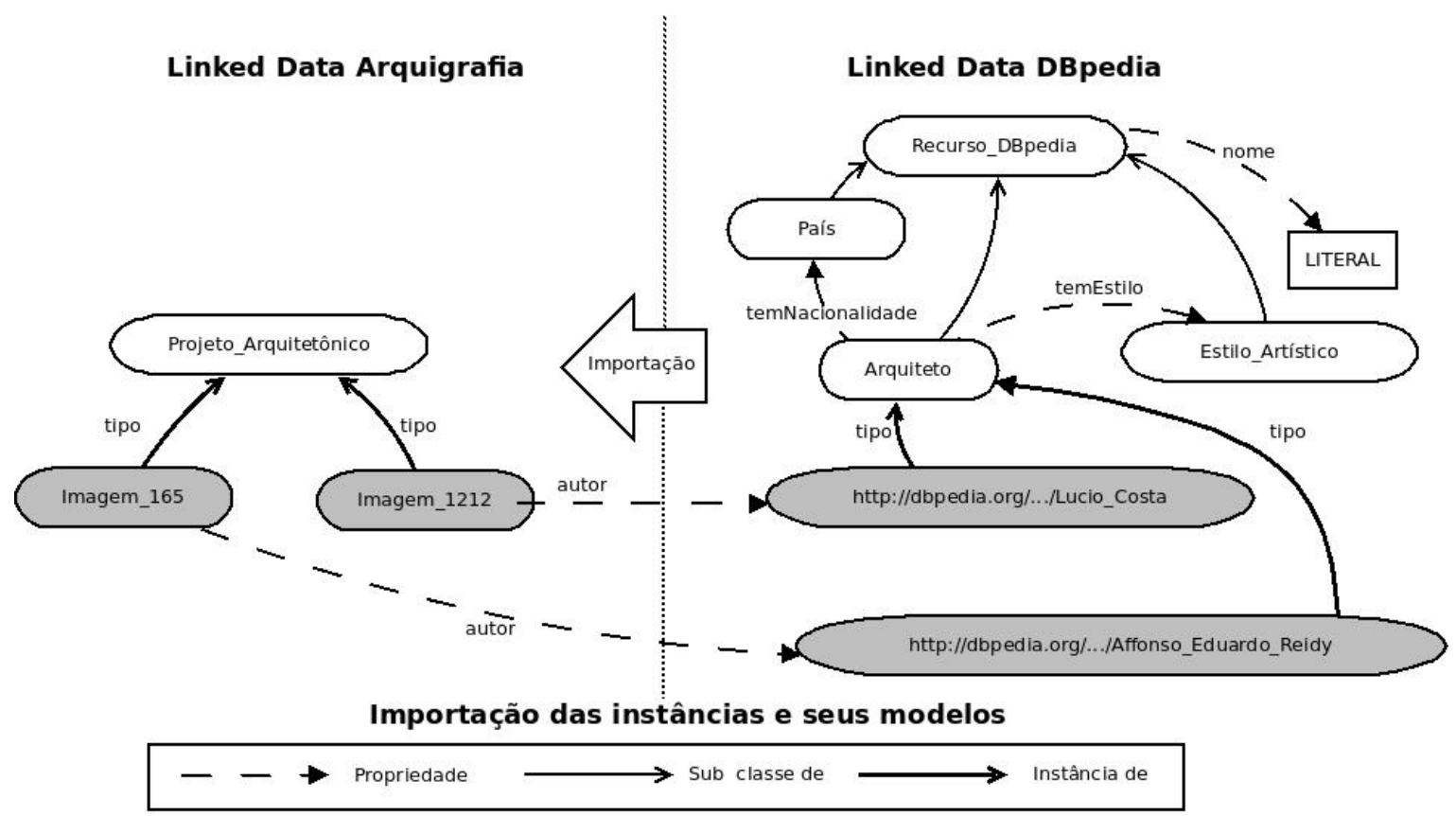

Figura 4.9: Importação das instâncias do DBpedia e dos modelos que a definem, através da propriedade Autor.

\section{Propriedade temEstiloArtistico}

- Seleção e atribuição de referências ao Arquigrafia. Primeiramente, são selecionadas as instâncias no DBpedia que correspondem aos valores literais atribuídos à propriedade temEstiloArtistico das instâncias do Arquigrafia. A Figura 4.10 mostra um exemplo de duas imagens, Imagem_168 e Imagem_1225, que pertencem ao estilo artístico Modernismo e Pós-modernismo, respectivamente. Em seguida, a referência é realizada, substituindo o va- 
lor da propriedade temEstiloArtistico pela respectiva URI no DBpedia. Por exemplo, na Figura 4.11 o valor da propriedade temEstiloArtistico Modernismo é substituído pela URI "http://dbpedia.org/resource/Modern_architecture" do DBpedia.

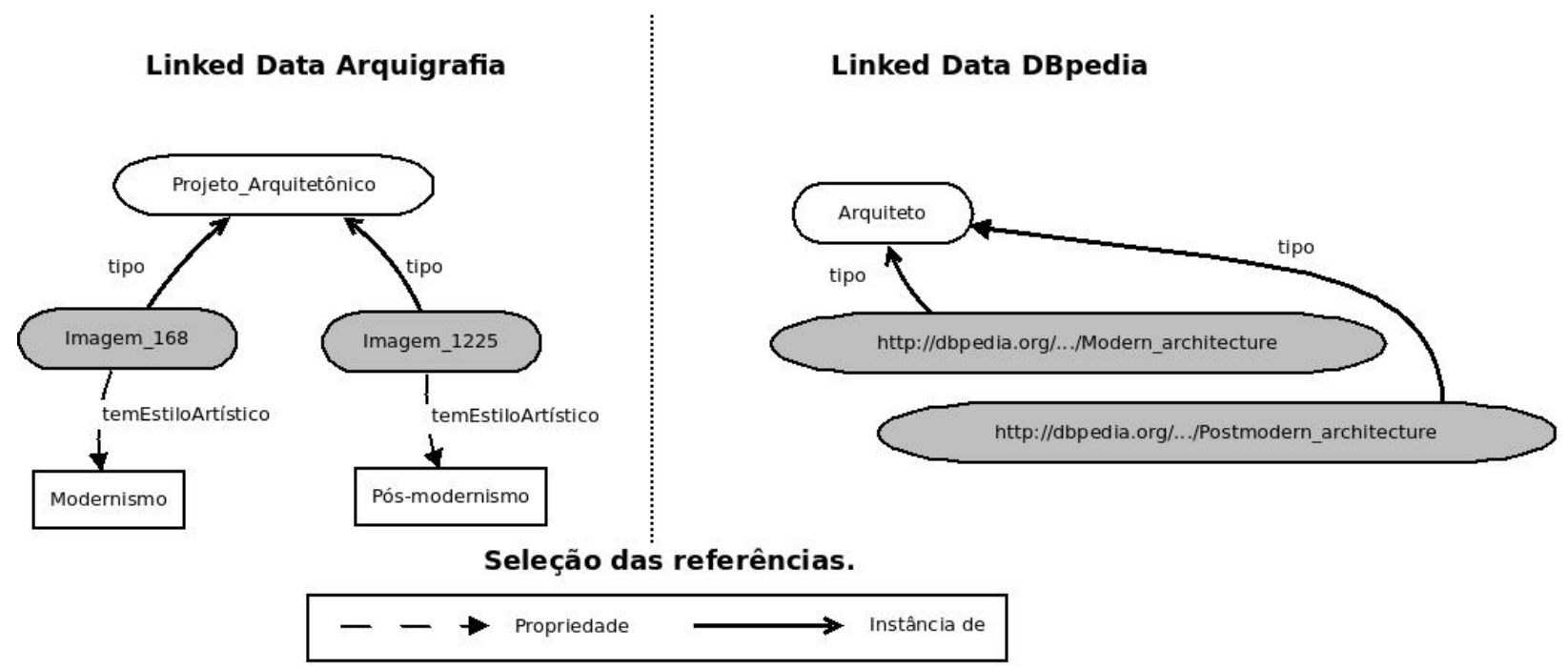

Figura 4.10: Seleção no DBpedia das instâncias que correspondem aos valores literais da propriedade temEstiloArtistico no Arquigrafia.

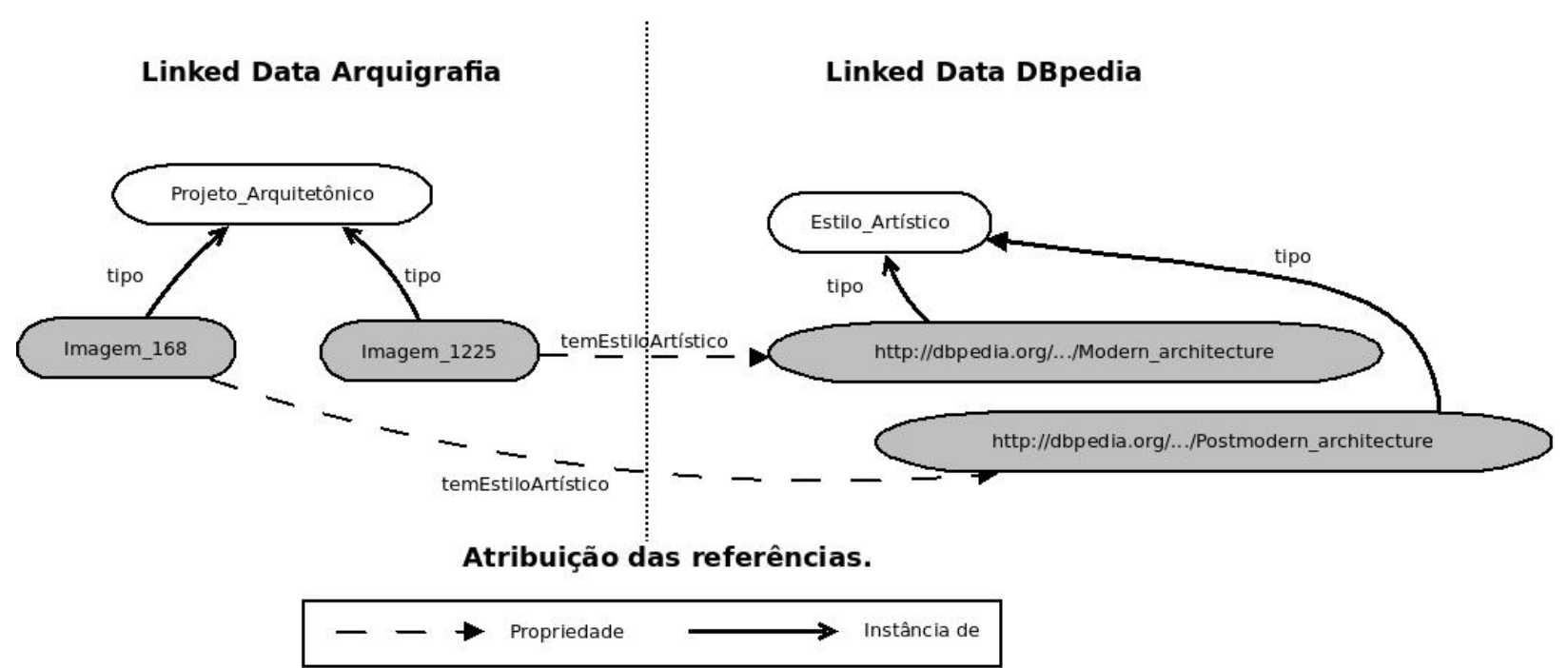

Figura 4.11: Atribuição às referências no DBpedia através da propriedade temEstiloArtistico.

- Importação das instâncias e parte do modelo DBpedia. Ao acessar as instâncias referenciadas pela propriedade temEstiloArtistico no DBpedia, também são importadas pelo módulo Explorador, a classe Estilo_Artístico e algumas de suas propriedades, a saber: Nome e Material (ambas literais). A Figura 4.12 exibe a propriedade temEstiloArtistico que relaciona o Projeto_Arquitetônico do Arquigrafia à classe Estilo_Artistico no DBpedia. A parte do modelo DBpedia que é importada: as classes Estilo_Artístico e Recurso_DBpedia, bem como as propriedades nome e materiais, com seus respectivos valores. Note que a classe Estilo_Artistico é subclasse da classe geral Recurso__DBpedia, e por isso herda a propriedade Nome.

\subsection{Trabalhos relacionados}

Neste trabalho, a recomendação de tags é realizada baseando-se no quanto as instâncias são similares umas às outras, utilizando uma métrica de similaridade entre documentos descritos na 


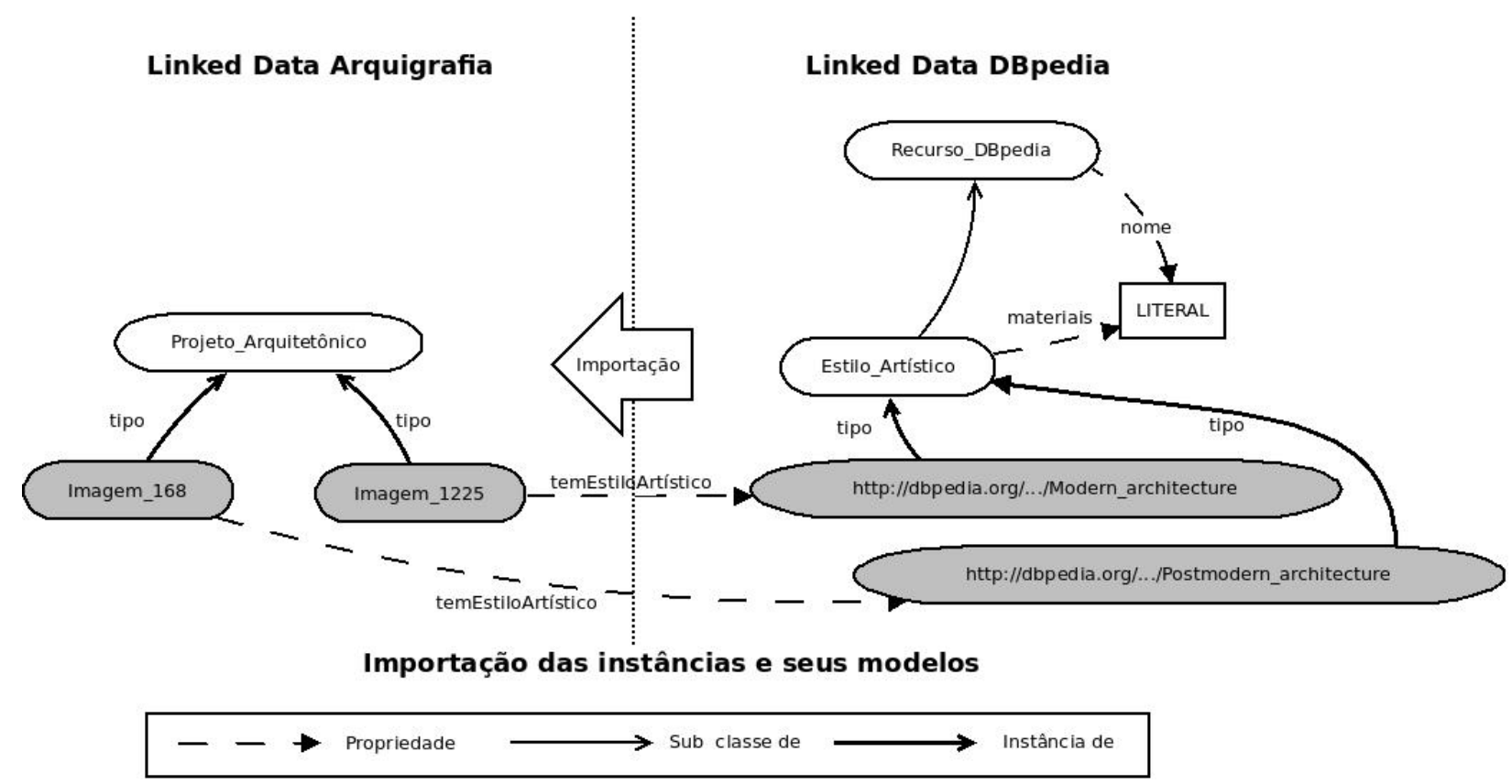

Figura 4.12: Importação das instâncias do DBpedia e dos modelos que a definem, através da propriedade temEstiloArtistico.

linguagem RDF. Existem diversos outros trabalhos que realizam a recomendação de tags, porém poucos a fazem com base no conteúdo das instâncias. Parte dos trabalhos utilizam uma técnica de colaboração entre tags, onde, basicamente, se uma tag t é atribuída manualmente a uma instância então as tags que co-ocorrem com $t$ em instâncias diferentes serão também recomendadas.

Há três trabalhos que utilizam essa técnica: [Begelman et al., 2006, Marinho e Schmidt-Thieme, 2008, Xu et al., 2006]. Porém, cada trabalho a aplica de forma diferente. Em [Begelman et al., 2006], os autores buscam agrupar o espaços de tags, criando agrupamentos de tags fortemente relacionadas. Em seguida, determina-se quais dessas relações são significantes. Os autores argumentam que o número de co-ocorrências representa um nível de similaridade entre duas tags e, dessa forma, tags que estão fortemente relacionadas com outras tags podem ser utilizadas para realizar a recomendação. No trabalho de [Xu et al., 2006], a recomendação de tags é baseada na probabilidade com que uma tag $t$ aparece juntamente com uma tag $u$. Em [Marinho e Schmidt-Thieme, 2008], são utilizadas matrizes que associam um conjunto de tags a um conjunto de recursos. Essa matriz é decomposta em vetores $t_{0}, \ldots, t_{n}$ e é utilizada uma expressão de similaridade sobre esses vetores para determinar o quão similares são duas tags.

Dos trabalhos que realizam a recomendação de tags com base no conteúdo dos recursos, citam-se [Oliveira et al., 2008] e [Sood et al., 2007]. Em [Oliveira et al., 2008], os autores criaram o sistema Tess, o qual avalia recursos que contenham textos. Cada recurso possui um conjunto de termos extraídos diretamente de seu texto, e é então comparado aos demais termos de outros recursos já existentes afim de encontrar os $k$ recursos mais similar. Dos termos desses recursos, esses são extraídos, classificados e recomendados como tags. Por sua vez, em [Sood et al., 2007] os autores apresentam TagAssist, um sistema que recomenda tags para postagens em blogs. Para cada nova postagem, esse sistema busca pelas postagens mais similares usando o conteúdo textual e sugere as tags para serem usadas pelos visitantes. No caso do ArquiTag, as tags não são extraídas do texto da descrição das imagens, mas são termos introduzidos por visitantes do Arquigrafia. Os textos descritos são usados para comparar a similaridade entre as imagens e as tags existentes são também sugeridas para novas imagens.

Uma outra forma de visualizar o problema da recomendação de tags é através da Folkosonomia (Folksonomy), também conhecida como mecanismos de tags sociais [Mika, 2005]. Folkosonomia é um neologismo para a atribuição de tags (livremente escolhidas) a recursos por usuários [Mika, 2005]. Del.icio.us e Flickr são exemplos de sites Web que aplicam esse mecanismo. Dos trabalhos 
relacionados a esse tema, pode-se citar [Si et al., 2009] e [Harvey et al., 2010]. Em [Si et al., 2009], os autores realizam a recomendação de tags num grafo Usuário $\times$ Recurso $\times$ Tag utilizando diferentes técnicas, tais como a classificação das tags mais utilizadas e o algoritmo FolkRank. Finalmente, em [Harvey et al., 2010] os autores apresentam um sistema de recomendação aplicado a um grafo Usuário $\times$ Recurso $\times$ Tag, que recomenda tags calculando um valor de probabilidade para que sejam recomendadas. 


\section{Capítulo 5}

\section{Avaliação Experimental}

Este capítulo apresenta os experimentos realizados para recomendação de tags no Arquigrafia. O objetivo dessa avaliação é analisar a qualidade das recomendações por similaridade e como elas podem variar usando os diferentes modelos do Arquigrafia, discutidos na Seção 4.6 do Capítulo 4 e resumidos na Tabela 5.1.

Tabela 5.1: Modelos do Arquigrafia.

\begin{tabular}{|l|l|}
\hline Modelo & Descrição \\
\hline \hline Modelo original & $\begin{array}{l}\text { Modelo original do Arquigrafia, sem referências ao DB- } \\
\text { pedia. }\end{array}$ \\
\hline Modelo estendido & $\begin{array}{l}\text { Modelo estendido do Arquigrafia, sem referências ao } \\
\text { DBpedia. }\end{array}$ \\
\hline DB_Autor & $\begin{array}{l}\text { Modelo estendido do Arquigrafia com referência ao } \\
\text { DBpedia para a propriedade Autor, incluindo o res- } \\
\text { pectivo modelo importado }\end{array}$ \\
\hline DB_temEstiloArtístico & $\begin{array}{l}\text { Modelo estendido do Arquigrafia com referência ao ao } \\
\text { DBpedia para a propriedade temEstiloArtistico, in- } \\
\text { cluindo o respectivo modelo importado }\end{array}$ \\
\hline DB_Autor_temEstiloArtístico & $\begin{array}{l}\text { Modelo estendido do Arquigrafia com referência ao } \\
\text { DBpedia para a propriedade Autor e temEstiloArtis- } \\
\text { tico, incluindo o respectivo modelo importado }\end{array}$ \\
\hline
\end{tabular}

Todas as instâncias selecionadas possuem 10 ou mais tags, resultando num total de 501 instâncias. Instâncias repetidas (que possuem valores iguais para todas as propriedades, mas com imagens diferentes) foram desconsideradas.

Nos experimentos, para cada tipo de modelo (Tabela 5.1) variou-se também os pesos associados aos cálculos de similaridade taxonômica $(\alpha)$, relacional $(\beta)$ e literal $(\gamma)$, com valores 0 , 1 e 5 . Na Seção 5.1 são mostrados os resultados de precisão e cobertura considerando todas as tags do Arquigrafia, num total de 518 tags. Na Seção 5.1 .2 são mostrados os resultados considerando as 10 tags mais populares e tags em que o uso do modelo estendido resulta em recomendações com maior predição e cobertura.

\subsection{Experimentos}

\subsubsection{Recomendação do conjunto completo de tags}

Nessa seção, os experimentos foram realizados para os modelos da Tabela 5.1, considerando todas as tags do Arquigrafia e diferentes combinações de $[\alpha, \beta, \gamma]$.

Para os modelos com referência ao DBpedia, são apresentados os valores de precisão e cobertura para as combinações de $\alpha, \beta$ e $\gamma$ iguais a $[1,1,5]$ e $[1,5,5]$, que correspondem aos melhores resultados. Para o modelo original foi usado $\alpha=0, \beta=0$ e $\gamma=5$, uma vez que no modelo original não existe taxonomia e relação entre classes. Para o modelo estendido foi usado $\beta=0$, uma vez que no modelo estendido não existe relação entre classes. 
A Figura 5.1 exibe os valores de precisão (incluindo o desvio-padrão - DP) para os modelos da Tabela 5.1, fazendo-se a validação cruzada, com uma partição de 10 blocos de instâncias. O modelo utilizado com melhor resultado foi o DB_Autor_temEstiloArtístico (i.e. o modelo estendido que faz referências através das propriedades Autor e temEstiloArtistico), com 72,02\% de precisão para a combinação $[1,1,5]$, e em segundo lugar foi o modelo estendido sem referências ao DBpedia, com $71,20 \%$ de precisão para $[1,0,5]$, seguido do modelo original, com $71,18 \%$.

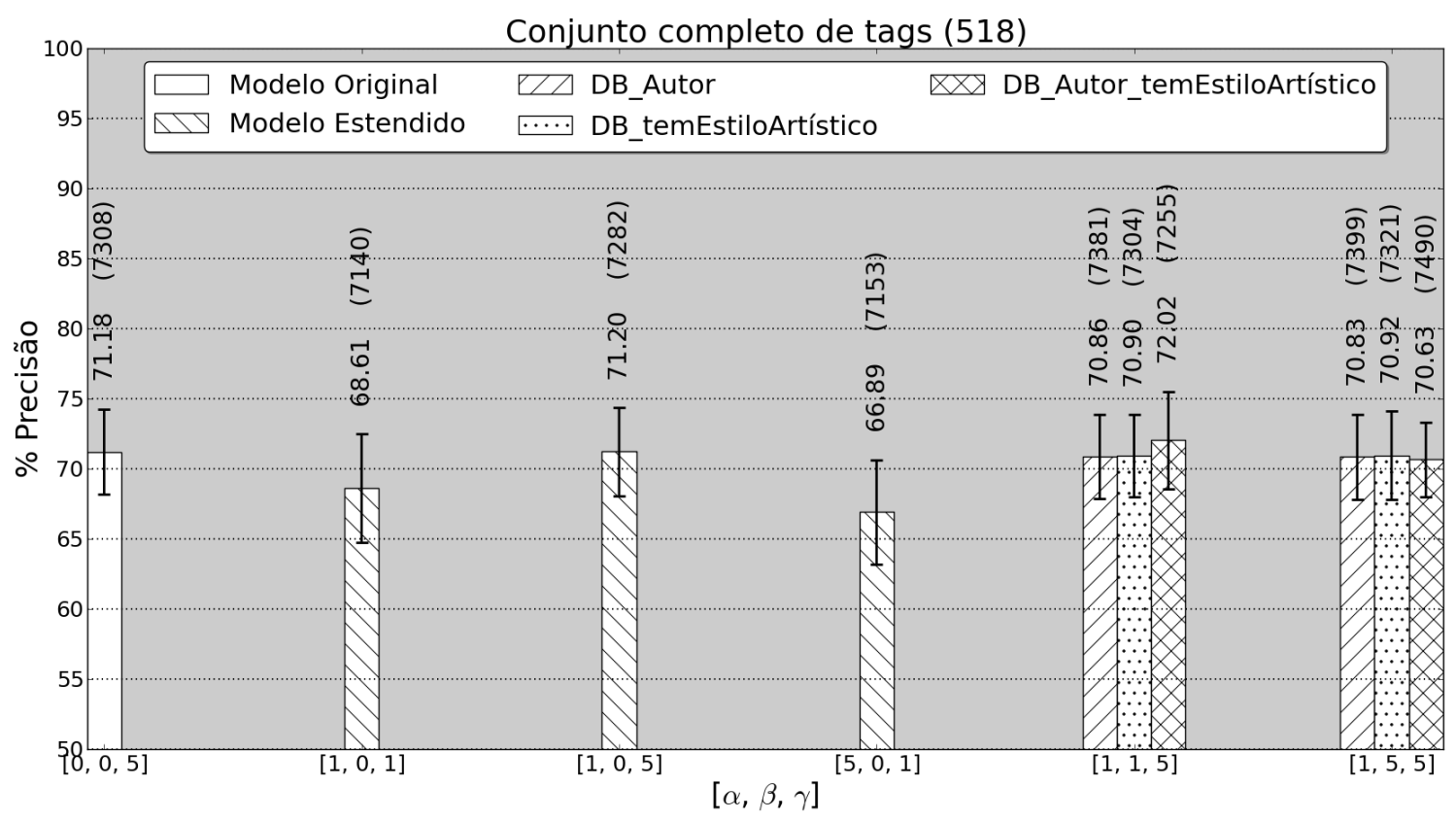

Figura 5.1: Medidas de precisão, com desvio-padrão, para os modelos da Tabela 5.1 com diferentes combinações de $[\alpha, \beta, \gamma]$ considerando o conjunto completo de tags. Os valores entre parenteses indicam o número médio de tags recomendadas por experimento.

Uma explicação para a pequena diferença de precisão de 72,02\% (modelo estendido com referências ao DBpedia) para 71,18\% (modelo original) é que, analisando as instâncias do Arquigrafia, nota-se que instâncias similares possuem valores (textos) muito semelhantes, o que pode explicar os maiores valores de precisão para combinações com $\gamma=5$. Assim, considerando o conjunto completo de 518 tags as referências ao DBpedia atribuídas às instâncias não parece contribuir de maneira significativa para as predições de tags, nem tampouco a taxonomia criada no modelo estendido.

A Figura 5.2 exibe os valores de cobertura para os modelos da Tabela 5.1. Novamente, os melhores resultados foram novamente obtidos para as combinações com $\gamma=5$, indicando a forte similaridade literal das instâncias do Arquigrafia. Novamente, o modelo que obteve o melhor resultado foi o DB_Autor_temEstiloArtístico $(55,3 \%)$ para a combinação $[1,5,5]$, que indica que a similaridade relacional também colaborou para melhorar a cobertura.

\subsubsection{Recomendação das 10 tags mais populares}

A Tabela 5.2 mostra o conjunto das 10 tags mais populares do Arquigrafia, isto é, as tags que ocorrem com maior frequência nas instâncias do Arquigrafia e a Figura 5.3 mostra a distribuição das tags em termos de número de ocorrência. Note que apenas 100 das 518 tags ocorrem mais do que 20 vezes. Assim, ao construir a árvore de similaridade para as 10 tags mais populares espera-se obter maiores valores de precisão e cobertura. De fato, a Figura 5.4 mostra que a precisão usando apenas o modelo original, subiu de $71,18 \%$ (com o conjunto completo de tags) para $84 \%$ (com as tags mais populares).

Pode-se observar que com o modelo original, os testes apresentam precisão e cobertura (Figura 5.5) um pouco superiores dos testes com o uso do modelo estendido, evidenciando novamente que para esse conjunto de tags o modelo estendido não contribui para a melhoria da qualidade das recomendações. 


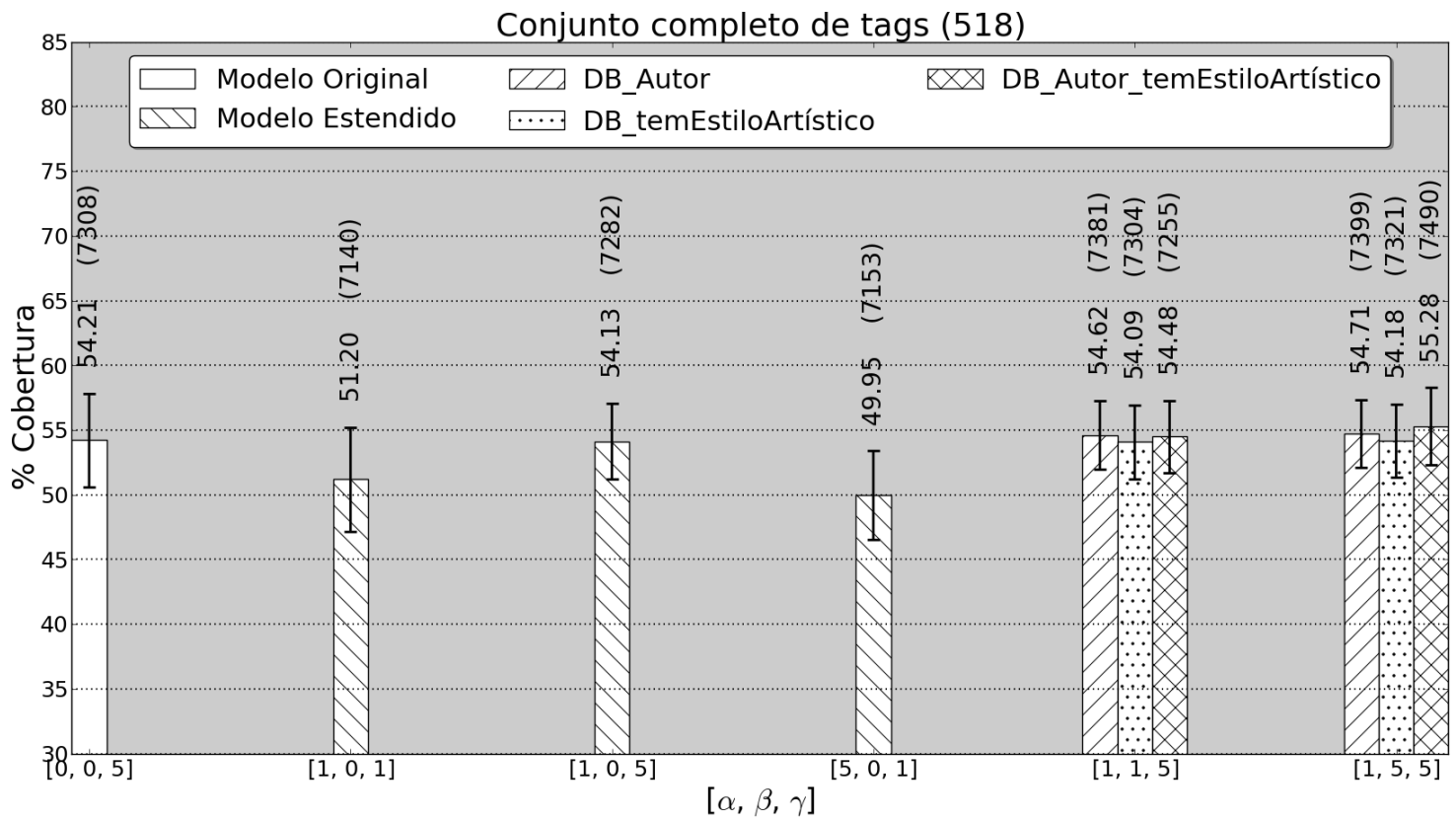

Figura 5.2: Medidas de cobertura, com desvio-padrão, para os modelos da Tabela 5.1 com diferentes combinações de $[\alpha, \beta, \gamma]$ considerando o conjunto completo de tags. Os valores entre parenteses indicam o número médio de tags recomendadas por experimento.

Tabela 5.2: As 10 tags mais populares no Arquigrafia e o número total de vezes que elas ocorrem.

\begin{tabular}{|l|l|}
\hline Tag & Ocorrências \\
\hline \hline Concreto & 387 \\
Vidro & 368 \\
Ferro & 367 \\
Concreto Aparente & 283 \\
Pano de vidro & 226 \\
Alvenaria & 219 \\
Esquadria & 212 \\
Habitação & 184 \\
Madeira & 167 \\
Pilar & 156 \\
\hline
\end{tabular}

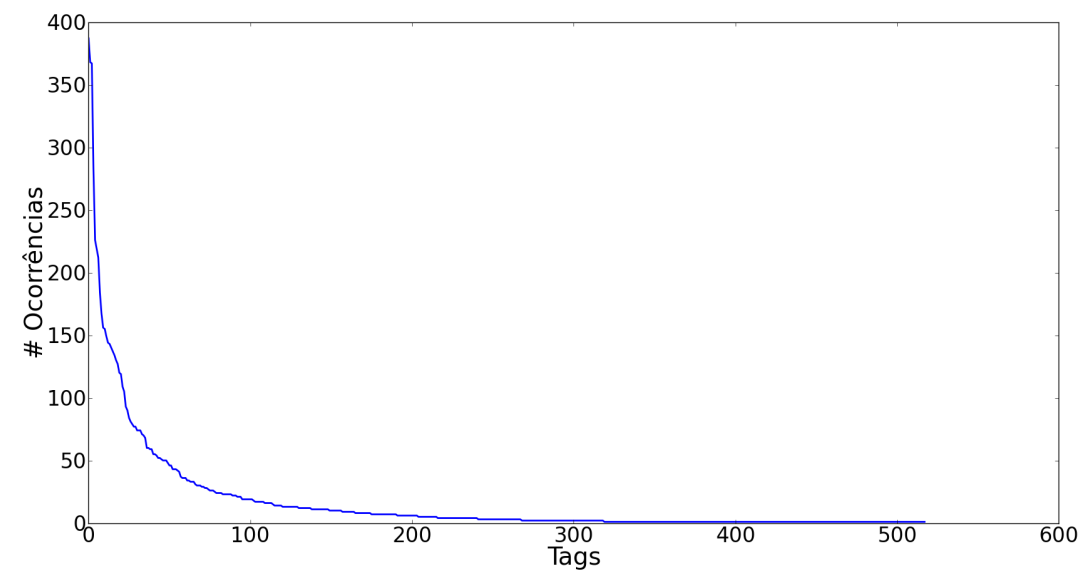

Figura 5.3: Número de ocorrências por tag. Note que somente 100 tags ocorrem mais do que 20 vezes nas instâncias do Arquigrafia. 
10 tags mais populares

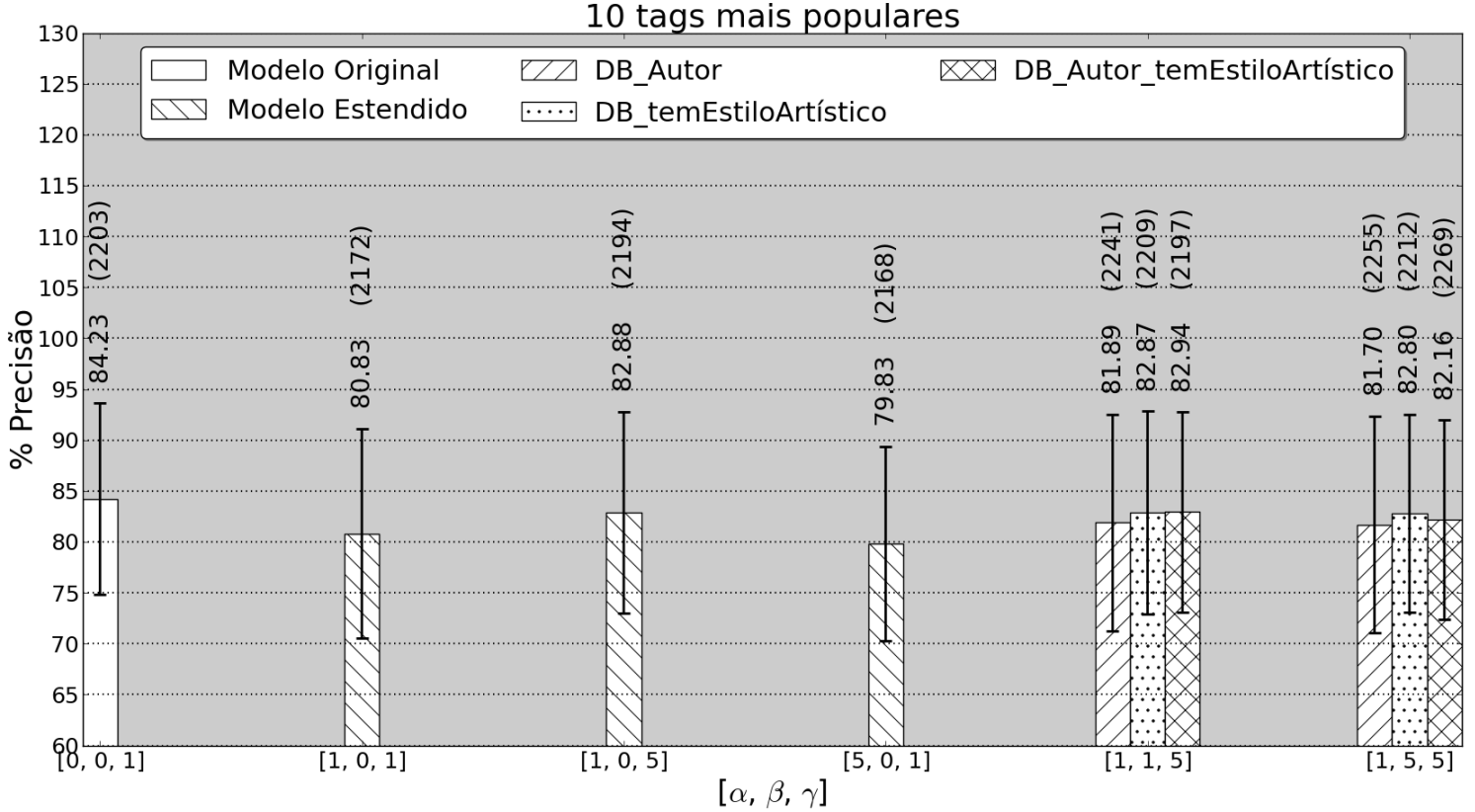

Figura 5.4: Medidas de precisão para os modelos da Tabela 5.1 com diferentes combinações de $[\alpha, \beta, \gamma]$ considerando somente as 10 tags mais populares.

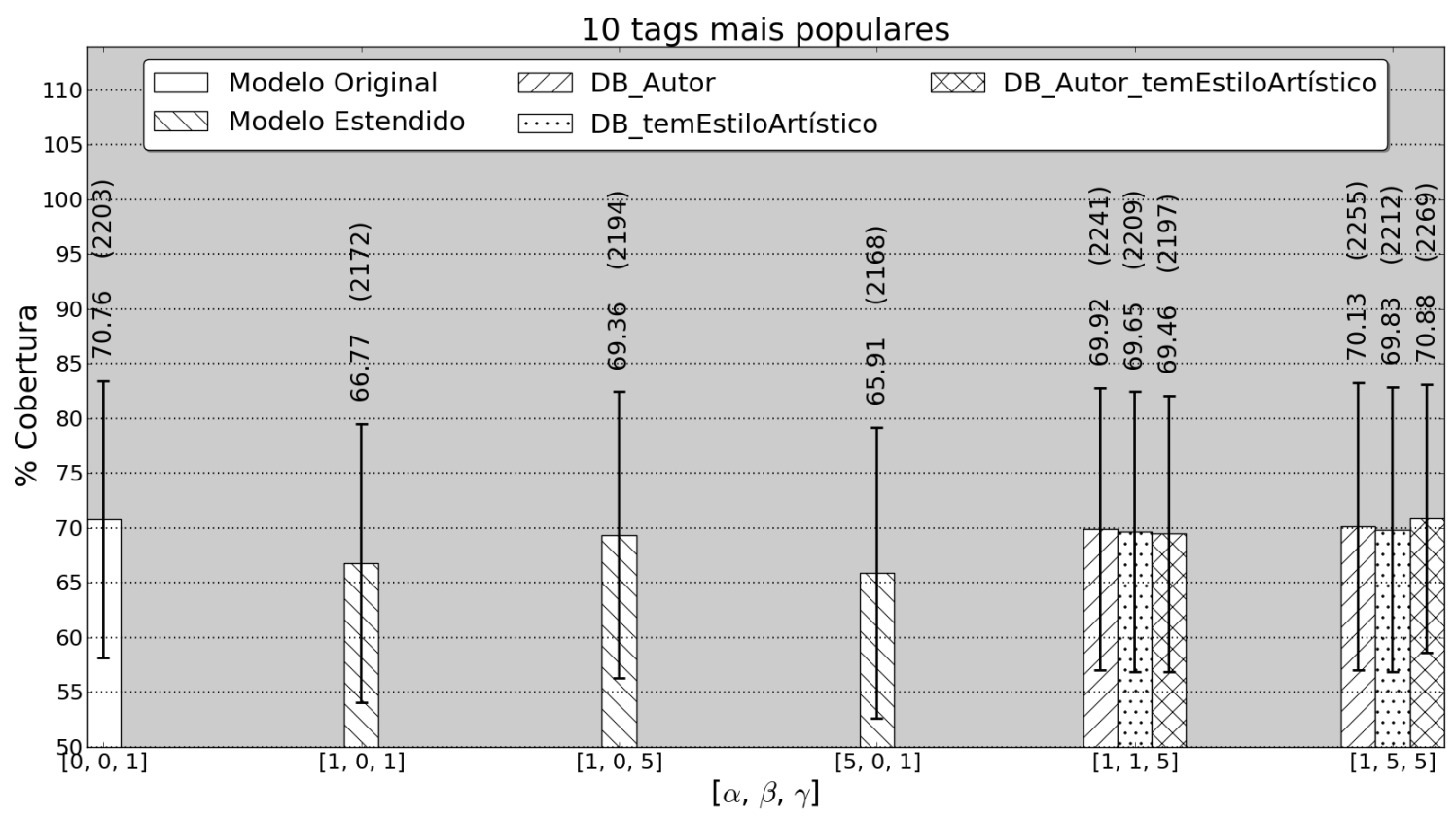

Figura 5.5: Medidas de cobertura para os modelos da Tabela 5.1 com diferentes combinações de $[\alpha, \beta, \gamma]$ considerando somente as 10 tags mais populares.

e Residência, observa-se que com o uso do modelo estendido os testes apontam uma melhora na qualidade da recomendação. Essas duas tags ocorrem no Arquigrafia, respectivamente, 77 e 137 vezes.

As Figuras 5.6 e 5.7 mostram os valores de precisão para as tags Estrutura e Residência, respectivamente. Para a tag Estrutura, a precisão da recomendação com o uso do modelo original foi de $58,49 \%$ enquanto que com o uso do modelo estendido foi de $70,69 \%$ com a combinação $[1,0,5]$ que dá peso 1 à similaridade taxonomia $(\alpha=1)$ e 5 à similaridade literal $(\gamma=5)$. O melhor resultado foi obtido com o modelo estendido com referência ao Estilo Artístico, DB_temEstiloArtístico, com a combinação $[1,5,5]$, que dá peso à similaridade relacional $(\beta=5)$ e literal $(\gamma=5)$. O aumento de $16,06 \%$ de precisão com o uso do modelo estendido DB_temEstiloArtístico, mostra uma melhora 
significativa de precisão quando usa-se as instâncias do DBpedia.

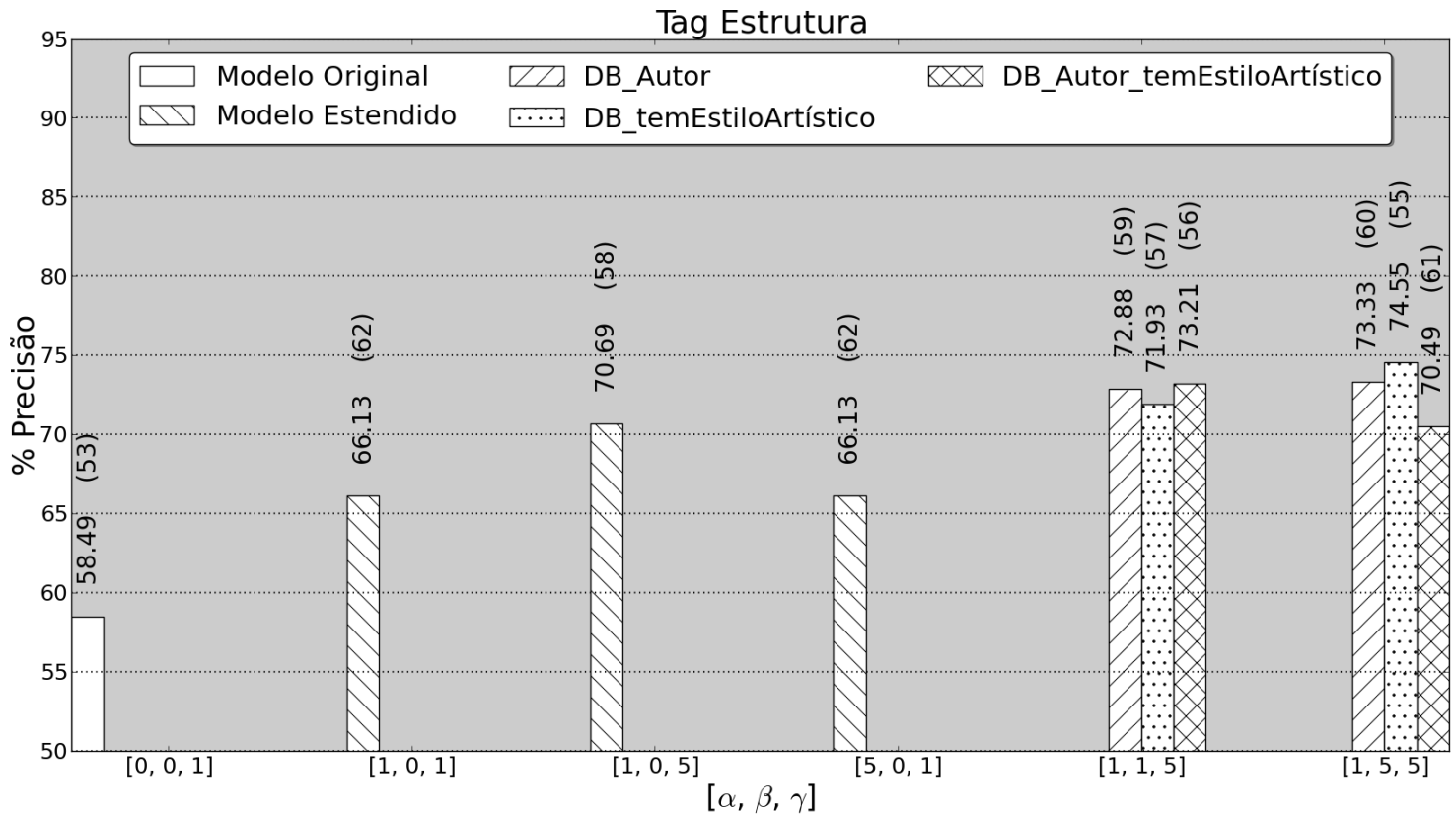

Figura 5.6: Medidas de precisão da tag Estrutura.

A recomendação da tag Residência, mostra uma diferença na precisão de 95,87\% (com o uso do modelo original) para 99,15\% (com o uso do modelo estendido). O melhor resultado foi obtido com os modelos DB_Autor e DB_Autor_temEstiloArtístico para a combinação $[1,1,5]$, que sugere que as instâncias do DBpedia contribuem para aumentar a similaridade literal das instâncias que recomendamos a tag Residência.

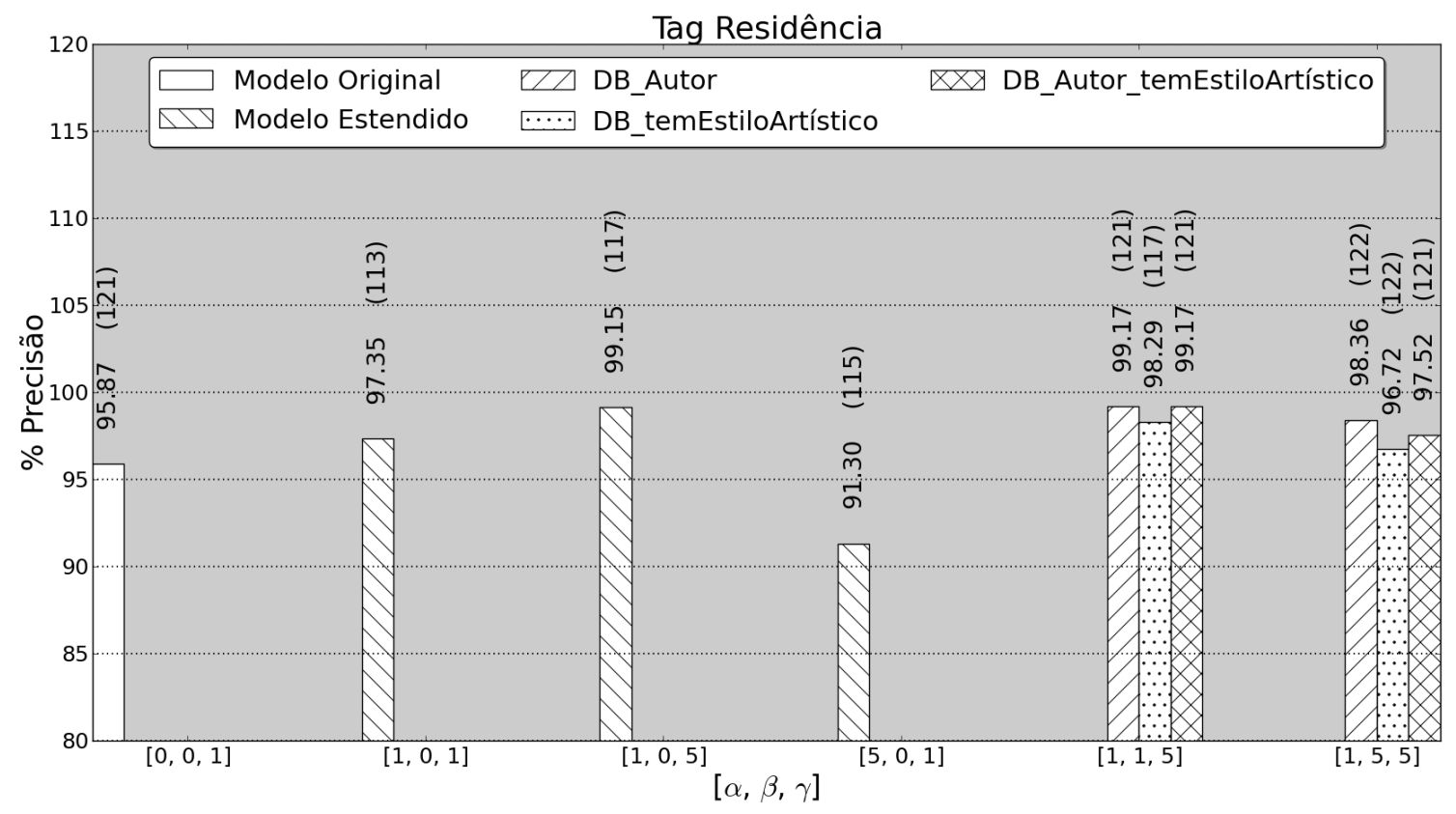

Figura 5.7: Medidas da precisão da tag Residência. 


\section{Capítulo 6}

\section{Conclusão e Trabalhos Futuros}

O objetivo deste trabalho foi construir um sistema de predição de tags que utiliza-se de recursos no Linked Data. A predição foi realizada através de um algoritmo de agrupamento hierárquico, onde as instâncias mais similares são agrupadas de acordo com uma métrica de similaridade capaz de comparar recursos RDF. Foi feito um estudo de caso em um banco de dados de projetos arquitetônicos, o Arquigrafia. O sistema desenvolvido, chamado de ArquiTag foi analisado usando diferentes modelos RDF do Arquigrafia: o modelo original do Arquigrafia e o modelo estendido com dois tipos de referências ao DBpedia, pela propriedade Autor e temEstiloArtistico.

O conjunto de instâncias foi dividido em conjunto de treino e conjunto de testes, e a predição foi realizada através do método da validação cruzada. Os resultados das predições foram analisados através das medidas de precisão e cobertura e mostram que a predição considerando o conjunto total de tags possui as mesmas medidas de precisão e cobertura que o modelo original. Porém, para algumas tags, o sistema foi capaz de recomendá-las com maior precisão, utilizando o modelo estendido com referências para o Linked Data DBpedia. Isso mostra que o cálculo de similaridade pode ser melhorado com modelos estendidos do Linked Data.

Como trabalhos futuros propomos:

- Aplicar o método produzido em repositórios contendo dados mais heterogêneos. O banco de dados do sistema Arquigrafia, embora contenha um número razoável de instâncias (aproximadamente 615, excluindo-se as instâncias repetidas), contém grande parte das instâncias com valores de propriedades muito parecidos, prejudicando o método utilizado. Por exemplo, várias instâncias possuem o valor "São Paulo" para a propriedade cidade, ou há um pequeno número de arquitetos diferentes (aproximadamente 30) para todas as instâncias do banco. Portanto, aplicar o método produzido neste trabalho em um contexto diferente pode trazer resultados que apresentam uma maior diferença ao utilizar recursos do Linked Data.

- Utilizar outras métricas de similaridade. Embora a métrica utilizada tenha trazido bons resultados, não houve uma diferença muito sensível nos resultados da precisão e cobertura ao usar ou não os recursos existentes no Linked Data. Aliada a ideia de aplicar este método em outro contexto, um aprimoramento da métrica pode trazer outros resultados.

- Utilizar outros métodos de mineração. Embora o agrupamento hierárquico tenha tido sua eficácia em termos de precisão e cobertura comprovada, a comparação deste método com outros que também possibilitem a predição de tags, e que possam utilizar-se da mesma métrica de similaridade usada neste trabalho (em conjunto com Linked Data) interessante. A bibliografia contempla alguns trabalhos que também realizam a predição de tags em outros contextos (mas nenhum faz uso do Linked Data). A ideia é adaptar alguns desses métodos para que possam vir a ser comparados com este trabalho

- Recomendar tags a partir das descrições. Com base no trabalho de [Oliveira et al., 2008], pode-se adaptar o sistema proposto para a recomendação de novas tags extraídas das descrições das instâncias do Arquigrafia. 


\section{Referências Bibliográficas}

Adida et al.(2012) Ben Adida, Ivan Herman, Manu Sporny e Mark Birbeck. RDFa 1.1 primer. http://www.w3.org/TR/xhtml-rdfa-primer/, 2012. Citado na pág. 16

Almeida(2002) Mauricio Barcillos Almeida. Uma introdução ao XML, sua utilização na internet e alguns conceitos complementares. Ciência da informação, 31(2):5-13. Citado na pág. 6

Auer et al.(2007) Sören Auer, Christian Bizer, Georgi Kobilarov, Jens Lehmann, Richard Cyganiak e Zachary Ives. Dbpedia: A nucleos for a web of open data. International Semantic Web Conference $(I S W C)$. Citado na pág. xiii, 3, 16, 17

Aurnhammer et al.(2006) Melanie Aurnhammer, Peter Hanappe e Luc Steels. Integrating collaborative tagging and emergent semantics for image retrieval. Citado na pág. 2

Autayeu et al.(2009) Aliaksandr Autayeu, Vincenzo Maltese e Pierre Andrews. Best practices for ontology matching tools evaluation. Citado na pág. 42

Beckett(2004) Dave Beckett. RDF/XML syntax specification (revised). http://www.w3.org/TR/2004/REC-rdf-syntax-grammar-20040210/, 2004. Citado na pág. 9

Begelman et al.(2006) Grigory Begelman, Philipp Keller, Frank Smadja et al. Automated tag clustering: Improving search and exploration in the tag space. Em Collaborative Web Tagging Workshop at WWW2006, Edinburgh, Scotland, páginas 15-33. Citado na pág. 19, 48

Berners-Lee(2009) Tim Berners-Lee. Linked data.

http://www.w3.org/DesignIssues/LinkedData.html, 2009. Citado na pág. 12, 15

Bizer e Health(2011) Christian Bizer e Tom Health. Linked Data: Evolving the Web into a Global Data Space. Morgan \& Claypool. Citado na pág. xiii, 12, 13, 14, 15, 16

Bizer et al.(2009) Christian Bizer, Tom Health e Tim Berners-Lee. Linked data - the story so far. International Journal on Semantic Web and Information Systems (IJSWIS). Citado na pág. 12

Bray et al.(2008) Tim Bray, Jean Paoli, C. M. Sperberg, Eve Maler e François Yergeau. Extensible markup language (XML) 1.0 (fifth edition). http://www.w3.org/TR/2008/REC-xml-20081126/, 2008. Citado na pág. 6

Breitman et al.(2007) K Karin K Breitman, Marco Antonio Casanova e Walter Truszkowski. Semantic web: concepts, technologies and applications. Springer. Citado na pág. 1, 6, 9, 10, 11

Brickley e Guha(2004) Dan Brickley e R.V. Guha. RDF vocabulary description language 1.0: RDF schema. http://www.w3.org/TR/2004/REC-rdf-schema-20040210/, 2004. Citado na pág. 9, 10,26

Broekstra et al.(2002) Jeen Broekstra, Arjohn Kampman e Frank Van Harmelen. Sesame: A generic architecture for storing and querying RDF and RDF schema. Em The Semantic WebISWC 2002, páginas 54-68. Springer. Citado na pág. xiii, 5, 17, 18

Clark et al.(2008) Kendall Grant Clark, Lee Feigenbaum e Elias Torres. SPARQL protocol for RDF.

http://www.w3.org/TR/2008/REC-rdf-sparql-protocol-20080115, 2008. Citado na pág. 11 
Fallside e Walmsley(2004) David C. Fallside e Priscilla Walmsley. XML schema part 0: Primer second edition.

http://www.w3.org/TR/xmlschema-0/, 2004. Citado na pág. 7, 8

Grimnes et al.(2008) Gunnar Grimnes, Peter Edwards e Alun Preece. Instance Based Clustering of Semantic Web Resources. Em Sean Bechhofer, Manfred Hauswirth, Jörg Hoffmann e Manolis Koubarakis, editors, The Semantic Web: Research and Applications, volume 5021 of Lecture Notes in Computer Science, chapter 24, páginas 303-317. Springer Berlin / Heidelberg, Berlin, Heidelberg. ISBN 978-3-540-68233-2. doi: 10.1007/978-3-540-68234-9 \_24. URL http://dx.doi.org/10.1007/978-3-540-68234-9_24. Citado na pág. 19, 32, 33

Harvey et al.(2010) Morgan Harvey, Mark Baillie, Ian Ruthven e Mark J Carman. Tripartite hidden topic models for personalised tag suggestion. Em Advances in Information Retrieval, páginas 432-443. Springer. Citado na pág. 49

Hastie et al.(2001) Trevor. Hastie, Robert. Tibshirani e J Jerome H Friedman. The elements of statistical learning, volume 1. Springer New York. Citado na pág. 19

Hausenblas(2009a) Michael Hausenblas. Exploiting linked data for building web applications. National University of Ireland. Citado na pág. 11, 12, 13

Hausenblas(2009b) Michael Hausenblas. Linked data applications. Digital Enterprise Research Institute (DERI). Citado na pág. 15, 16

Hayes(2004) Patrick Hayes. RDF semantics. http://www.w3.org/TR/2004/REC-rdf-mt-20040210/, 2004. Citado na pág. 10

Heymann et al.(2008) Paul Heymann, Daniel Ramage e Hector Garcia-Molina. Social tag prediction. Citado na pág. 2, 19, 24

Hogan et al.(2011) Aidan Hogan, Andreas Harth, Jürgen Umbrich, Sheila Kinsella, Axel Pollores e Stefan Decker. Searching and browsing linked data with SWSE: the semanticweb search engine. Preprint submitted to Elsevier. Citado na pág. 1

Klyne e Carroll(2004) Graham Klyne e Jeremy J. Carroll. Resource description framework (RDF): Concepts and abstract syntax. http://www.w3.org/TR/2004/REC-rdf-concepts20040210/, 2004. Citado na pág. 8

Koivunen e Miller(2001) Marja-Riitta Koivunen e Eric Miller. W3c semantic web activity. http://www.w3.org/2001/12/semweb-fin/w3csw, 2001. Citado na pág. xiii, 1, 5

Levenshtein(1966) Vladimir I Levenshtein. Binary codes capable of correcting deletions, insertions and reversals. Em Soviet physics doklady, volume 10, página 707. Citado na pág. 30

Maedche e Zacharias(2002) Alexander Maedche e Valentin Zacharias. Clustering OntologyBased Metadata in the Semantic Web. Em Tapio Elomaa, Heikki Mannila e Hannu Toivonen, editors, Principles of Data Mining and Knowledge Discovery, volume 2431 of Lecture Notes in Computer Science, chapter 29, páginas 383-408. Springer Berlin / Heidelberg, Berlin, Heidelberg. ISBN 978-3-540-44037-6. doi: 10.1007/3-540-45681-3\_29. URL http://dx.doi.org/10. 1007/3-540-45681-3_29. Citado na pág. 26, 28, 30, 31

Manning e Schütze(1999) Christopher D Manning e Hinrich Schütze. Foundations of statistical natural language processing. MIT press. Citado na pág. 19, 20, 21

Manola e Miller(2004) Frank Manola e Eric Miller. RDF primer. http://www.w3.org/TR/2004/REC-rdf-primer-20040210/, 2004. Citado na pág. 8, 10 
Marinho e Schmidt-Thieme(2008) Leandro Balby Marinho e Lars Schmidt-Thieme. Collaborative tag recommendations. Em Data Analysis, Machine Learning and Applications, páginas 533-540. Springer. Citado na pág. 48

Marzal e Vidal(1993) Andres Marzal e Enrique Vidal. Computation of normalized edit distance and applications. Pattern Analysis and Machine Intelligence, IEEE Transactions on, 15(9):926932. Citado na pág. 30

McBride(2001) Brian McBride. Jena: Implementing the RDF model and syntax specification. Em SemWeb. Citado na pág. 5

McGuinness e van Harmelen(2004) Deborah L. McGuinness e Frank van Harmelen. OWL web ontology language guide. http://www.w3.org/TR/owl-features/, 2004. Citado na pág. 11

Mika(2005) Peter Mika. Ontologies are us: A unified model of social networks and semantics. Em The Semantic Web-ISWC 2005, páginas 522-536. Springer. Citado na pág. 48

Montes-y Gómez et al.(2000) Manuel Montes-y Gómez, Alexander Gelbukh e Aurelio LópezLópez. Comparison of conceptual graphs. Em MICAI 2000: Advances in Artificial Intelligence, páginas 548-556. Springer. Citado na pág. xiv, 33, 34

Oliveira et al.(2008) Bruno Oliveira, Pável Calado e Sofia H. Pinto. Automatic tag suggestion based on resource contents. Citado na pág. 24, 48, 57

Prud'hommeaux e Seaborne(2008) Eric Prud'hommeaux e Andy Seaborne. SPARQL query language for RDF.

http://www.w3.org/TR/rdf-sparql-query/, 2008. Citado na pág. 11

Si et al.(2009) Xiance Si, Zhiyuan Liu, Peng Li, Qixia Jiang e Maosong Sun. Content-based and graph-based tag suggestion. Proceedings of the ECML PKDD Discovery Challenge, páginas 243-260. Citado na pág. 49

Smith et al.(2004) Michael K. Smith, Chris Welty e Deborah L. McGuinness. OWL web ontology language guide. http://www.w3.org/TR/2004/REC-owl-guide-20040210/, 2004. Citado na pág. 11

Sood et al.(2007) Sanjay C. Sood, Sara H. Owsley, Kristian J. Hammond e Larry Nirnbaum. Tagassist: Automatic tag suggestion for blog posts. Citado na pág. 24, 48

Witten e Frank(2005) Ian H Witten e Eibe Frank. Data Mining: Practical machine learning tools and techniques. Morgan Kaufmann. Citado na pág. 19, 20, 21, 42

$\mathrm{Xu}$ et al.(2006) Zhichen Xu, Yun Fu, Jianchang Mao e Difu Su. Towards the semantic web: Collaborative tag suggestions. Em Collaborative web tagging workshop at WWW2006, Edinburgh, Scotland. Citado na pág. 1, 2, 48

Yujian e Bo(2007) Li Yujian e Liu Bo. A normalized levenshtein distance metric. Pattern Analysis and Machine Intelligence, IEEE Transactions on, 29(6):1091-1095. Citado na pág. 30 